\title{
DEVELOPMENT OF A PROTOTYPE LIGNIN CONCENTRATION SENSOR
}

Prepared for:

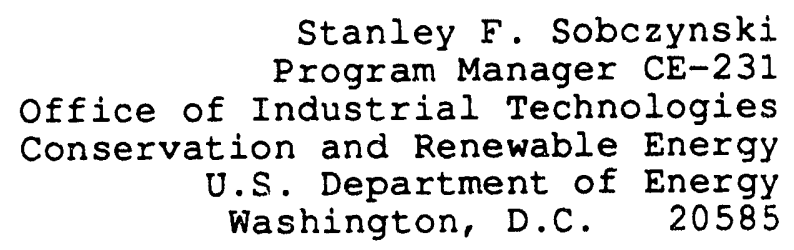

Prepared by:

M. L. Malito and L. A. Jeffers

The Babcock \& Wilcox Company Research and Development Division Alliance Research Center 1562 Beeson Street Alliance, $\mathrm{OH} 44601$

DOE Report No. DOE/CE/40905-32

Contract No. DE-FC05-90CE 40905

\section{MASTER}

DISTRIBUTION OF THIS DOCUMENT IS UNLIMLTED 


\section{IEGAL NOTICE}

This report was prepared by the Babcock \& Wilcox Company (B\&W) for the U.S. Department of Energy (DOE), and neither B\&W, DOE, nor any person acting on behalf of either:

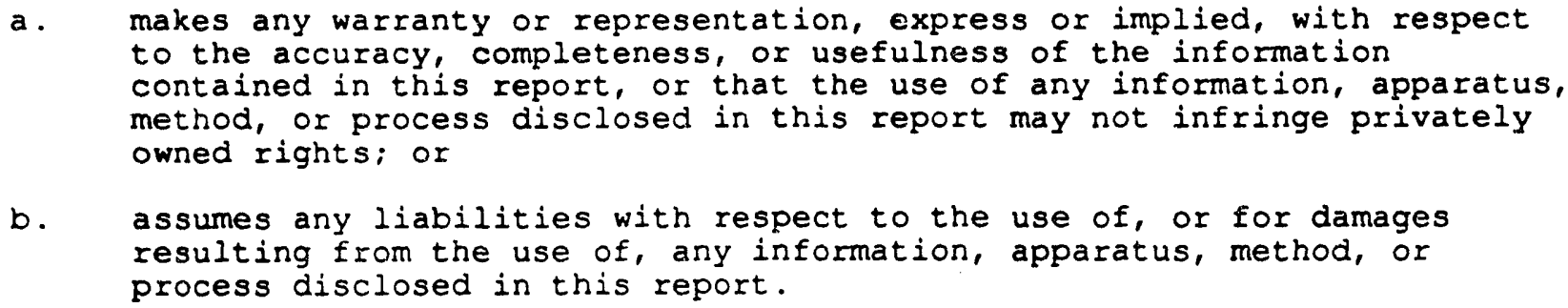

$\mathrm{DOE} / \mathrm{CE} / 40905--32$

DE93 009767

\section{DISCLAIMER}

This report was prepared as an account of work sponsored by an agency of the United States Government. Neither the United States Government nor any agency thereof, nor any of their employees, makes any warranty, express or implied, or assumes any legal liability or responsiprocess disclosed, or represents that its usefulness of any information, apparatus, product, or ence herein to any specific commerciat use would not infringe privately owned rights. Refermanufacturer, or otherwise mendation, or favoring by the not necessarily constitute or imply its endorsement, recomand opinions of authors expressed States Government or any agency thereof. The views United States Government or any agency thereof. 
EXECUTIVE SUMMARY

1.0 INTRODUCTION ... . . . . . . . . . . . . . . . . 1-1

1.1 PROJECT OBJECTIVES . . . . . . . . . . . . . . . . 1-1

1.2 BACKGROUND - THE NEED FOR CONTROL OF IIGNIN

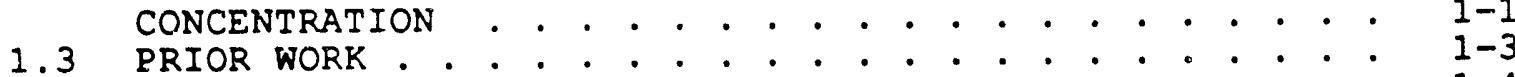

1.4 SCOPE OF THIS REPORT . . . . . . . . . . . . . . . . $1-4$

2.0 PHASE I RESULTS AND OPEN QUESTIONS . . . . . . . . . . . . . . . . . . 2-1

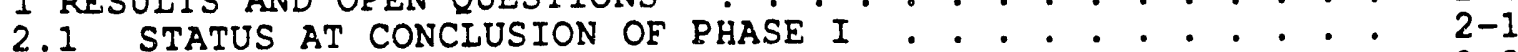

2.2 INITIATION OF PHASE II................ . . 2-3

3.0 OVERVIEW OF PHASE II LABORATORY CHARACTERIZATION STUDY . . . . . . 3-1

3.1 ORIGIN OF SCATTER . . . . . . . . . . . . . . . . . 3-1

3.2 STRATEGY FOR DEALING WITH SCATTER . . . . . . . . . . 3-2

4.0 RESULTS . . . . . . . . . . . . . . . . . . . 4-1

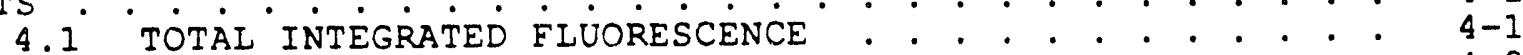

4.2 TEMPORAL BEHAVIOR OF FLUORESCENCE . . . . . . . . . . . 4-2

4.3 EXCITATION WAVELENGTH . . . . . . . . . . . . . . 4-3

4.4 SPECTRAI DISTRIBUTION . . . . . . . . . . . . . . . 4-3

4.5 THERMAL RESPONSE.................... . . $4-4$

5.0 CONCLUSIONS/RECOMMENDATIONS . . . . . . . . . . . . . . . . . . . . 5-1

5.1 CONCLUSIONS . . . . . . . . . . . . . . . . . . . . 5-1

5.2 RECOMMENDATIONS \& FUTURE WORK . . . . . . . . . . . . 5-2

6.0 APPARATUS . . . . . . . . . . . . . . . . 6-1

6.1 SYSTEM OVERVIEW . . . . . . . . . . . . . . 6-1

6.2 SYSTEM TIMING . . . . . . . . . . . . . . . . 6-3

6.3 DATA ACQUISITION PARAMETERS . . . . . . . . . . . . . 6-4

6.4 ELECTRONICS . . . . . . . . . . . . . . . . . . . . . 6-4

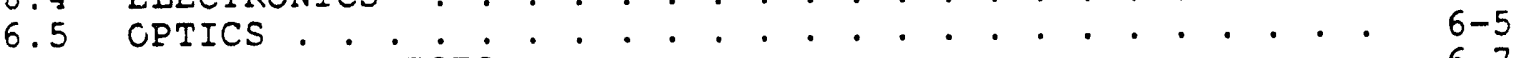

6.6 REFLECTION TESTS . . . . . . . . . . . . . . . . 6-7

6.7 PHASE-RESOLVED FLUORESCENCE . . . . . . . . . . . . 6-7

6.8 SYSTEM PERFORMANCE . . . . . . . . . . . . . . . . 6-7

6.9 FIUORESCENCE OF EMPTY CUVETS . . . . . . . . . . . . . . 6-8

7.0 PREPARATION AND TESTING OF PULP SAMPLES . . . . . . . . . . . . . . . . . $7-1$

7.1 PULP PROCUREMENT . . . . . . . . . . . . . . . . . . 7-1

7.2 KAPPA NUMBER TESTING ON SAMPLES . . . . . . . . . . . $7-1$

7.3 KLASON IIGNIN TESTS . . . . . . . . . . . . . . . . 7-3

7.4 PULP PH TESTING . . . . . . . . . . . . . . . . 7-5

7.5 EXTRACTIVES IN PULP SAMPLES . . . . . . . . . . . . . 7-5

8.0 ANALYSIS . . . . . . . . . . . . . . . . . . . . . . . . 8-1

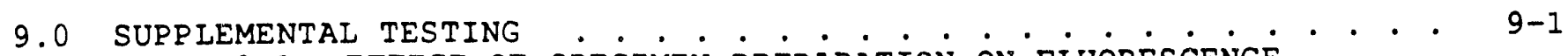

9.1 EFFECT OF SPECIMEN PREPARATION ON FLUORESCENCE

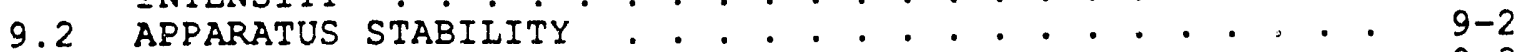

9.3 BLEACHING .. . . . . . . . . . . . . . . . . . 9-3

9.4 TEMPERATURE EFFECT TESTS . . . . . . . . . . . . . . . 9-4

9.5 pH TESTS . . . . . . . . . . . . . . . . . . . 9-4

9.6 REFLECTION TESTS . . . . . . . . . . . . . . . . . 9-5

9.7 DERIVATIVE SPECTROSCOPY . . . . . . . . . . . . . . . 9-6

10.0 REFERENCES . . . . . . . . . . . . . . . . . . . . . . 10-1 


\section{EXECUTIVE SUMMARY}

INTRODUCTION

The U.S. Department of Energy, Office of Industrial Technologies, is sponsoring a research and development program for the development of a real-time, in-situ sensor to measure the concentration of lignin in wood pulp. The program is composed of three phases:

- Phase I - Feasibility -- complete

- Phase II - Development and Testing of a Field Prototype -in progress

- Phase III - Commercialization -- future.

The Phase I work (funded entirely by B\&W) demonstrated a correlation between the fluorescence intensity and lignin concentration (as measured by TAPPI procedure, T $236 \mathrm{hm}-85$ "Kappa Number of Pulp") for undiluted wood pulp samples.

In Phase II, a laboratory test program directed at characterizing the fluorescence of wood pulp has been conducted as a prelude to the design of a prototype sensor. The current report summarizes the testing completed in Phase I and documents the Phase II laboratory testing completed through December 1991.

Future Phase II efforts include additional laboratory testing, design and fabrication of a prototype sensor, and field testing of the prototype sensor. Phase III of the program will concentrate on the incorporation of the sensor into a control system and commercialization of the sensor.

\section{TEST PROGRAM}

Very little data on the fluorescence characteristics of lignin exists in the open literature. What data does exist is on lignin in liquid form in very dilute concentrations. The research performed under the current program is the first attempt known to the authors to characterize the fluorescence of lignin in pulp. Since the purpose of the current program is to develop an instrument for industrial process control, the work reported here is not intended to be comprehensive. 
The research was carried only to the point which would permit the design of a field testable prototype sensor for industrial process control.

The Phase II testing was carried out on two sets of laboratory prepared pulp, each consisting of eight samples with Kappa numbers ranging from approximately 15 to 50. Pulp set number 1 was prepared from southern pine chips and pulp set number 2 was prepared from northern pine chips.

To perform the characterization tests, an apparatus was designed and constructed that employed:

- a pulsed nitrogen/dye laser as the excitation source.

- an intensified, diode-array detector capable of rapid (5 nsec) gating.

- an electronically scanned/controlled spectrometer employing digital data acquisition and processing.

Technologies investigated included:

- measurement of total fluorescence at various excitation wavelengths

- time-resolved fluorescence

- phase-resolved fluorescence

- multiple wavelength excitation

- diffuse reflectivity

A variety of post-test processing approaches were applied to the data in an attempt to determine the technique/processing combination most suitable for use in deriving a usable control function. The processing techniques included:

- integration of the fluorescence emission spectrum over the entire wavelength range to give the total fluorescent intensity.

- linear combination of the total fluorescence excited by two different excitation wavelengths.

- ratios of the fluorescence integrated over two different wavelength ranges. 
- calculation of the wavelength centroid of the emission spectrum.

- differentiation of the emission spectrum.

Tests were also conducted to investigate the effect of temperature and $\mathrm{pH}$ on the fluorescence.

\section{RESULTS AND CONCLUSIONS}

The results of the steady-state fluorescence tests confirmed the earlier feasibility results - namely that an inverse functional relationship exists between fluorescence intensity and Kappa number. The relationship is not monotonic over the entire range of Kappa numbers of interest and has poor resolution at high Kappa numbers. The non-monotonic nature of the relationship is suspected to be caused by the presence of an interfering compound.

A variety of approaches were identified that minimize the effects of the interferant and provide response functions more promising for cortrol purposes. These approaches included using:

- time-resolved and phase-resolved techniques.

- multiple excitation wavelengths.

- shift of the emission spectral distribution as measured by the wavelength centroid or ratio of intensities over two wavelength ranges.

Cf these three general approaches, the emission spectral distribution shift is the most promising for use in a field instrument. Advantages include:

- shift is independent of absolute intensity of the fluorescence so compensation for drift of the source, detector, or collection efficiency is not required.

- the equipment is less complex. It does not require highspeed, gateable detector/electronics as does the time or phase resolved approach and it requires only a single excitation wavelength. 


\subsection{INTRODUCTION}

\subsection{PROJECT OBJECTIVES}

The long-term objective of this DOE-sponsored program is to provide an instrument for real-time, in-situ measurement of lignin in pulp at a variety of locations in the pulp process stream. The instrument would ultimately be used as a primary sensor for process control in the pulp and paper industry. The program is composed of three phases:

- Phase I - Feasibility Demonstration

- Phase II - Development and Testing of a Field Prototype

- Phase III - Commercialization

This report summarizes the work to date on Phase II. The objectives of Phase II are to:

- Perform a carefully controlled set of laboratory experiments that characterize the fluorescent properties of wood pulp in order to answer various questions raised in Phase $I$ and to provide the background data required to design a field testable prototype.

- Design and fabricate a field testable prototype system for measurement of the lignin concentration in undiluted pulp at the last stage of a brownstock washer.

- Evaluate the performance of the prototype in actual field conditions.

\subsection{BACKGROUND - THE NEED FOR CONTROL OF LIGNIN CONCENTRATION}

Although somewhat of an oversimplification, wood can be characterized as consisting of holocellulose (cellulose and hemicellulose), lignin, and extractives [1]. Iignin, a polymer of complex chemical structure which "cements" the cellulose fibers together, must be partially removed in the paper making process. The removal process is referred to as delignification. It can be 
accomplished through a chemical pulping (digestion) process that converts the lignin to a soluble form using acid (sulfite) or alkaline (kraft) pulping agents.

Depending upon the paper product being produced, as much as 908 (or more) of the lignin may be removed from the wood. At a typical pulp mill, the pulp is sampled and tested for lignin concentration on a regular (usually hourly) basis. The test result is reported in terms of the Kappa number (or $\mathrm{K}$ Number depending on the specific procedure). The pulp Kappa number is an approximate measure of the lignin concentration in the pulp and is determined by measuring the consumption of potassium permanganate solution by moisture free pulp by back-titration [2]. Typical kappa numbers range from 10 or less, for fine white paper, to more than 80 for brown paper and heavier material.

Many pulp mills employ distributed process control to improve digester performance and often use the pulp Kappa number as a feedback parameter, especially on continuous digesters. In such a control system, the results from the hourly Kappa number (titration) tests at the pulp mill lab are used as feedback (via "keypunching" the test results into the process control system) to the digester in which the delignification process is taking place. The delays in obtaining Kappa numbers, the sampling error, and laboratory error result in uncertainty in the data provided to the control system. In addition, the delay of one hour or more between the time at which the sample is obtained and the time at which the Kappa number is determined in the lab, severely restrict.s the feed-forward control possibilities.

By eliminating the time lag, a real-time, on-line lignin sensor will provide improved control of the digestion process and will, for the first time, make possible feed-forward control of the bleach plant. This will result in a significant reduction in the amount of bleach consumed. In addition to the cost and material savings, reduction in bleach consumed has favorable environmental implications. 


\subsection{PRIOR WORK}

The National Institute of Standards and Technology (NIST) has conducted research with the objective of developing measurement science and technology for on-line measurement of process variables in the pulp and paper industry $[3,4]$. This research, sponsored by the U.S. Department of Energy, included studies of laser excited fluorescence of lignin in solution (e.g. spent liquor). Although the research concluded that this technique could be a strong candidate for in-situ monitoring of the pulping process [5], the method was limited to very dilute solutions whose concentration of lignin was well below the concentrations found in wood pulp at pulp mills. Other DOE sponsored work studied the feasibility of using mass spectroscopy [6] for determining the concentration of lignin in pulp. Although successful in a laboratory environment, this technique is not considered suitable for in-situ monitoring [7].

The motivation for in-situ measurement of lignin in pulp is better control of the delignification process (feedback to digester) and reduced consumption of bleaching chemicals (feedforward to the bleach plant). It is therefore desirable to develop a sensor which measures the lignin in pulp itself rather than in the spent liquor (focus of the NIST investigation), from which the lignin concentration in the pulp can only be inferred.

State-of-the-art instruments for quasi on-line measurement of lignin in spent liquors [8-10] and pulp [11,12] are based on the long known ultraviolet absorption characteristics of lignin [13-19]. Although much improved over automated titrating devices and conductivity probes, these still involve considerable sample preparation, sample handling (including dilution by as much as 10,000:1), and supplementary measurements (such as consistency) which affect instrument accuracy.

\section{Diffuse Reflectance Infrared Fourier Transform (DRIFT)}

Spectroscopy has also been studied as an off-line method for measuring the lignin in pulp [20\}. The DRIFT method's primary advantages are that it is nondestructive, fast, and not highly dependent upon sample size. The DRIFT method has not, however, resulted in acceptable 
precision. The precision of the DRIFT method has been reported to be approximately \pm 10 Kappa number [20].

After reviewing the technologies available for possible in-situ sensors for measuring lignin in pulp, B\&W decided to pursue an extension of the fluorescence work done at NIST [5], (i.e. laser induced fluorescence). Other investigators had also demonstrated the usefulness of fluorescence for detection of lignin in solution (2125]. B\&W reasoned that the device could be relatively inexpensive, rugged, and be mounted at the final stage of the traditional vacuum washer to the end-wash rollers or deckers at a pulp mill (where samples are currently obtained for mill lab testing). The device would be truly real-time and eliminate the need for sampling and sample preparation. Since NIST had only worked with black liquor and only in the highly diluted range, it was necessary to study the fluorescence of actual pulp samples without dilution. A feasibility study (Phase I of this program) was undertaken by $B \& W$ in which the fluorescence of undiluted pulp samples was investigated. The results of the Phase I feasibility tests, which are discussed in section 2 of this repoit, were very encouraging and led to the current Phase II effort.

\subsection{SCOPE OF THIS REPORT}

The first objective of Phase II was to provide the background data required for the design of a field testable prototype. The workscope planned to meet that first objective has been completed. The purpose of this report is to document the results of that study. To provide background for understanding the approach taken in the laboratory characterization study, the results of the Phase I feasibility tests and questions outstanding at the end of Phase I are reviewed in section 2.0. The work plan for the characterization study is outlined in section 3.0. Details of the characterization study in Sections 4.0 through 9.0 form the bulk of this report. 


\subsection{PHASE I RESULTS AND OPEN QUESTIONS}

\subsection{STATUS AT CONCLUSION OF PHASE I}

During the second half of calendar year 1988, B\&W conducted an in-house research effort into the feasibility of measuring lignin concentration in wood pulp using the fluorescence resulting from narrowband ultraviolet excitation of the pulp. This phase I research effort was performed at the Babcock \& Wilcox Alliance Research Center in Alliance, Ohio, using the laboratory instrumentation shown in Figure 2-1. The pulp used in the research was obtained from the Weyerhauser Plymouth, N.C. plant and included a total of 43 specimens from three mills operating at target Kappa numbers of 12, 24, and 80 respectively, as shown in Table 2-1.

\section{TABLE 2-1 PHASE I SAMPLES}

$\begin{array}{ccc}\text { TARGET KAPPA \# } & \text { \# OF SAMPLES } & \frac{\text { TYPE OF WOOD PULP }}{80} \\ 22 & 6 & \text { Southern Pine } \\ 12 & 23 & \text { Southern Pine } \\ & & \text { Mixed Hardwoods } \\ & \text { Percent Lignin } \propto \text { [Kappa \#] } \times 0.15\end{array}$

The results of the research indicated that the fluorescence intensity decreased with increasing Kappa number as shown in Figure 2-2. To verify this unexpected result, a single sample of black liquor was diluted with high purity water to various concentrations and excited in the same manner as the pulp samples. The results of the black liquor tests are presented in Figures $2-3$ and $2-4$. At very low concentrations, the fluorescence intensity increases with increasing lignin concentration. At concentrations of approximately $2,000-20,000 \mathrm{ppm}$ solids $(\approx 1,000-10,000 \mathrm{ppm}$ lignin), the fluorescence intensity peaks. Beyond concentrations of $20,000 \mathrm{ppm}$ solids, the fluorescence intensity decreases nonlinearly with increasing concentration. 
The fluorescence intensity of the pulp was demonstrated to be very repeatable, as indicated in Figure 2-5. The independent variable (Kappa number) was obtained from the pulp mill lab results and no statistical sampling within the specimens was performed. Therefore, it could not be determined if the fluorescence was due solely to lignin or to a combination of lignin and other fluorescing species, which might be present in concentrations not related to the concentration of lignin.

Specific Phase I results included:

- The fluorescence intensity is very repeatable despite a laboratory set-up which was not optimum.

- Washing the mill supplied pulp in distilled water had little or no effect on it's fluorescence intensity.

- Maximum fluorescence occurred in the region of $420-450 \mathrm{~nm}$ (see Figure 2-6).

- A functional relationship between fluorescence intensity and Kappa number was shown to exist (see Figure 2-2). The fluorescence intensity decreases with increasing Kappa number. This inverse relationship is due to "fluorescence quenching". The quenching behavior of lignin was not previously investigated or reported in the literature.

Some of the questions which remained outstanding at the end of the Phase I effort included:

- What is the source of the data scatter? Possible answers include:

1) Inaccuracy in the pulp mill Kappa numbers.

2) Fluorescence of non-lignins which could be interfering with the lignin fluorescence (i.e., aliasing).

3) Effect of temperature on the fluorescence.

4) Inaccuracies due to the Phase I laboratory apparatus.

5) Local variations within individual pulp samples. 
- How does the fluorescence intensity vs. Kappz number vary from wood species to wood species?

- What is the effect of other excitation frequencies on the fluorescence intensities?

- Could phase-resolved and/or time-resolved techniques be used to eiminate scatter?

- Could information from the emission spectra, other than intencity, be used to eliminate scatter?

\subsection{INITIATION OE PHASE II}

Altiough very encouraging, the Phase I results were based on limited testing with a relatively crude laboratory apparatus. In preparation for Phase II of the project, $B \& W$ procured a "state of the art" intensified optical multi-channel analyzer capable of being gated down to $5 \mathrm{~ns}$, a pulsed nitrogen laser, and a gigahertz oscilloscope. Additionally, B\&W arranged for phase-resolved fluorescence tests to be conducted at Duke University, Department of Chemistry (Duke owns an SIM 48000 fluorescence analyzer capable of phase-resolved fluorescence).

Arrangements were also made with Miami University (Ohio) Paper Science and Engineering Department to have two sets of pulp samples prepared from two different wood species. Each set spanned a range of Kappa numbers from approximately 15 - 50. Miami measured Kappa number on each sample in triplicate. Arrangements were also made with the Institute of Paper Science and Technology for duplicate Kappa number tests and Klason lignin tests on one of the two sets of pulp.

Phase II of the project was then initiated to investigate the pulp fluorescence phenomena more thoroughly and to design, fabricate, and field test a prototype sensor. 

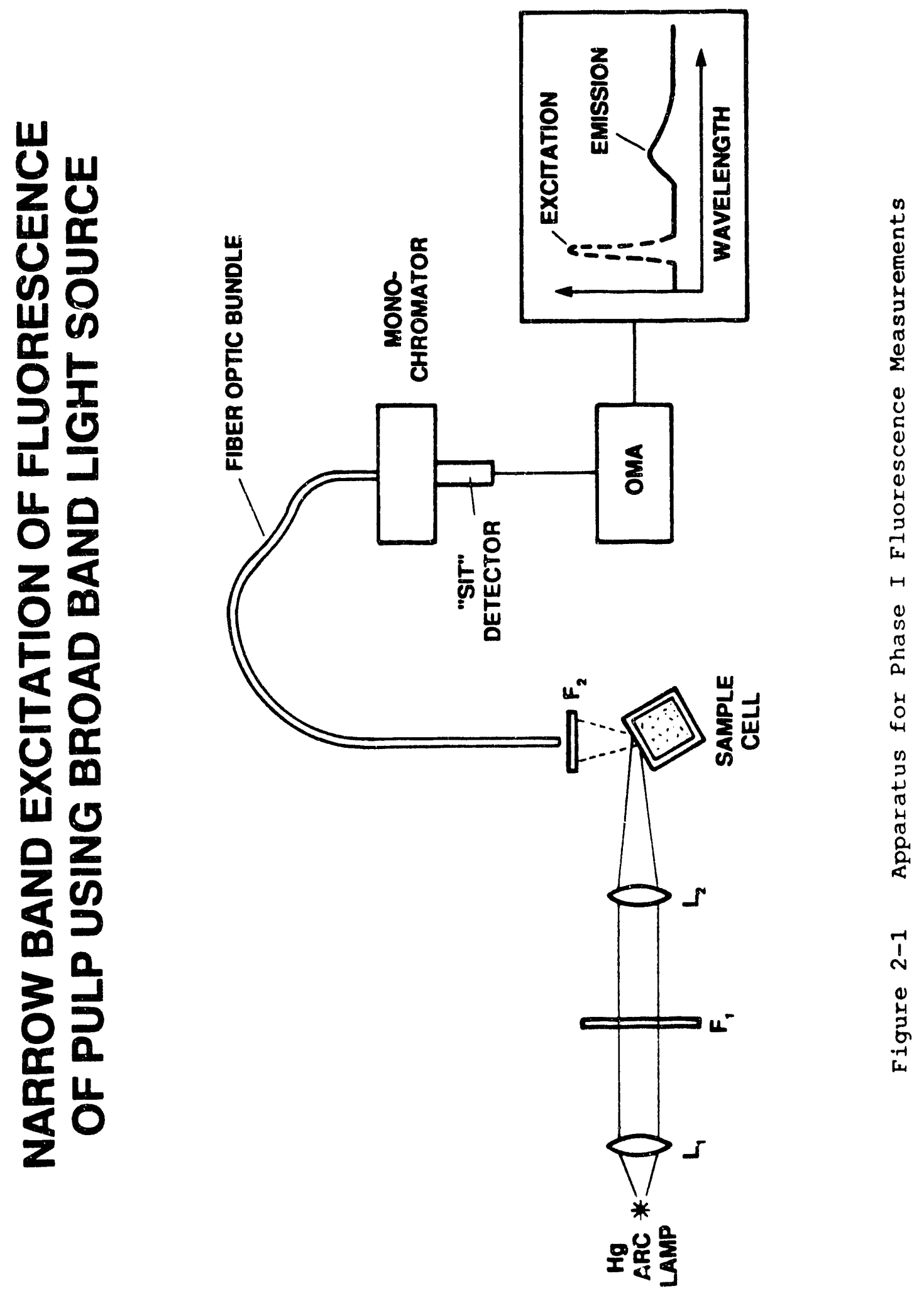


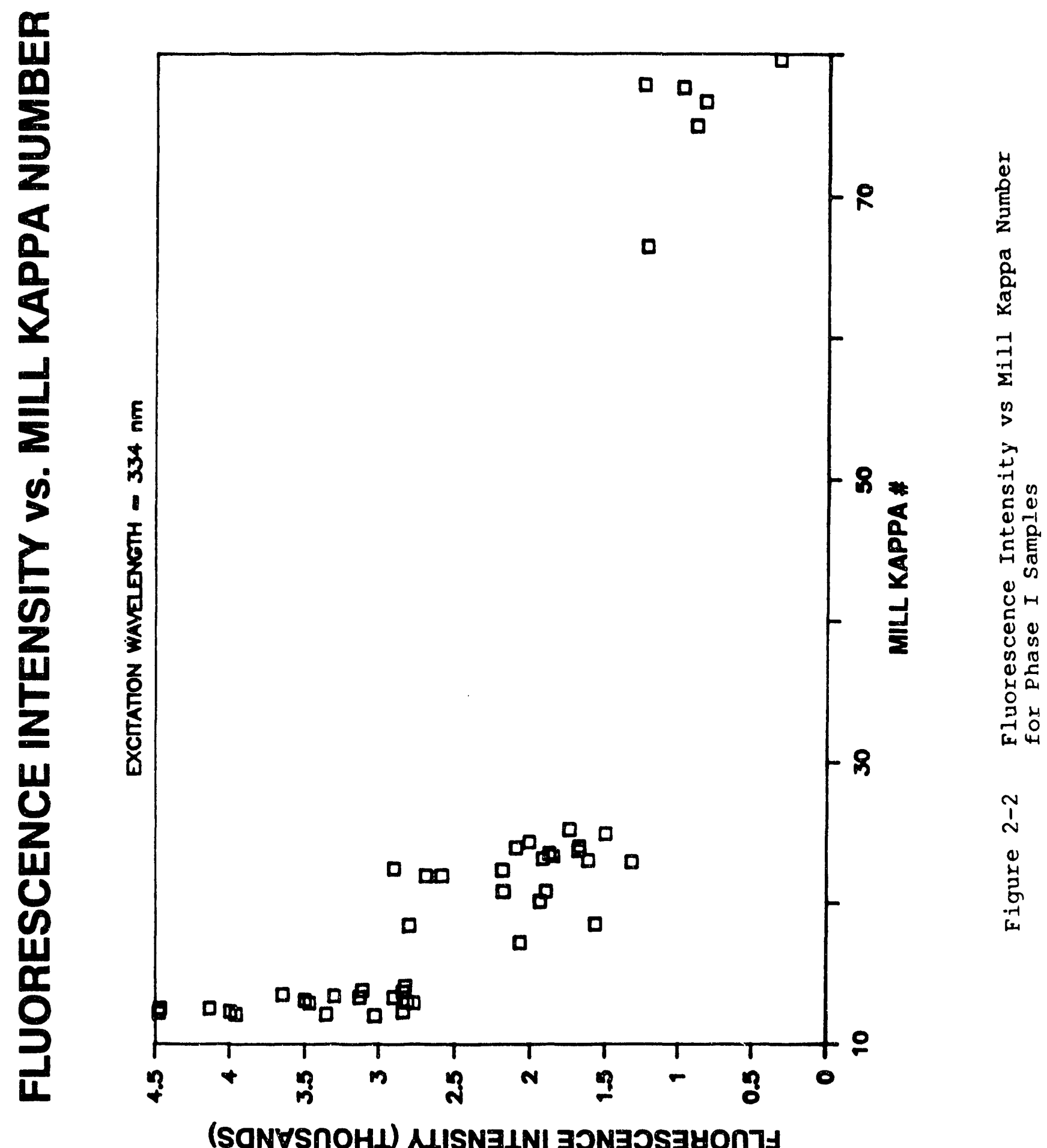




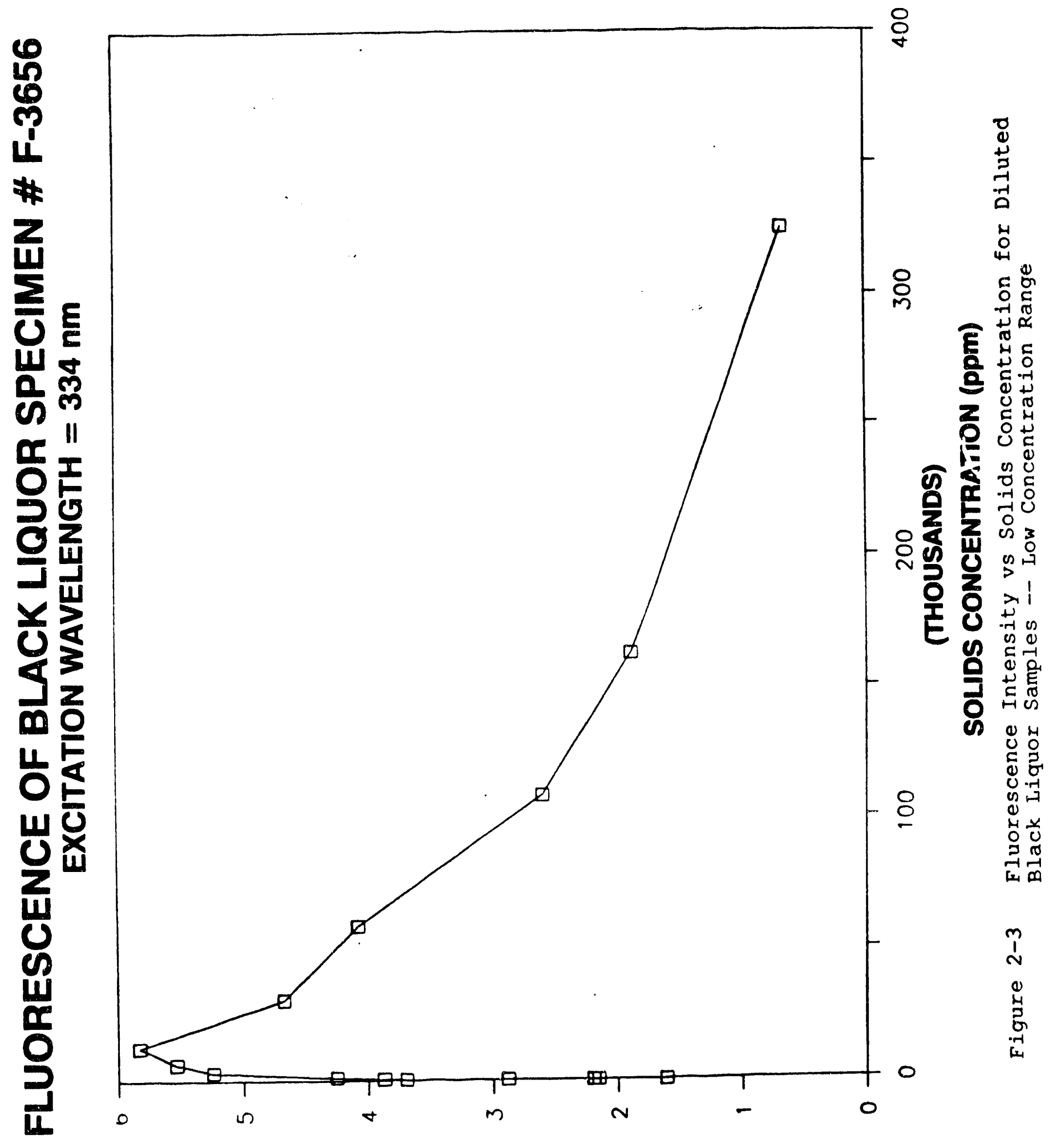

(SANZSกOHL)

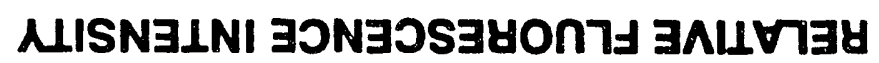




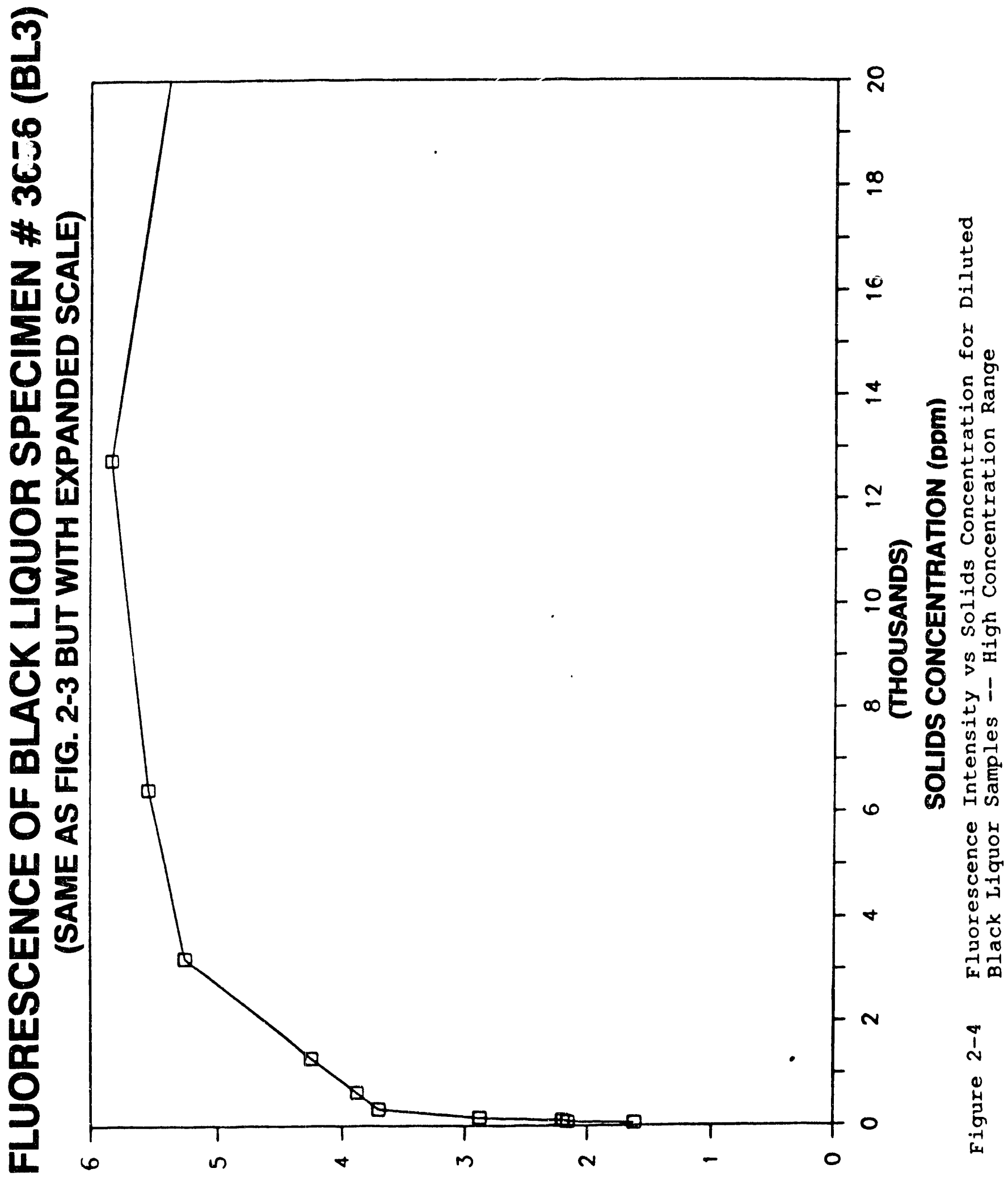



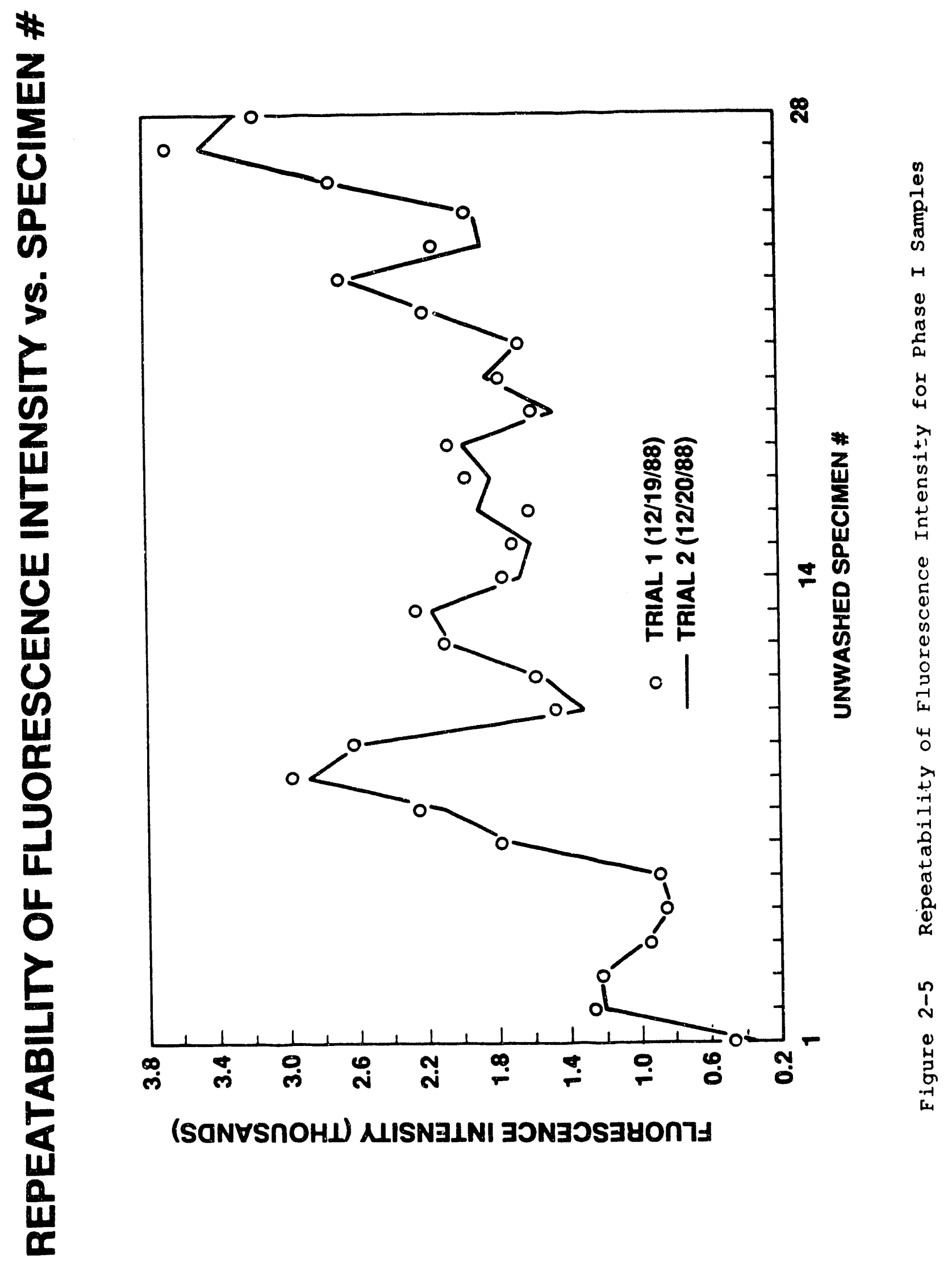


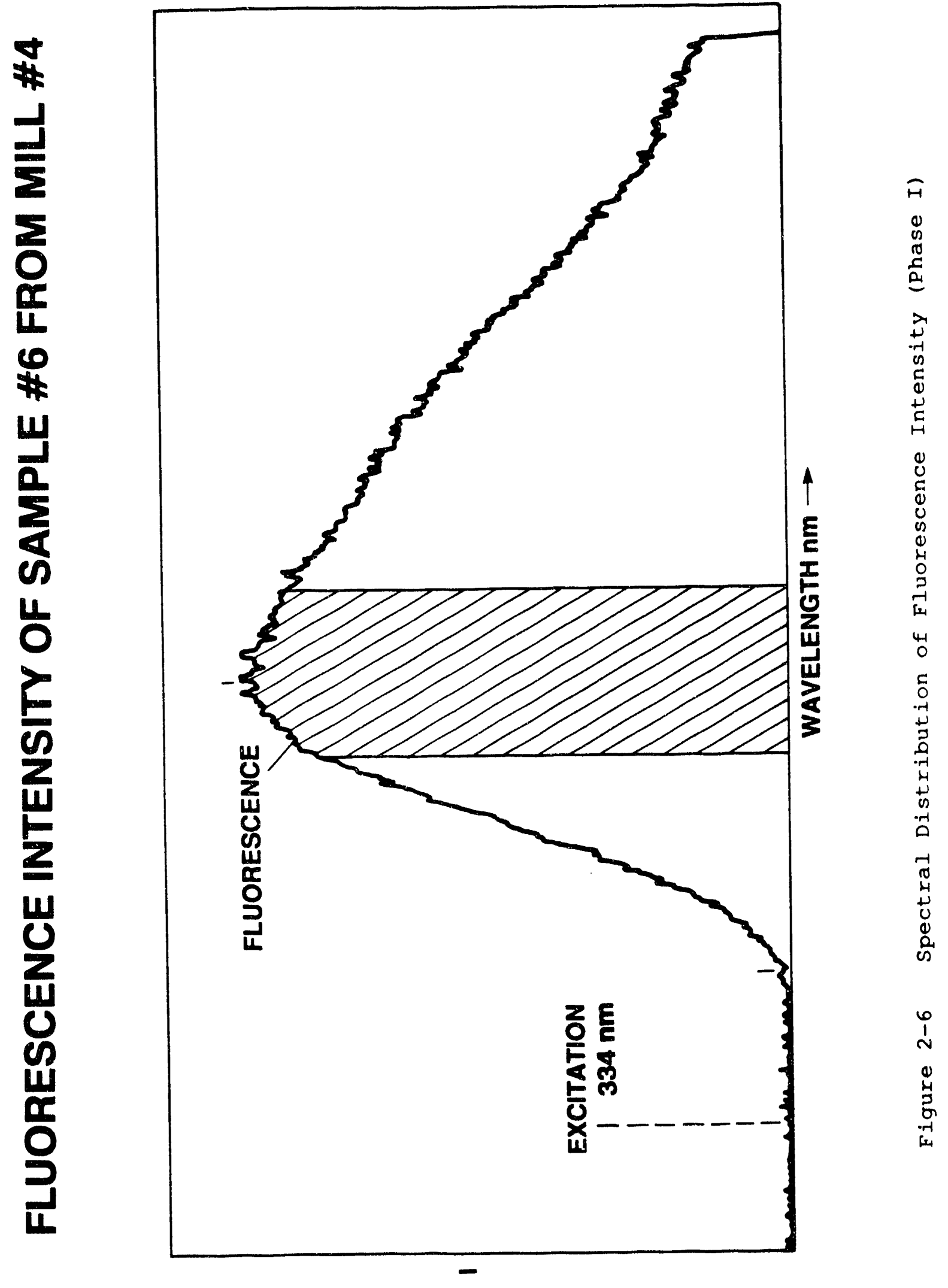




\subsection{OVERVIEW OF PHASE II LABORATORY CHARACTERIZATION STUDY}

During Phase I of the project, B\&W demonstrated that a functional relationship exists between fluorescence intensity of wood pulp and Kappa number over a range of Kappa numbers from 10 to 80 . The relationship occurs for pulp in the condition at which it exits the last stage of washing at an operating pulp mill, i.e., undiluted and without sample preparation. The relationship is one in which the fluorescence intensity emitted by a pulp sample decreases with increasing Kappa number, i.e. with increasing lignin concentration. This inverse relationship of fluorescence intensity with lignin concentration results from a fluorescence phenomenon known as "quenching".

\subsection{ORIGIN OF SCATTER}

The Phase I test results, as can be seen in Figure 2-2, exhibited a good deal of noise or data scatter. The Phase II tests were designed to eliminate this scatter or at the very least identify the cause. Possible causes considered were:

1) instrumentation error (drift of optical alignment, drift of source excitation intensity and wavelength, etc.)

2) Local variations of Kappa number within the pulp samples (area sampled by the fluorescence probe not representative of the bulk sample).

3) bleaching effects (the extent to which exposure to the excitation light caused irreversible chemical changes that effected the fluorescence efficiency) were unknown and the total exposure experienced during the tests was not controlled.

4) temperature effects (neither the sensitivity of the fluorescence to temperature changes, nor the magnitude of temperature variations during the tests were known).

5) uncertainties in the measured values of Kappa number. 
6) variations in fluorescence properties of lignin dependent on the wood type (fluorescence efficiency is commonly affected by interaction with non-fluorescing molecules in the sample).

7) fluorescence interference of non-lignins (the presence of species whose concentration does not correlate with Kappa number can affect the measured fluorescence either by adding a non-lignin fluorescence or by altering the efficiency of the fluorescence from the lignin.

\subsection{STRATEGY FOR DEALING WITH SCATTER}

The Phase II characterization tests were designed to deal with the possible causes of data scatter enumerated above in the manner described below.

The first four causes listed above were addressed through the design of the apparatus and testing procedure.

1) Instrumental error was minimized through careful design and then quantified by the use of on-line standards.

2) To minimize the effect of sample inhomogeneity, the sample cuvets were mounted on a motor driven table that was automatically scanned during the exposure period.

3) Not only did this spread the exposure over a wide area but it also avoided bleaching problems that would occur if the exposure was confined to a single small area.

4) The effect of sample temperature on fluorescence was quantified and, to rinimize variations due to temperature, the samples (which were normally stored in a refrigerator) were allowed to set out long enough to come to room temperature before any data was taken.

5/6) The questions concerning the Kappa number measurement and variations caused by wood species were addressed by having 
two controlled sample sets prepared for the test program. Ore set was made from a southern pine and the other from a northern pine. Each set consisted of eight samples spanning the range of Kappa numbers from approximately 15 to 55. The range of Kappa numbers was achieved by removing samples from the digester at different times so that within a set, each of the samples came from the same parent wood-chip stock, and all had been processed with the same chemistry. The sample sets were prepared by the Paper science and Engineering Department at Miami University in Oxford, Ohio. Miami University made Kappa number measurements, in triplicate, on each of the samples at the time of the preparation. In the case of the southern pine samples, Miami University repeated the Kappa measurements seven months later to insure that the samples were not changing with time. An independent set of Kappa number measurements were made on the southern pine samples by the Institute of paper science and Technology.

7) A wide range of testing techniques and data reduction approaches were used in the characterization of the lignin fluorescent properties. The objective was to determine the approach most suitable for incorporation in the field prototype. Early testing indicated that there were "interfering" components in the pulp samples that would preclude the straightforward use of a simple total fluorescence signal. The objective of the test program was to identify an approach that could give a measure of the Kappa number in the presence of the interfering components.

In fluorescence spectroscopy there are several parameters that can be manipulated. These are listed and discussed below:

- Amplitude of the total fluorescence emission - This is the most straightforward measurement, instrumentally. The sample is illuminated and the detector produces a signal proportional to the total amount of resultant emission. The first set of experiments involved measurement of total fluorescence emission. 
- Temporal behavior - Interference due to other fluorescing species can often be suppressed if the time ccnstant for fluorescent decay is significantly different for the two species. There are $t$ : / general methods for achieving discrimination based on time constant differences. Instrumentally they are quite different but they supply equivalent information about the sample. The first method is that of time-resolved fluorescence which was investigated using the apparatus described in section 6.0. The second method is that of phase-resolved fluorescence spectroscopy which was employed on the southern pine samples under subcontract to the Department of Chemistry at Duke University using a state-of-the-art SIM4800 fluorescence analyzer system.

Excitation spectrum - The amount of fluorescence from a given species is dependent on the spectral distribution of the light used to excite the fluorescence. Two interfering species can often be separated by observing differences due to excitation spectrum changes. This possibility was investigated by obtaining fluorescence response for several different wavelengths of excitation using a tunable dyelaser as the source.

Spectral distributions of fluorescence emission - Additional information about the fluorescing species can be obtained by analyzing the spectral distribution of the emission, since each species has its own characteristic emission spectrum. The spectral distribution of the fluorescence emission was recorded during the time-resolved and variable excitation wavelength tests discussed above, and analyzed in three ways. The first was simply to calculate the total. fluorescence over all wavelengths - which is the approach discussed above that makes no use of the spectral distribution. The second method involved taking the ratio of the intensities in two different spectral bands. The third method was to determine the centroid wavelength of the spectral distribution. To understand the way either of these methods might discriminate between two interfering 
species, consider the case where we have two species: one which fluoresces in the blue and one in the red portion of the spectrum. For an equal mix of the two, the resultant emission spectrum would "peak" at some point between red and blue. As the relative concentration of the red emitter increases the distribution and peak wavelengths will shift toward the red. Thus, the peak wavelength or the centroid of the distribution provides a measure of the concentration of the red fluorescing species. 


\subsection{RESULTS}

\subsection{TOTAL INTEGRATED FLUORESCENCE}

The fluorescence resulting from excitation by a pulsed source is distributed over both time and wavelength in a manner characteristic of the fluorescing species. The most straightforward and instrumentally simplest approach would be to take the total fluorescence integrated over the entire wavelength range and all time. Unfortunately the relationship between this "total integrated fluorescence" and the measured Kappa number is not suitable, as can be seen in Figure 4-1. While there is a general downward trerd of the fluorescence with increasing Kappa number, the irregularities suggest the presence of a non-correlating component along with the component that correlates as a monotonically decreasing function with the Kappa number.

As discussed in Section 7.0, the Kappa numbers of the southern pine samples were measured at both Miami University and at the Insticute of Paper Science and Technology (IPST) with differing results. The results presented in this section are plotted against Miami Kappa for northern pine data and IPST Kappa for southern pine data.

Most of the results presented in this section (4.0) are from a series of tests conducted over the two-day period from october 31 to November 1, 1992. Several test series had been performed ciuring the months preceding this definitive series, which was intended as a confirmation of the results already obtained. This final series incorporated all of the instrumental and procedural improvements developed over the course of the earlier tests. Figure 4-2 compares the results of this final test series to those of a previous series $(5$ months earlier). It can be seen that the general response is quite similar, indicating good long-term stability of the samples. Also, the repeatability from sample to sample with the same Kappa number is very good. The y-axis of Figure 4-2 is normalized to allow comparison. The absolute intensities of the two test series are approximately $30 \%$ different owing to differences in the test setup (e.g., monochromator slit opening, optical alignment, etc.). 


\subsection{TEMPORAL BEHAVIOR OF FLUORESCENCE}

Because the distribution of fluorescence over time is characteristic of the fluorescing species, it is often possible to discriminate against the effects of an interfering species on the basis of the temporal distribution of the fluorescence.

Instrumentally there are two approaches that are commonly used to exploit the temporal behavior. These are called time-resolved and phase-resolved spectroscopy.

Figure 4-3 shows the results obtained using the time-resolved approach. In this set of tests, the detector measures only the fluorescence that occurred more than $12 \mathrm{nsec}$ after the initial laser pulse. Comparison of Figure 4-3 with 4-2 shows that the time-delayed fluorescence provides a "better" response c"rve, i.e., the disruptions due to the non-correlating components are less severe. Figure 4-3 shows only the results for a $12 \mathrm{nsec}$ delay. As the delay is increased from zero (a delay of zero gives the total integrated fluorescence shown in Figure 4-1) the disruptions gradually decrease up to delays of $12 \mathrm{nsec}$. As the delay increases the total remaining signal decreases. Delay time much more than 12 nsec results in an impractically low signal level, i.e., the signal becomes dominated by noise.

Although the time-delayed fluorescence shown in Figure 4-3 is an improvement over the basic response showr in Figure 4-1 it is still far from ideal as a control signal, particularly at higher Kappa numbers.

In Figure 4-4 we combine the two curves by taking the ratio of the $12 \mathrm{nsec}$ delayed response to the total (delay $=0$ ) response. The resultant response function is much more suitable. It is particularly significant that the species dependence is greatly reduced, i.e., the difference between the northern and southern pine samples is minimal.

Figures $4-5$ and $4-6$ show results obtained using the phaseresolved approach to temporal discrimination. As in the case of the time-resolved approach, the selection of the proper time response in 
Figure 4-6 discriminates against the non-correlating component that is present in Figure $4-5$.

\subsection{EXCITATION WAVELENGTH}

Fluorescence is dependent on the wavelength of the source used for excitation. Since the dependence is characteristic of the fluoresing species, this is another approach commonly used to discriminate against interfering species. Figure 4-7 shows the total fluorescence intensity as a function of Kappa number for an excitation wavelength of $442 \mathrm{~nm}$. Clearly the response function is no improvement over that for excitation at $337 \mathrm{~nm}$ which is shown in Figure 4-1.

Several excitation wavelengths between 337 and 488 were investigated. "The general trend was that the response curve became more erra:ic as the wavelength was increased. This suggests that the function might improve for excitation wavelengths below $337 \mathrm{~nm}$. Unfortunately the $\mathrm{N}_{2}$ /Dye laser cannot provide wavelengths shorter than $337 \mathrm{~nm}$. Because of the non-ivailability of a practical source at shorter wavelengths, we have not pursued testing at excitation wavelengtins less than $337 \mathrm{~nm}$.

The $442 \mathrm{~nm}$ response shown in Figure 4-7 indicates that the noncorrelating component is more of a factor in the total than is the case for the $337 \mathrm{~nm}$ response. This suggests the possibility of combining the two. In Figure 4-8 we show the response function obtained as a linear combination of the $337 \mathrm{~nm}$ excited response with the $442 \mathrm{~nm}$ excited response. The constant 4 (see y-axis in. Figure 4-8: was chosen empirically as that which gave the smoothest response curve.

\subsection{SPECTRAI DISTRIBUTION}

The spectral distribution of the fluorescence emission is another factor commonly used to provide discrimination against an interfering species.

One instrumentally simpie but crude way to implement an emission spectrur. analysis is to use a pair of broadband filters to separate

$$
4-3
$$


the fluorescence into a long and a short wavelength component. Figure 4-9 shows the ratio of two wavelength bands as a function of the Kappa number. Although there is some species dependence (the curves for northern and southern pine are different) the resultant response function looks very promising as a potential control signal. Particularly important is the fact that the sensitivity does not appear to drop off at higher Kappa numbers.

Figure 4-10 shows the wavelength centroic, as a function of the pulp Kappa numbers. The response function is very similar to that for the band ratios, which is to be expected since the centroid is just an alternative measure of the shape of the emission spectrum. Although somewhat more complex to implement, the centroid approach should provide a more stable measurement since it is unaffected by filter and detector response drift. Figure 4-10 also shows how well the front and back surface agree -- on the order of $\Delta k \approx 1$. The front and back surfaces are essentially two different samples.

\subsection{THERMAL RESPONSE}

Figure 4-11 shows the effect of pulp temperature on the total fluorescence. The data was obtained from a sample with a Kappa number of 15. The total fluorescence intensity decreases inearly with temperature at approximately $0.28 /{ }^{\circ} \mathrm{F}$. This corresponds to approximately $0.03 \mathrm{Kappa} /{ }^{\circ} \mathrm{F}$ for low Kappa numbers (e.g., 15). No temperature tests were conducted at higher Kappa numbers, but the effect on Kappa number is expected to be much higher due to the flatness of the intensity curve at high Kappa numbers. The effect is large enough that a Kappa number measurement approach based on the intensity of the fluorescence may need to be compensated for temperature, depending on the natural range of temperature variation at the measurement location. An approach such as that shown in Figure 4-4 might be self-compensating, i.e., the temperature effect may be the same on both the numerator and denominator of the ratio. At this point we do not have the data required to answer this question.

Figure 4-i2 shows the effect of temperature on the wavelength centroid. The effect is again a linear decrease which could be easily compensated. The magnitude of the effect on Kappa in this case is 
nearly independent of Kappa number. The slope of the curve is approximately $0.025 \mathrm{~nm} /{ }^{\circ} \mathrm{F}$ (see Figure 4-10). Since the centroid change with Kappa number is on the order of $0.37 \mathrm{~nm} / \mathrm{Kappa}$, the temperature effect on measured Kappa is approximately $0.07 \mathrm{Kappa} /{ }^{\circ} \mathrm{F}$. 


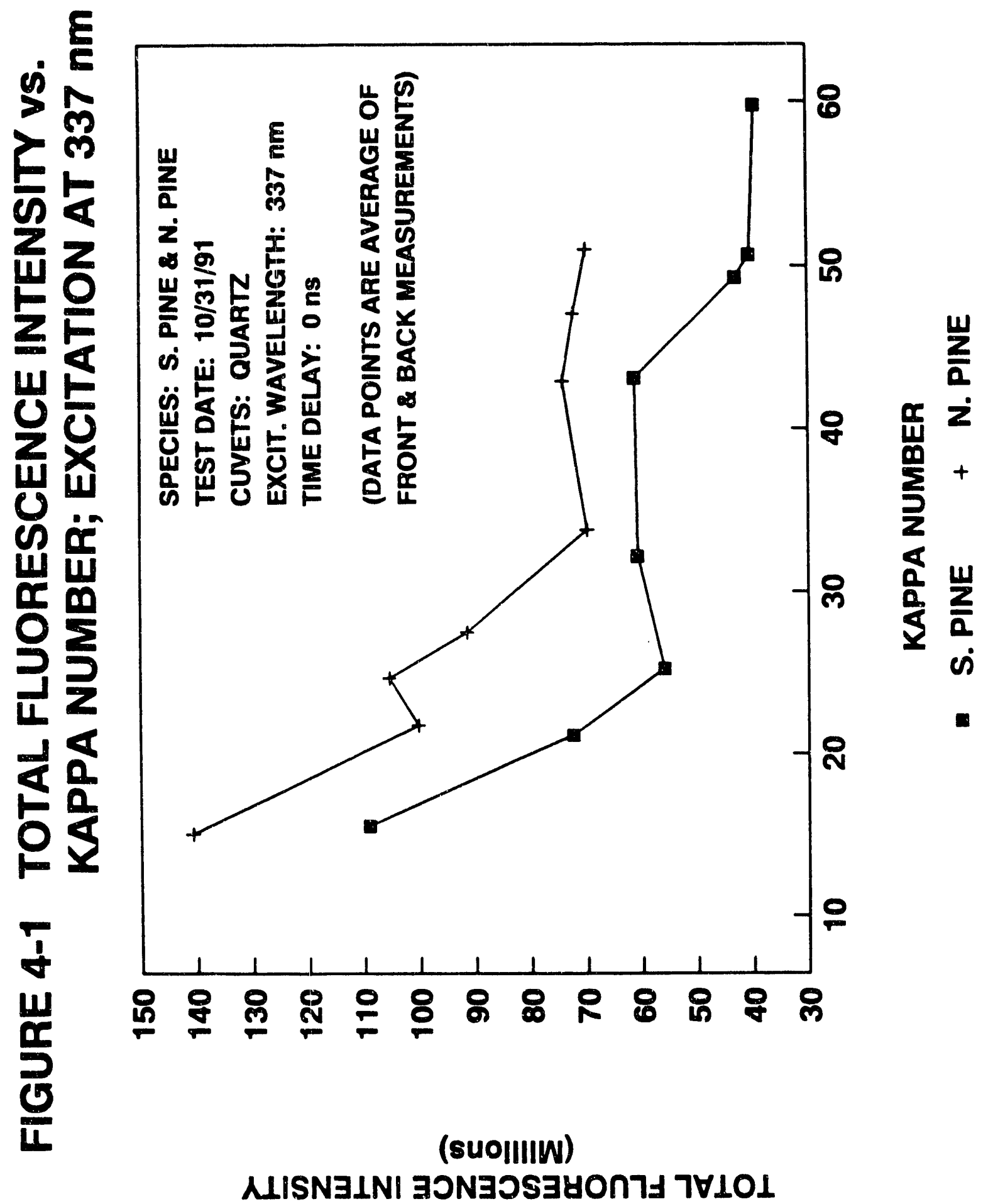




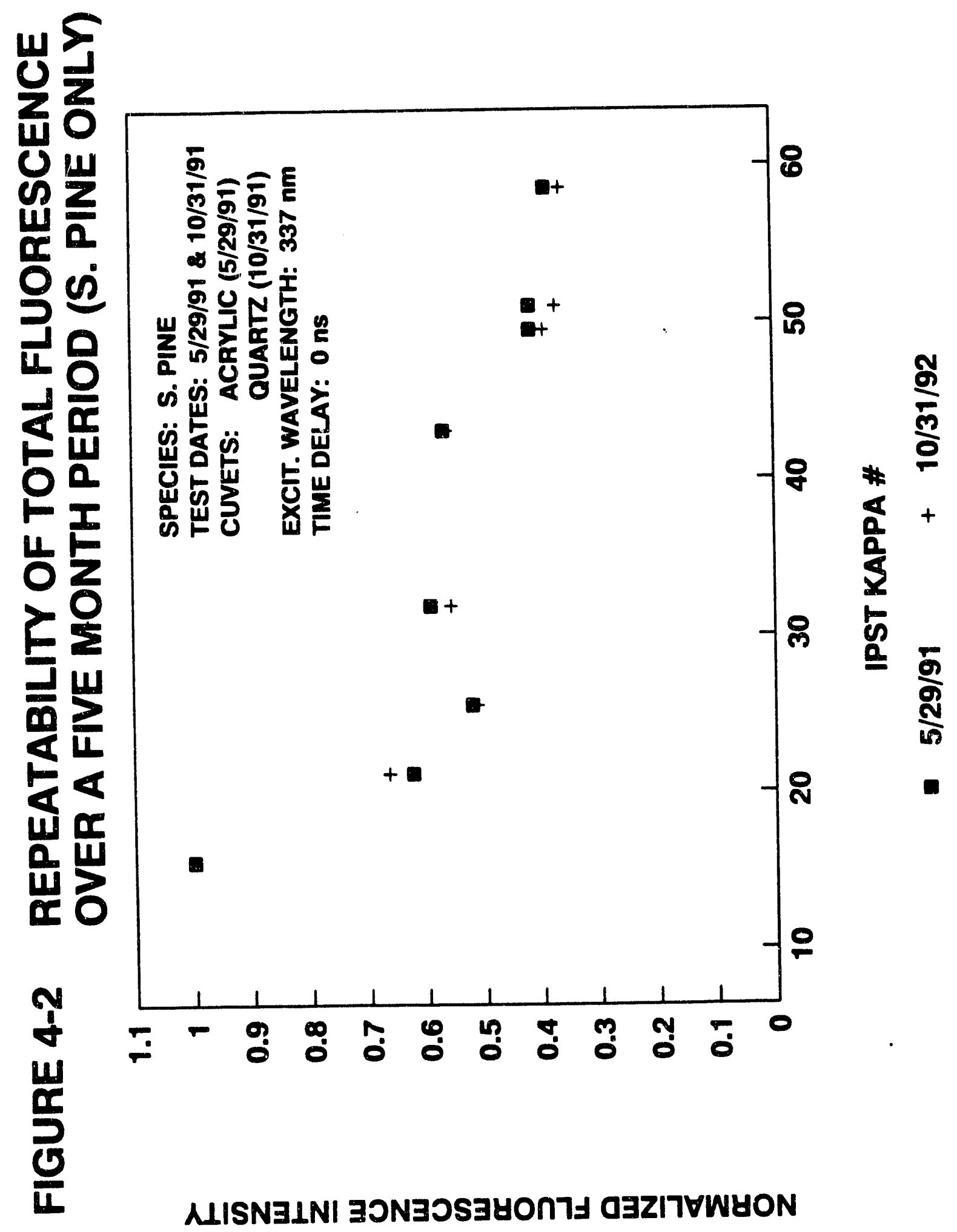




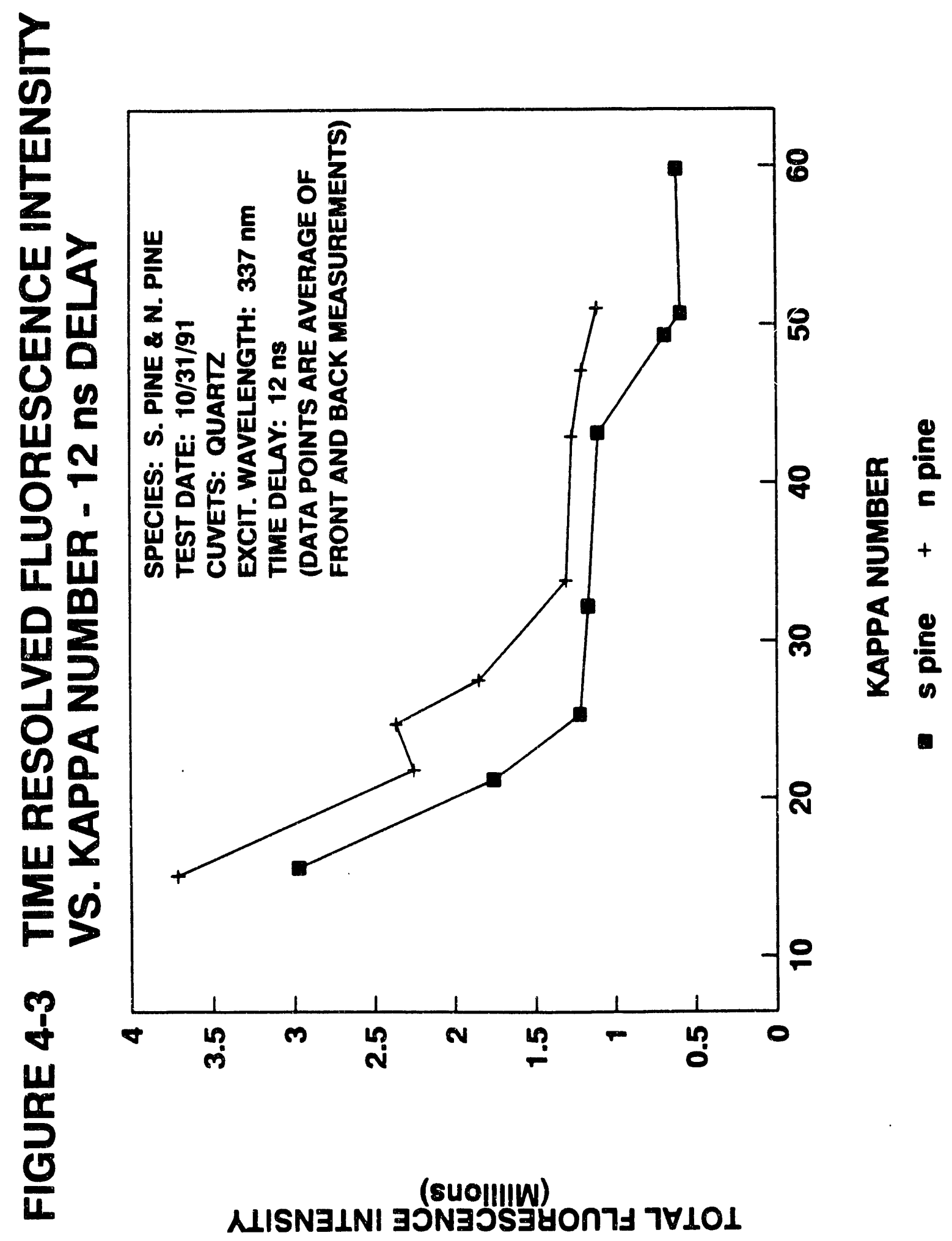




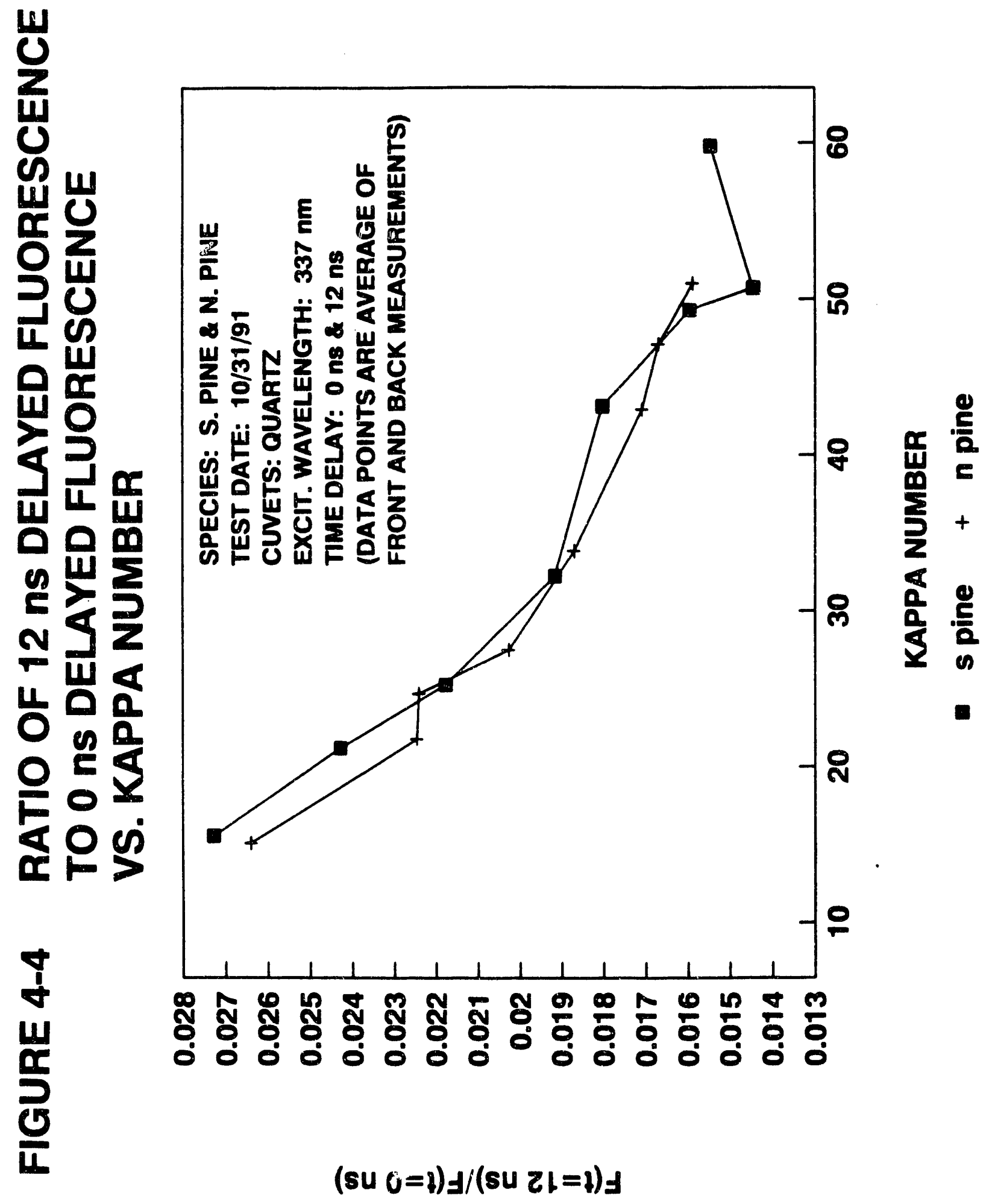




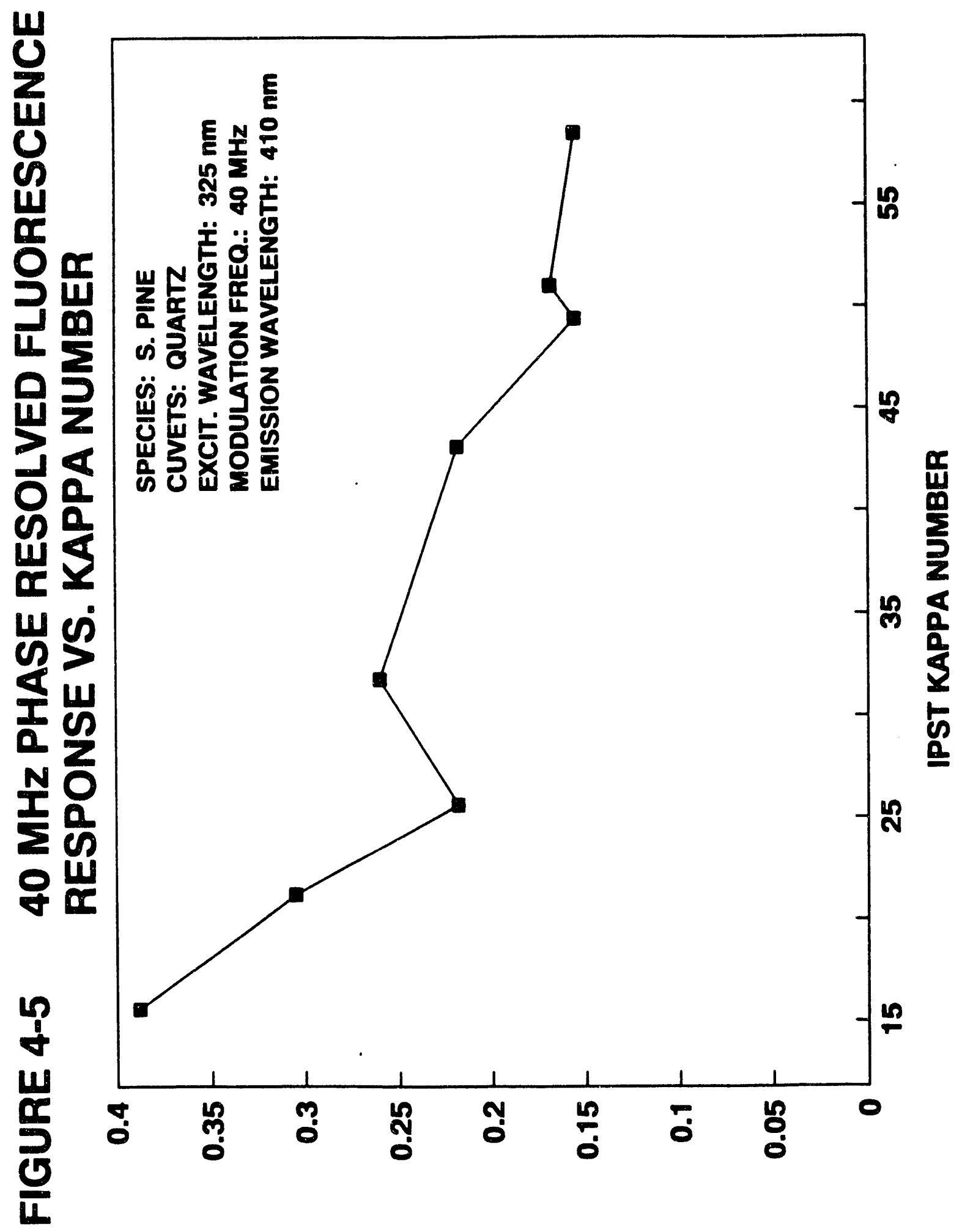

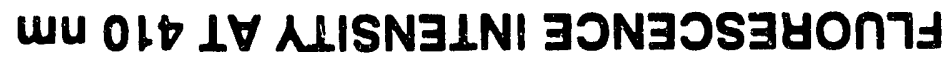




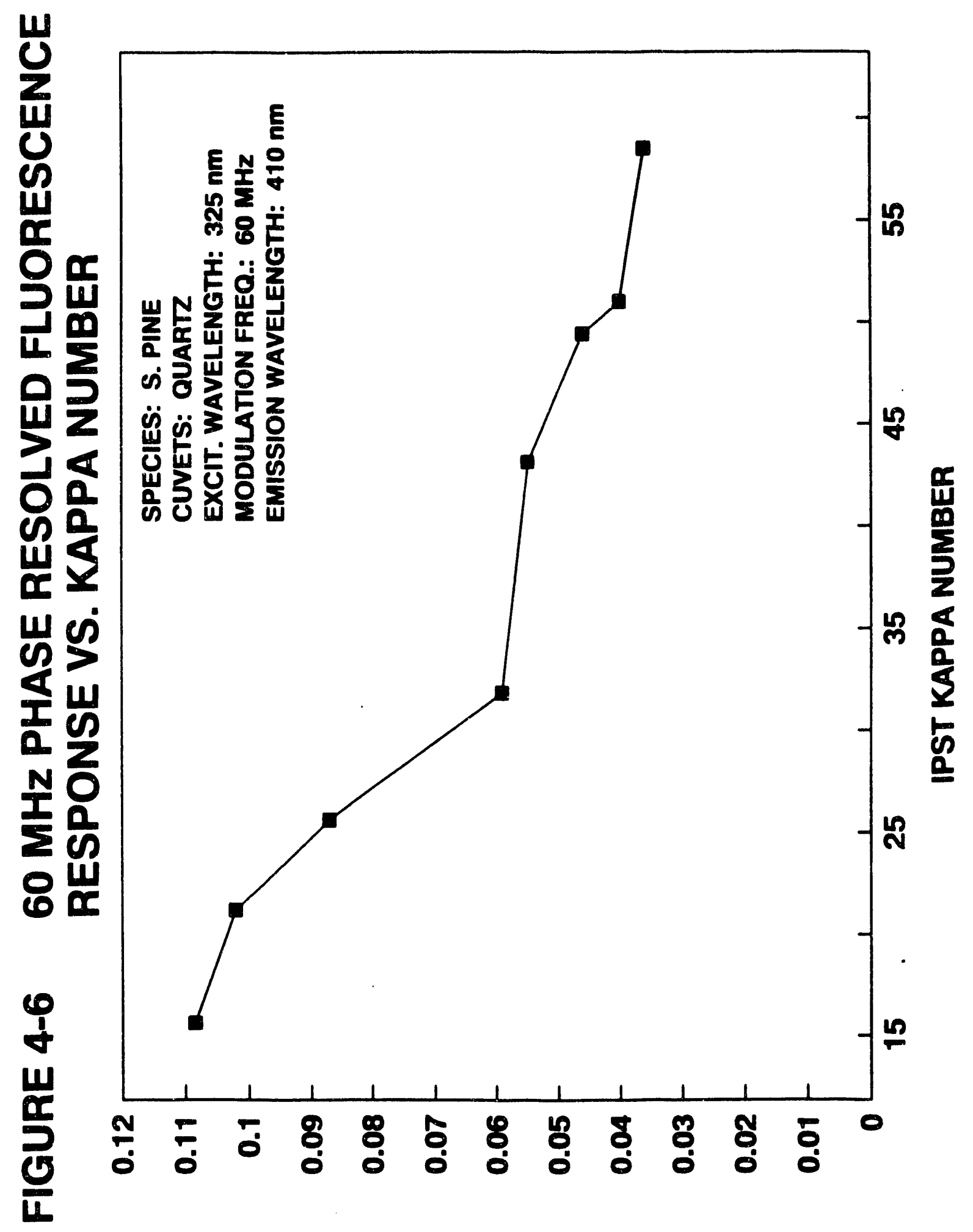

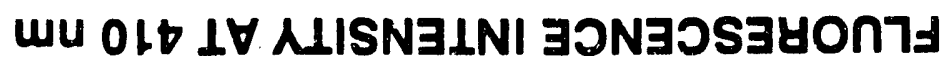




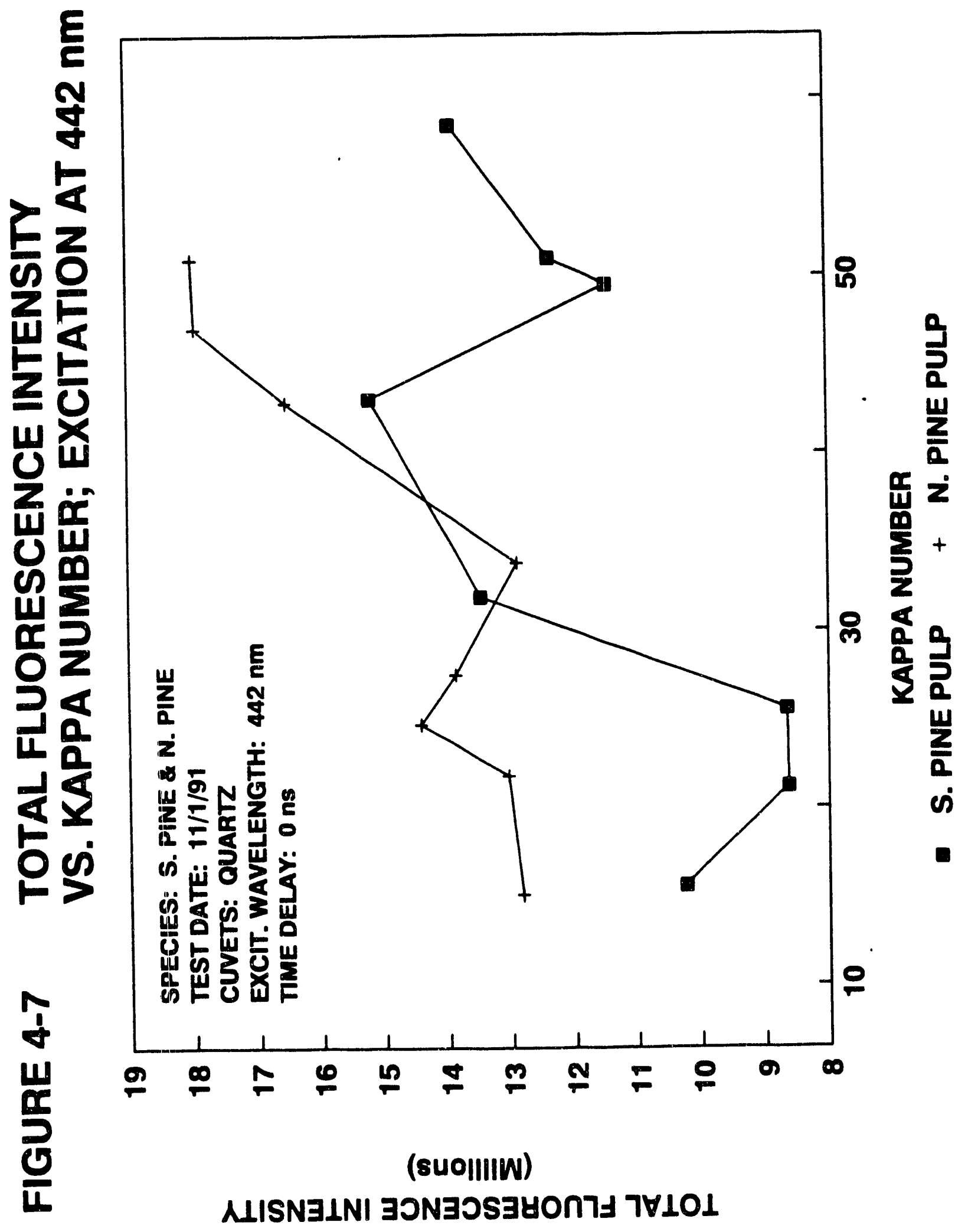




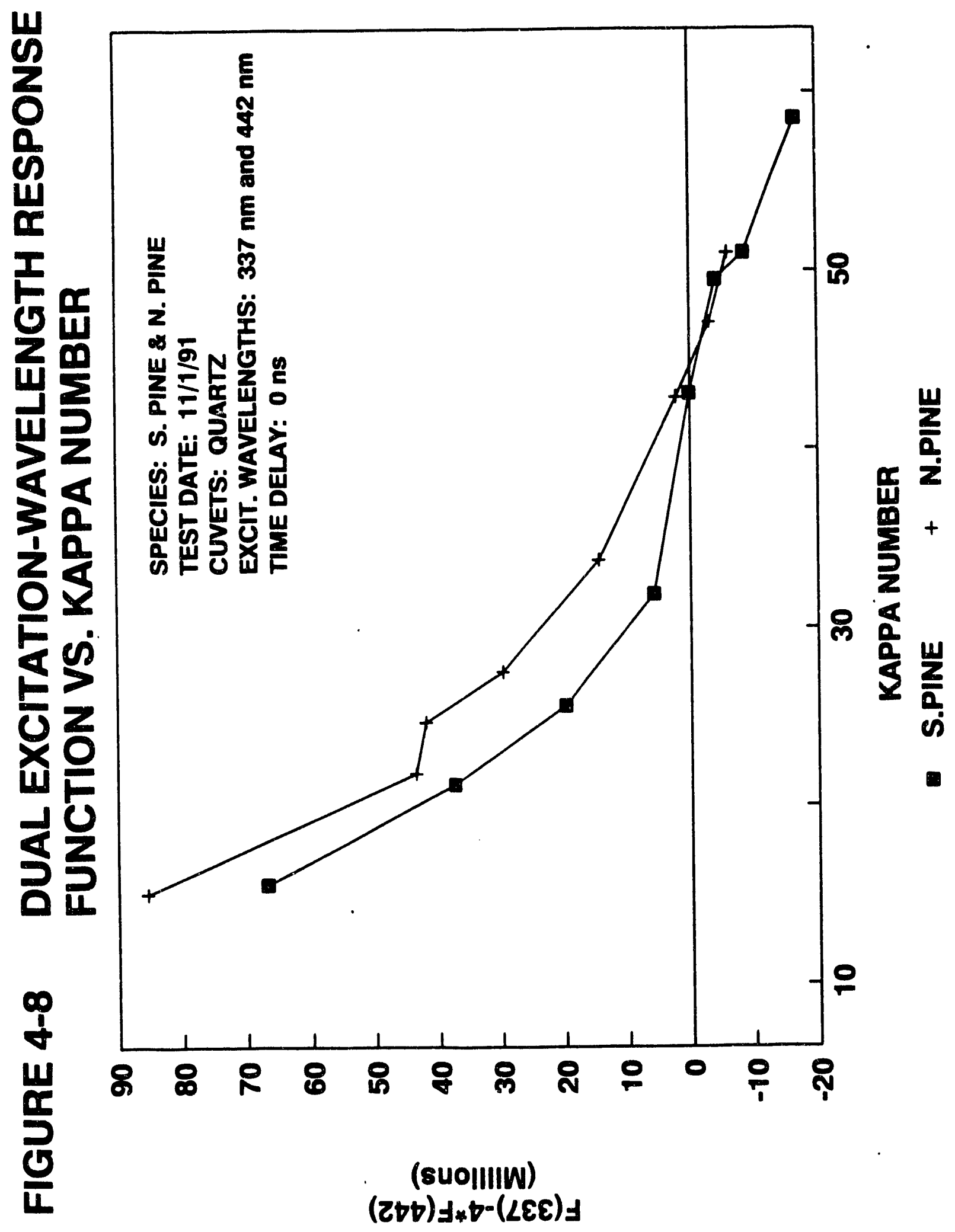




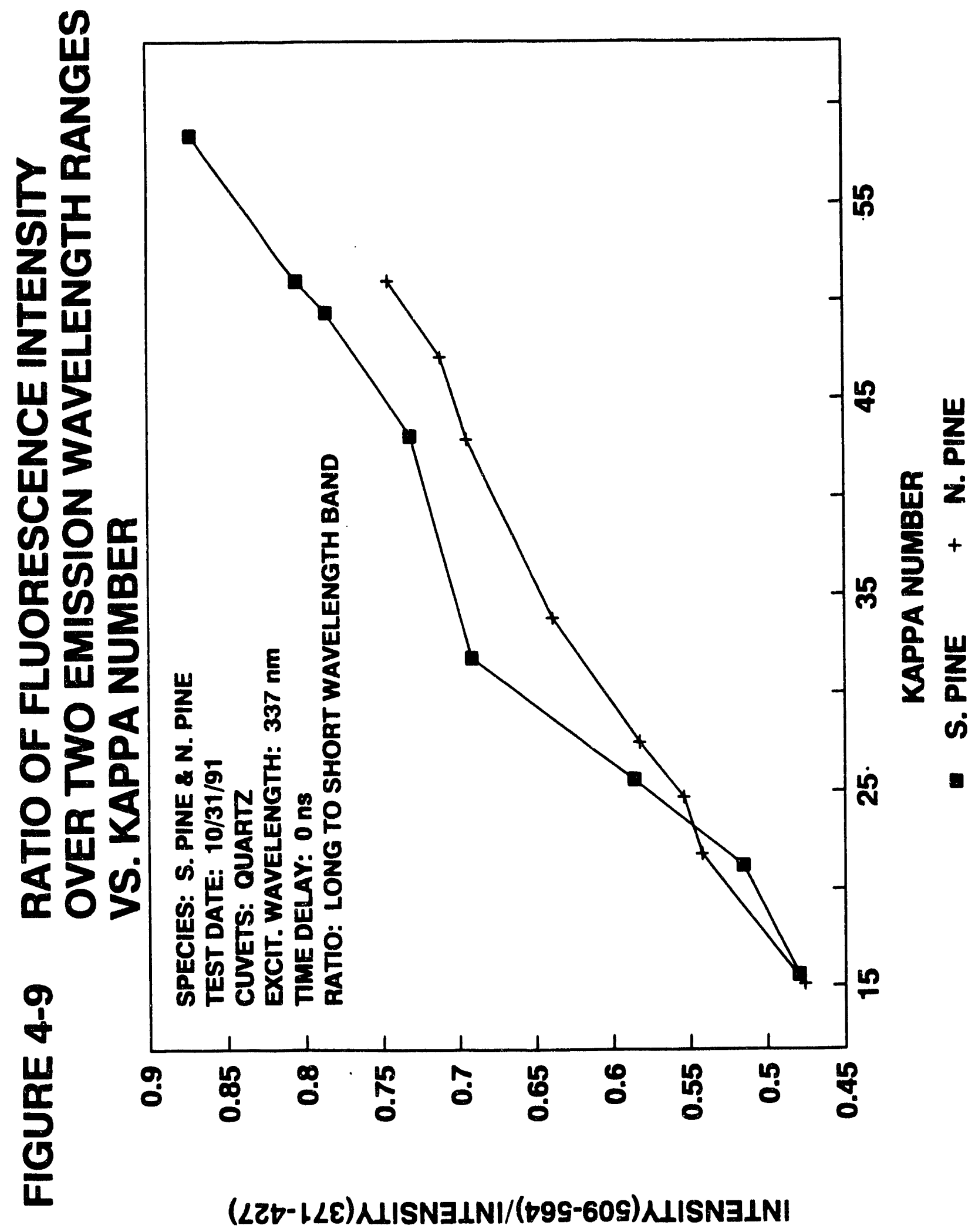




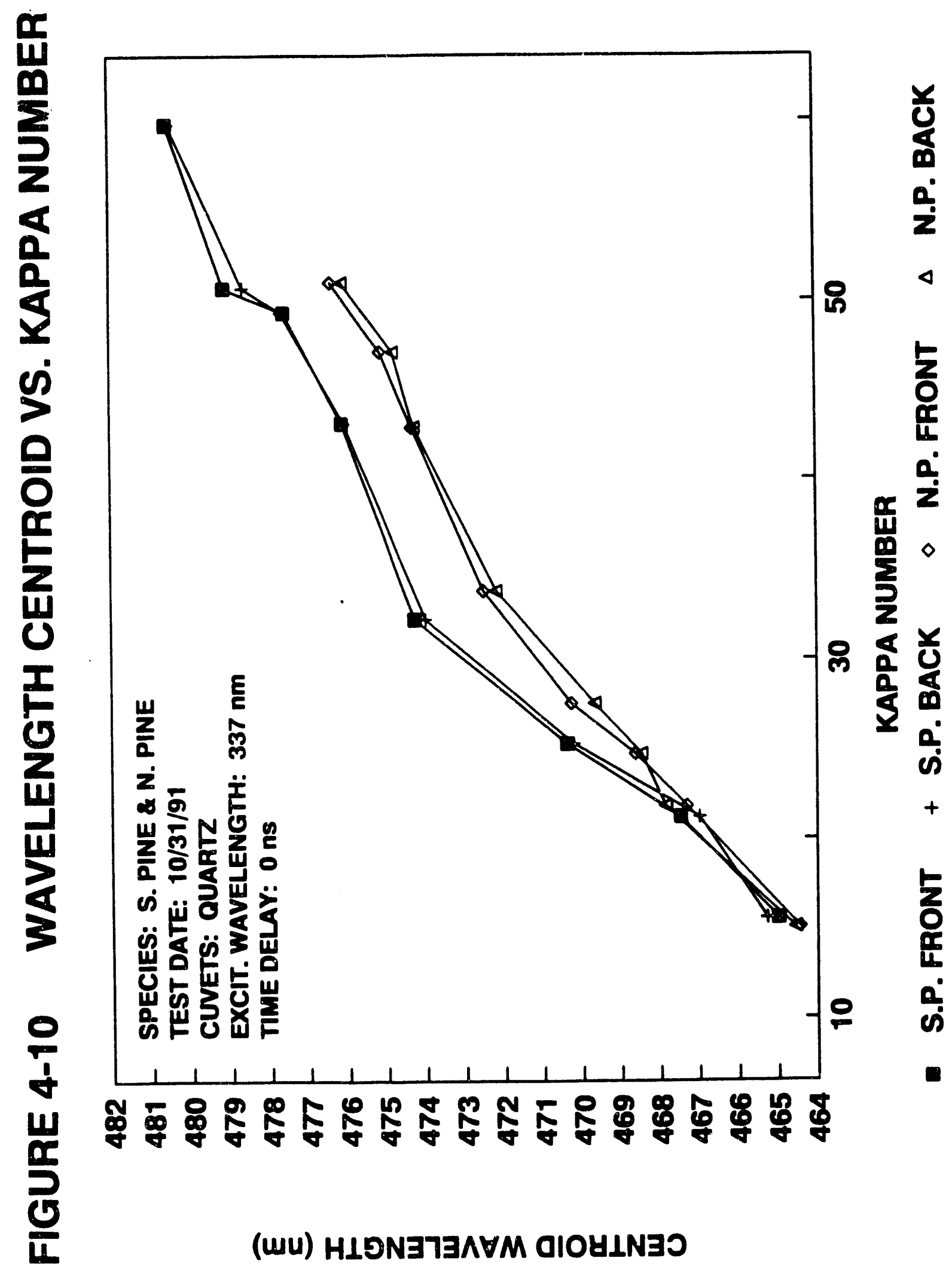




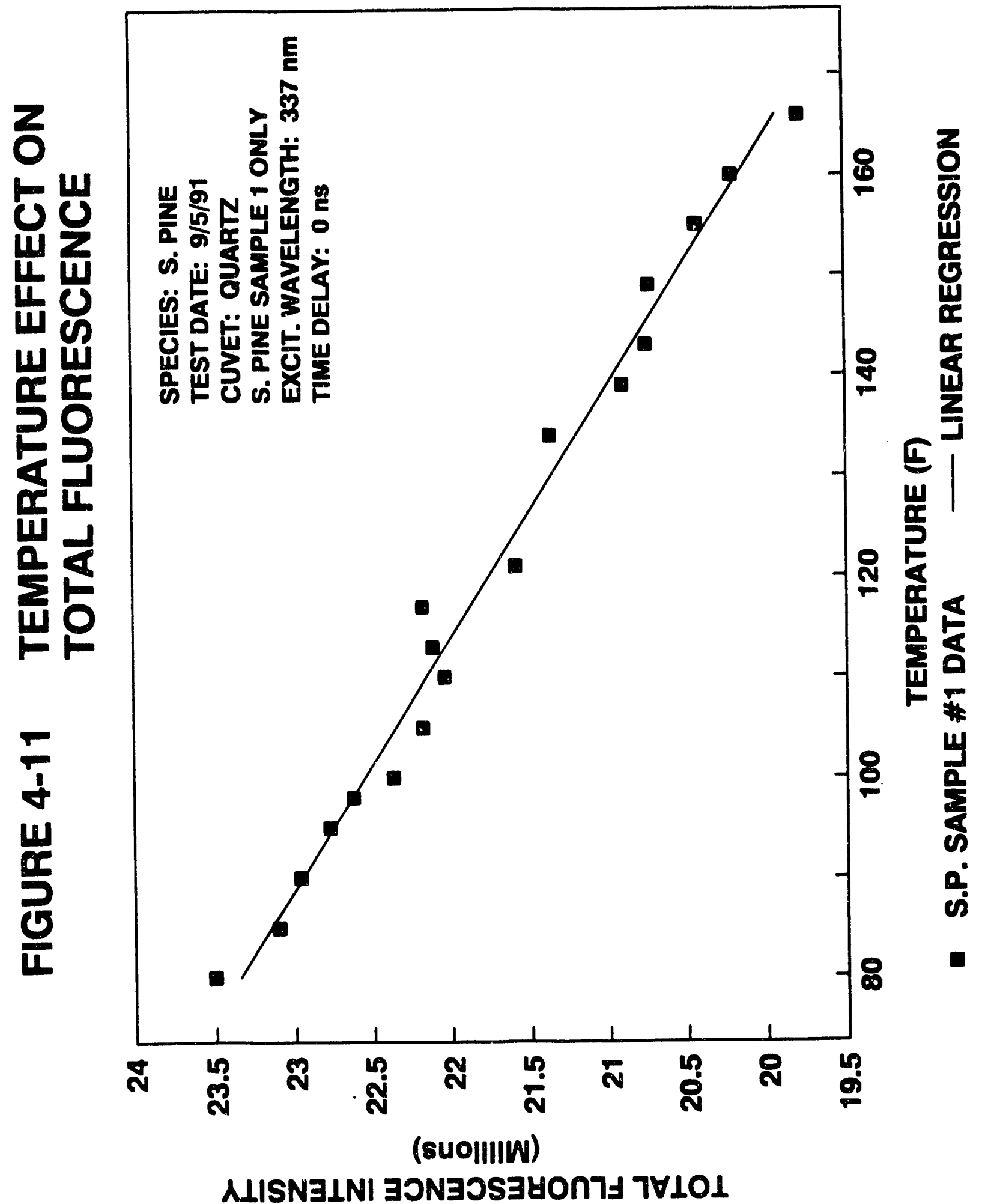




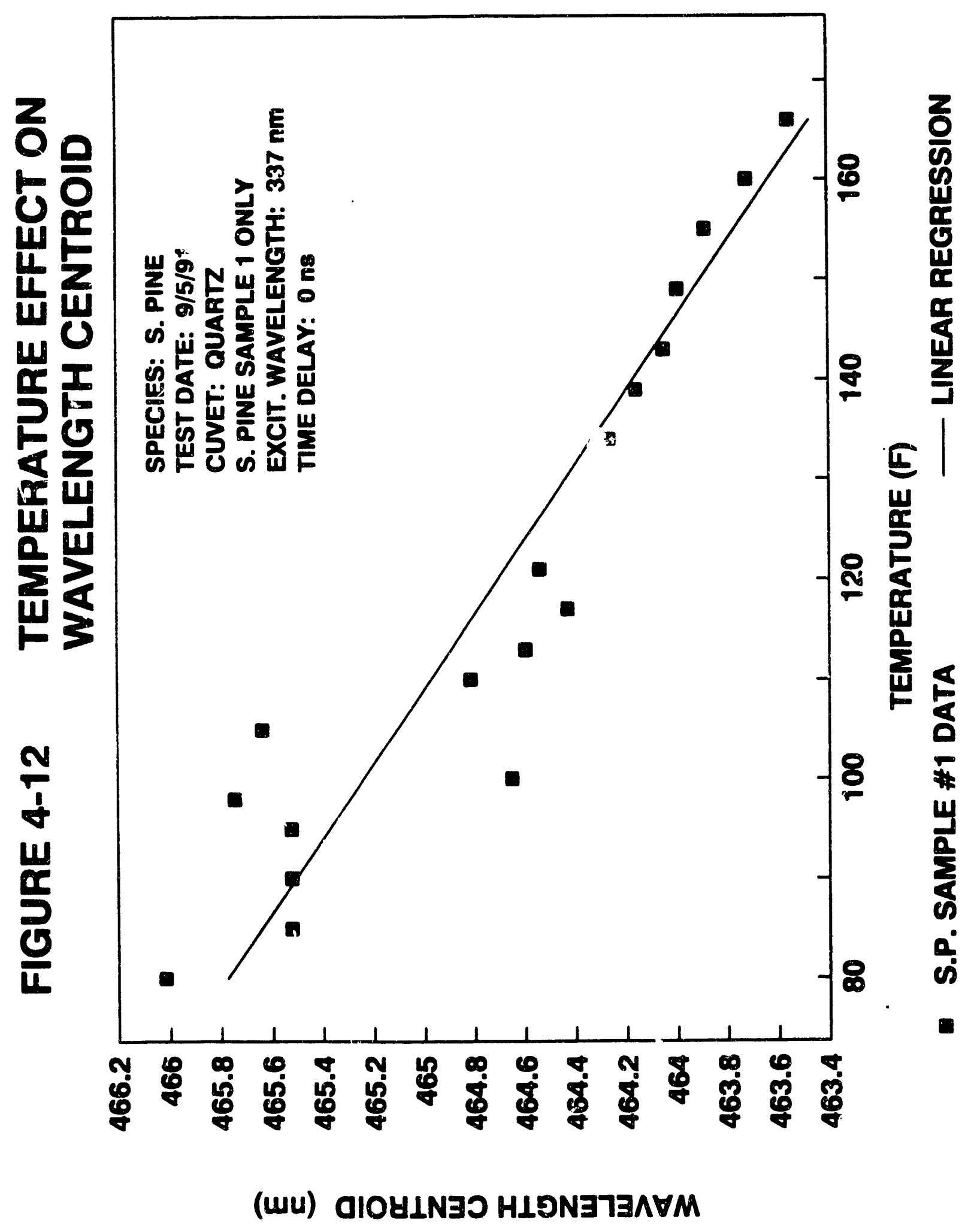




\subsection{CONCLUSIONS/RECOMMENDATIONS}

\subsection{CONCLUSIONS}

The laboratory characterization tests were undertaken to determine the source of the scatter observed in the Phase I feasibility tests and to provide the background data required for the design of a field prototype. As discussed in section 6.8, instrumental artifacts were ruled out as a factor in the data. Nevertheless, it was found that the total fluorescence intensity is not a monotonically decreasing function of Kappa number and, therefore, not suitable as a control signal. The problem seems to be associated with the presence of an interfering species that disrupts the general downward trend of the curve.

Several of the techniques commonly used in fluorescence spectroscopy for dealing with interferants were investigated to determine if they could be used to provide a suitable control signal. These tests showed that:

- Both time and phase-resolved techniques provide discrimination against the interference, as shown in Figures $4-3$ and 4-6. However, in both cases the sensitivi.y of the response function decreases at higher Kappa numbers. The ratio approach displayed in Figure 4-4 does improve resolution at high Kappa and results in species independence (at least for the two wood species tested). Hovever, since these approaches are among the most complex and costly, we shall not pursue them as a first choice.

Excitation of the fluorescence with wavelengths longer than the $337 \mathrm{~nm}$ nitrogen laser line results in total fluorescence vs Kappa number plots that are less monotonic than those for $337 \mathrm{~nm}$ excitation. This indicates that the longer wavelengths excite the fluorescence of the compound(s) not related to lignin concentration more strongly than the 337 nm excitation. 
- Linear combination of the total fluorescence generated by excitation of the fluorescence with two different wavelengths (e.g., $337 \mathrm{~nm}$ and $442 \mathrm{~nm}$ ) yields a response function that decreases monotonically with Kappa number (see Figure 4-8). This function could be used as a control function, although the sensitivity at high Kappa numbers is less than the sensitivity at low Kappa numbers.

- Two methods based on the Kappa number induced shift of the fluorescence spectral distribution were shown to give response functions very promising for control use. These are the "two wavelength band ratio method" shown in Figure 4-9, and the "wavelength centroid function" shown in Figure 4-10. Although both functicns appear to shcw a dependence on wood species, they have several significant advantages over the other methods identified. Specifically:

- instrumentally they do not require a fast gateable detector, or high-speed response detector as required by the time- and phase-resolved approaches.

- they require excitation by only one wavelength rather than two as in the dual excitation wavelength approach.

- they show no loss of sensitivity at higher Kappa numbers.

- the control function is independent of the absolute intensity of the fluorescence, so long-term intensity changes due to window/fiber transmission, detector sensitivity, source output, etc., will not present a problem.

- the sensitivity of the centroid function to temperature of the pulp is only $0.07 \mathrm{Kappa} /{ }^{\circ} \mathrm{F}$.

\subsection{RECOMMENDATIONS \& FUTURE WORK}

The objective of the characterization tests discussed in this report was to generate the background information necessary for the design of a field testable prototype.

The information in this report was presented orally at the November 11, 1991 DOE'Industry Advanced Sensors Technical Conference. 
Industry representatives recommended that the following additions to the scope of the project be carried out prior to the design of the field prototype.

- Develop laboratory test data on a wider variety of wood species.

- Investigate more fully the effect of various concentrations of black liquor on the results.

- Examine the "in-pipe" sensor applications as well as the washroller applications.

- Obtain pulp samples covering a greater range of Kappa numbers (3 through 100), including bleached pulps.

The characterization rests reported here have identified the wavelength centroid measurement as the preferred approach for incorporation into the field prototype. Although the wavelength centroid approach has been shown to provide a good measure of Kappa number under the conditions of our laboratory tests, the range of conditions included in the tests was limited. The four additions to the workscope enumerated above are intended to determine if the approach is applicable as the range of experimental conditions is expanded in various "dimensions".

We propose to design and conduct additional laboratory characterization studies aimed at addressing the four recommended additions. The tests will be designed to determine the range of applicability of the wavelength centroid approach.

After completion of the additional laboratory tests the remaining Phase II work will consist of the following:

- Design a prototype sensor using the "wavelength centroid function" as the primary measurement technique. The prototype will be designed using electronics and post-processing capabilities similar to those used in the laboratory tests. The prototype will include the capability of employing time-

$$
5-3
$$


resolution and variable wavelength excitation. Although the results to date indicate that variable excitation and time resolution are not needed in the instrument, the variable excitation and time-resolved capability can be carried along with little additional effort and would make the prototype sensor more versatile. Once field testing is complete, some of the capabilities of the prototype could be dropped to make a more cost-effective production unit for the application. The prototype will include temperature and $\mathrm{pH}$ measurements online.

- Fabricate and debug the prototype sensor in the laboratory.

- Field test the prototype sensor at the final stage of a typical vacuum washer of one or more operating pulp mills.

- Conduct laboratory testing as required to support the prototype design and investigate questions raised during the field tests.

One of the reviewers of the draft version of this report recommended laboratory testing to demonstrate the capability to provide precision necessary for control over several narrow ranges of kappa, e.g., 13-22, 22-40, and 80-100. While we agree that this information is crucial to the final success of the product, we feel that the most cost effective way to get this information is through prototype tests at an operating mill. The test plan for the prototype sensor will therefore address this issue. 


\subsection{APPARATUS}

\subsection{SYSTEM OVERVIEW}

Figure 6-1 is a block diagram showing the major components of the fluorescence spectroscopy system used in the laboratory test program.

A Laser Science, Inc., Model VSL-337 pulsed nitrogen laser is used to either directly excite the fluorescence in the wood pulp, or to optically pump a tunable dye laser (Laser Science, Inc. Model DLM120) which is then used to excite the fluorescence. The nitrogen laser provides peak power of 40 kilowatts with a pulse width of 3 nsec, and pulse rate from 1 to 20 pulses per second at a wavelength of $337 \mathrm{~nm}$. The dye laser provides output at any wavelength from the near UV through the visible spectrum. The power level of the dye-laser output is reduced by a factor of 4 to 20 from the nitrogen laser depending on the wavelength of operation.

The collection/excitation optics consists of a set of lenses and mirrors that:

- focus the laser beam to a small (less thar. $1 \mathrm{~mm}$ ) spot on the sample.

- focus the resultant fluorescent light onto a long fiber optic bundle, FBl, that delivers it to the monochromator.

- focus a portion of the original laser light onto an optical fibex, FB2, that delivers it to the gate pulse generator as a trigger signal.

The pulp sample is loaded into a standard cuvet $110 \mathrm{~mm} \times 10 \mathrm{~mm} \times$ $45 \mathrm{~mm}$ ) that is mounted on an $X-Y-z$ translation stage. The $z$-axis is manually adjusted to put the sample surface at the focus of the laser. The $X$ and $Y$ axes are stepper-motor driven to provide a raster scan of the pulp surface during data acquisition.

The function of the gate pulse generator (Princeton Instruments Model FG-100) is to provide a voltage pulse that rapidly turns the detector on and off. The detector is turned on for the duration of the gate pulse which can be varied from $5 \mathrm{nsec}$ to $2000 \mathrm{nsec}$. The beginning of the gate pulse can be varied from about $25 \mathrm{nsec}$ to 1700 
nsec after the arrival of the trigger pulse to the gate pulse generator from the laser light through fiber FB2. The ability to turn the detector on and off in sync with the pulsing of the laser provides a very high degree of discrimination against background light. For example, if the laser is pulsed once per second and the detector is turned on for only $10 \mathrm{nsec}$, it will only "see" $10^{-8} \mathrm{~B}$, where $B$ is the intensity of the constant background light. As a result, it is possible to perform all measurements with room lights on and no detectable interference. In addition to background light rejection, the gating provides the means to obtain time-resolved data.

The oscilloscope is used to monitor the time delay (at subnanosecond resolution) between the laser firing and the detector gating. It enables the time delay to be adjusted precisely for experiments employing "time-resolved fluorescence".

The function of the monochromator is to spread the incoming fluorescent light into a spectrum and focus that spectrum onto the 700 individual elements of the detector array such that each detector element receives light of a different wavelength. The detector array actually contains 1024 elements, but only the center 700 are used due to size limitations of the intensifier stage.

The detector (Princeton Instruments Model IRY-690G/B/PAR) consists of a thermoelectrically cooled array of silicon photodiodes equipped with an image intensifier (microchanel plate). The intensifier provides the gating capability as well as very high sensitivity.

The detector controller (Princeton Instruments Model ST120) provides periodic readout of the detector under software control through a PC/AT compatible computer. The readout of the detector array is synchronized with the laser pulses via a readout pulse that is derived from the gate pulse. Readout consists of:

- performing an $A / D$ conversion of the signal from each of the 1024 individual elements of the detector array. 
- storing the results of the conversions to the computer's hard disk.

- resetting the photodiodes for the next reading.

The computer provides:

- operator interface

- storage of results

- real-time display of the results

- post-test display and analysis of the results.

\subsection{SYSTEM TIMING}

As discussed above, the laser, detector gating, and readout are ail synchronized. Figure 6-2 shows the timing involved. The 3 nsec laser pulse is the reference event.

The fluorescent signal begins a few nsec after the beginning of the laser pulse (the time required for the light to travel from the laser to the sample) and rises very quickly to a peak that coincides with the arrival of the end of the laser pulse. The fluorescence then decays over a period of less than $200 \mathrm{nsec}$.

There is a delay of roughly $35 \mathrm{nsec}$ between the start of the laser pulse and the time when the gate pulse arrives at the detector. Part of this delay is due to the time required for the trigger pulse to travel to the gate pulse generator but most of it is due to inherent speed-of-response limitations in the electronic circuitry of the gate pulse generator itself. Note that this delay means that, unless special provisions are taken, the detector will not be turned on until after the bulk of the fluorescent light has been emitted.

To circumvent this problem, the fiber optic bundle, FB1, used to carry the light to the monochromator, was selected to be 10 meters long. The transit time through the bundle is approximately $50 \mathrm{nsec}$ and the light arrives on the detector after the gate pulse has turned on the detector. The combination of the FG100 gate pulse generator and the IRY microchannel plate allows "gate on" or "gate off" speeds of approximately 7 ns. 


\subsection{DATA ACQUISITION PARAMETERS}

The detector readout trigger, which is generated by the transition at the end of the gate pulse, triggers a read and reset of the detectors. A readout of the detector array occurs, therefore, for each pulse of the laser. During set-up of the equipment, via the software running on the computer, the user can specify that several readouts be automatically added together to produce a final result which is then saved as a spectrum. This accumulation improves the signal-to-noise ratio in the resultant spectrum by roughly the square root of the number of pulses accumulated. Another feature of the setup software is the ability to specify that a given number of consecutive spectra be recorded, each consisting of the addition (accumulation) of multiple pulses. One can, for example, set an experiment where 100 spectra are recorded, each one being the result of 50 lasez pulses.

For the majority of the tests, the system was set to accumulate the results of 90 to 100 laser shots to provide a single spectrum. The only data obtained with different set-up parameters was taken to determine the extent to which the pulp samples are sensitive to bleaching. In the bleaching tests, the sample was held stationary, the accumulation was set to 10 , and 10 spectra were recorded. Data recording was, however, not continuous. Each spectra was recorded 1000 pulses after the preceeding one, giving data over a 10,000 pulse exposure. These bleaching tests provided a measurement of the drop in fluorescence intensity as a function of successive laser pulses.

\subsection{ELECTRONICS}

Figure 6-3 shows the interconnection of the electronic system. Fiber, FB2, delivers a trigger pulse from the laser into the optical trigger input on the back of the FB-100 gate pulse generator. The gate pulse to the detector is taken from the output labeled VARIABLE. None of the other back panel connectors are used in the present mode of operation. The front panel connector labeled INPUT is intended for the input of an electronic trigger signal. Because it is internally connected to the signal generated by the optical trigger input, it is used to monitor the arrival of the optical trigger through the front 
panel "INPUT" connector. This signal is displayed on channel 1 of the high-speed oscilloscope (Hewlett Packard Model 54510A) and the gate pulse is monitored on channel 2 using the PULSE MONITOR output on the front of the FG-100.

Displaying the laser pulse and the gate pulse on the oscilloscope allows quantitative determination of the pulse delay and pulse width, both of which are adjustable by the use of 10 turn potentiometers on the front panel of the FG-100. The third potentiometer labeled REP RATE is used to set the frequency of an internally generated trigger signal which is not used in the present mode of operation. For the testing reported here, the internal trigger on the laser was used (adjustable from $1-20 \mathrm{~Hz}$ ).

The signal from the pulse monitor output is split and used, not only for the scope display, but also to generate the readout trigger pulse which is connected to the EXT-SYNC port on the back of the ST120 controller.

\subsection{OPTICS}

Figure 6-4 shows the layout of the optical system. The specimens (samples) are contained within standard $10 \mathrm{~mm}$ cuvets which mount on a precision $X, Y, Z$ translation stage. During a standard 100 pulse data run, the laser is pulsed at a rate of 2 pulses/sec and the stepper motors provide a raster scan of the cuvet at a rate of $2 \mathrm{~mm} / \mathrm{sec}$. The focused laser spot is less than $1 \mathrm{~mm}$ in diameter, so each pulse strikes the pulp at a previously unexposed point. This provides two important functions. First, it assures that the resultant data is independent of bleaching effects. Second, it distributes the exposure over an extended area to minimize the effect of localized variations in the pulp properties.

Both acrylic and quartz cuvets were employed to hold pulp specimens during fluorescence tests. The quartz cuvets were more uniform and had much less background fluorescence than the acrylic cuvets. Acrylic cuvets were used extensively during early testing for convenience in testing large numbers of samples. Since the acrylic 
cuvets did introduce some aliasing and data scatter (see Section 6.9), the most critical tests were repeated using only quartz cuvets.

The fluorescence delivery bundle, FBI, consists of seven fibers each with a 365 micron core diameter. At the pick-up end, they are arranged in a circular pattern approximately $1.2 \mathrm{~mm}$ in diameter which is the same as the nominal diameter of the spot to which the fluorescent light is focused by the spherical mirror, M4. At the output end of the bundle, the seven fibers are aligned in a single file row to provide a good geometrical match to the entrance slit of the monochromator. A set of relay lenses focuses an image of the $1 \times 7$ fiber array onto the monochromator's entrance slit. The monochromator's entrance slit is continuously adjustable and was not necessarily set to the same opening each time a set of tests were conducted. Therefore, comparison of absolute values of fluorescence intensity from one test period to another may not be valid.

The laser beam, which exits the laser with a rectangular cross sectional area $(\approx 2 \times 8 \mathrm{~mm})$, is diverged by lens $\mathrm{Ll}$, and then focused by lens 12 to a spot on the specimen less than $1 \mathrm{~mm}$ in either dimension. The absorbance of the pulp sample is high, so the laser beam is essentially absorbed at the pulp surface.

The fluorescent light is focused by the spherical mirror onto the end of the fiber bundle FBI with a slight $(\approx 1.2 \mathrm{X})$ magnification. $A$ $380 \mathrm{~nm}$ long pass filter, $F$, just in front of FBl absorbs most of the scattered $337 \mathrm{~nm}$ laser light to prevent it from entering the fiber where it could produce noise fluorescence in the fiber material and scatter in the monochromator.

The beam splitter, BS, reflects about $8 \%$ of the laser beam towards lens 13 which focuses it onto the end of the trigger fiber FB2.

All of the components, with the exception of the monochromator and detector, shown in Figure 6-4 are attached firmly to an optical breadboard. 


\subsection{REFLECTION TESTS}

Not shown in Figures $6-1$ or $6-4$ are a pair of He-Ne lasers (one with output at $633 \mathrm{~nm}$ and the other at $543 \mathrm{~nm}$ ) and their associated beam steering optics that were used in the series of diffuse reflection tests. In these tests both lasers were focused simultaneously to a spot about $1 \mathrm{~mm}$ in diameter that coincided at the sample surface with the position of the fluorescence excitation laser spot. The scattered (diffusely reflected) light was collected and input to the monochromator/detector with the same optical collection system used for the fluorescence tests.

\subsection{PHASE-RESOLVED FLUORESCENCE}

The phase-resolved fluorescence tests were conducted at Duke University, Department of Chemistry, using an SLM-48000 system and a Licon $2 x$ model $4240 \mathrm{NB}$ HeCd CW laser with $15 \mathrm{~mW}$ of power at $325 \mathrm{~nm}$. A front surface adapter was employed. All phase-resolved testing was conducted with quartz cuvets.

\subsection{SYSTEM PERFORMANCE}

The procedures and apparatus developed for the Phase II tests reported here provide true characterization of the pulp fluorescence properties free of instrumental artifacts. Specifically:

- The apparatus exhibits repeatability on the order of \pm 5 .

- The procedure for scanning the excitation beam over an extended area of the sample surface provided good representative sampling. This was evidenced by the fact that the measurements taken by exposing the front surface of the sample cuvet matched those from back surface exposure within about $5 \%$.

- The fluorescence properties of the pulp samples remained stable over a five-month period of refrigerated storage. 
- The pulp samples were subject to bleaching such that the total fluorescence decreased about $0.18 /$ laser pulse. Since the testing procedure insured that no spot would receive more than two laser pulses the effect of bleaching on the reported data is negligible.

- The total fluorescence from the quartz cuvets used to hold the samples was negligible, being less than 0.38 of the fluorescence from the pulp samples.

- The greatest source of uncertainty in the results presented here is due to questions about the true Kappa number of the pulp sampies (see section 7.2 ).

\subsection{ELUORESCENCE OF EMPTY CUVETS}

Figure 6-5 shows the fluorescence intensity spectra for a typical empty quartz cuvet and a typical acrylic (Fisher brand) cuvet. The empty quartz cuvet intensity is not appreciably higher than the detector background signal, while the empty acrylic cuvet has a peak intensity of approximately 6000 counts. This compares to the peak intensity of 130,000 counts for an acrylic cuvet filled with southern pine sample \#1, as shown in see Figure 6-7 (note that both the empty cuvets and the pulp filled cuvets were tested at the same conditions; e.g. number of laser pulses per spectra, entrance slit opening, etc.). The empty cuvet fluorescence spectra depicted in Figure 6-5 is typical of the majority of all cuvets used. Many hundreds of acrylic cuvets were used in the course of the test program and approximately 30 empty cuvets were tested at random during the course of the program. Until August of 1991, all empty cuvets tested displayed fluorescence spectra nearly identical to that shown in Figure 6-5. In August 1991, during the $\mathrm{pH}$ test series, tests on six empty acrylic cuvets fxom a cuvet carton of 50 were tested. The results of these tests are presented in Figure 6-6. As can be seen, three of the cuvets produced spectra nearly identical to that shown on Figure 6-5, while the others displayed significantly different spectra (significantly higher in intensity and shape). The $\mathrm{pH}$ testing had already been completed on acrylic filled cuvets and was not repeated. The peak intensity from the "worst" empty cuvet in Figure $6-6$ is approximately 37,000 counts. 
This is a significant portion of the 130,000 counts for southern pine pulp sample 1 and approaches the intensity of southern pine sample \#. Although the pH tests already completed were not repeated, subsequent testing was conducted in quartz cuvets. 


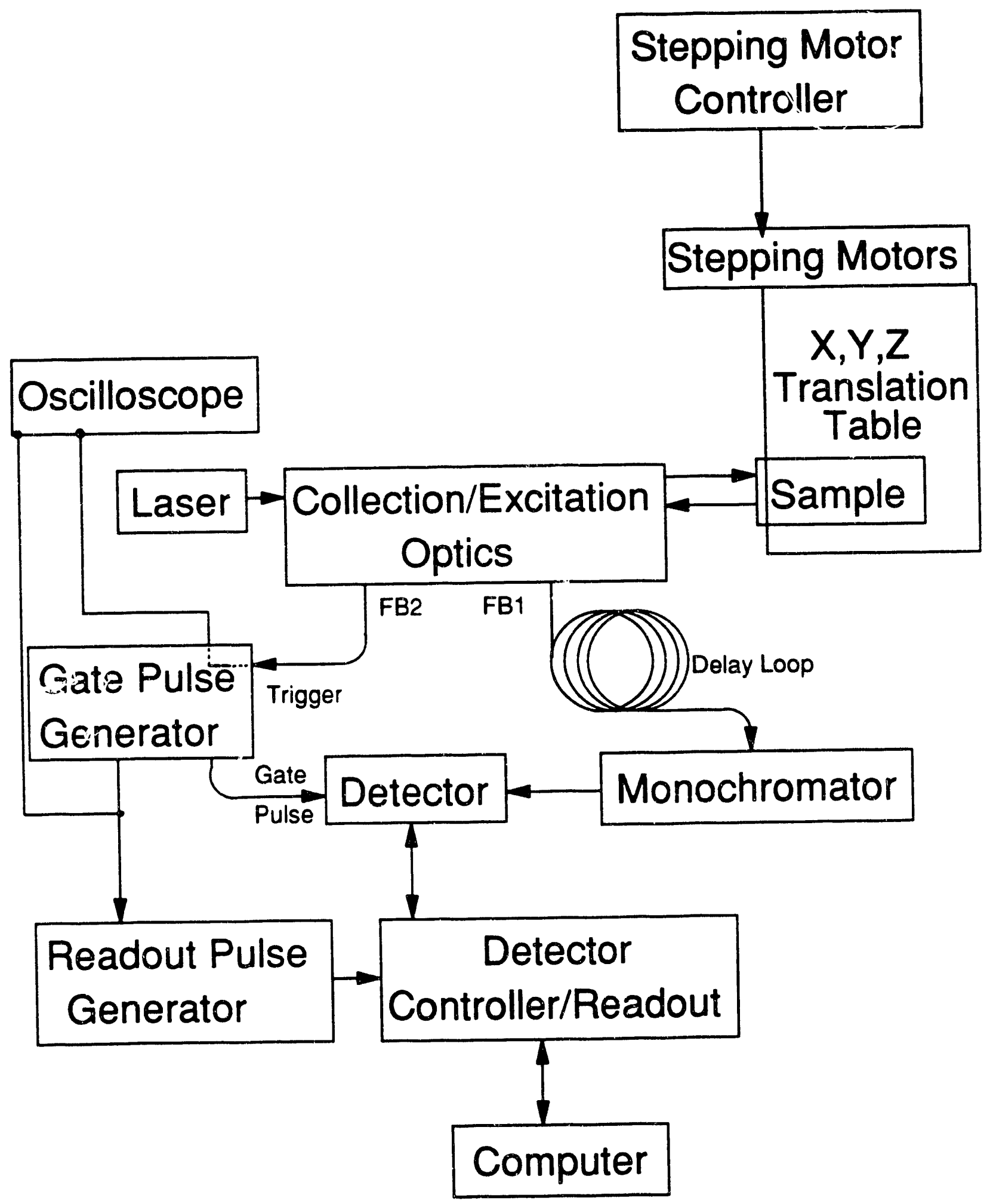

Figure 6-1. Block Diagram of Fluorescence Spectroscopy System 


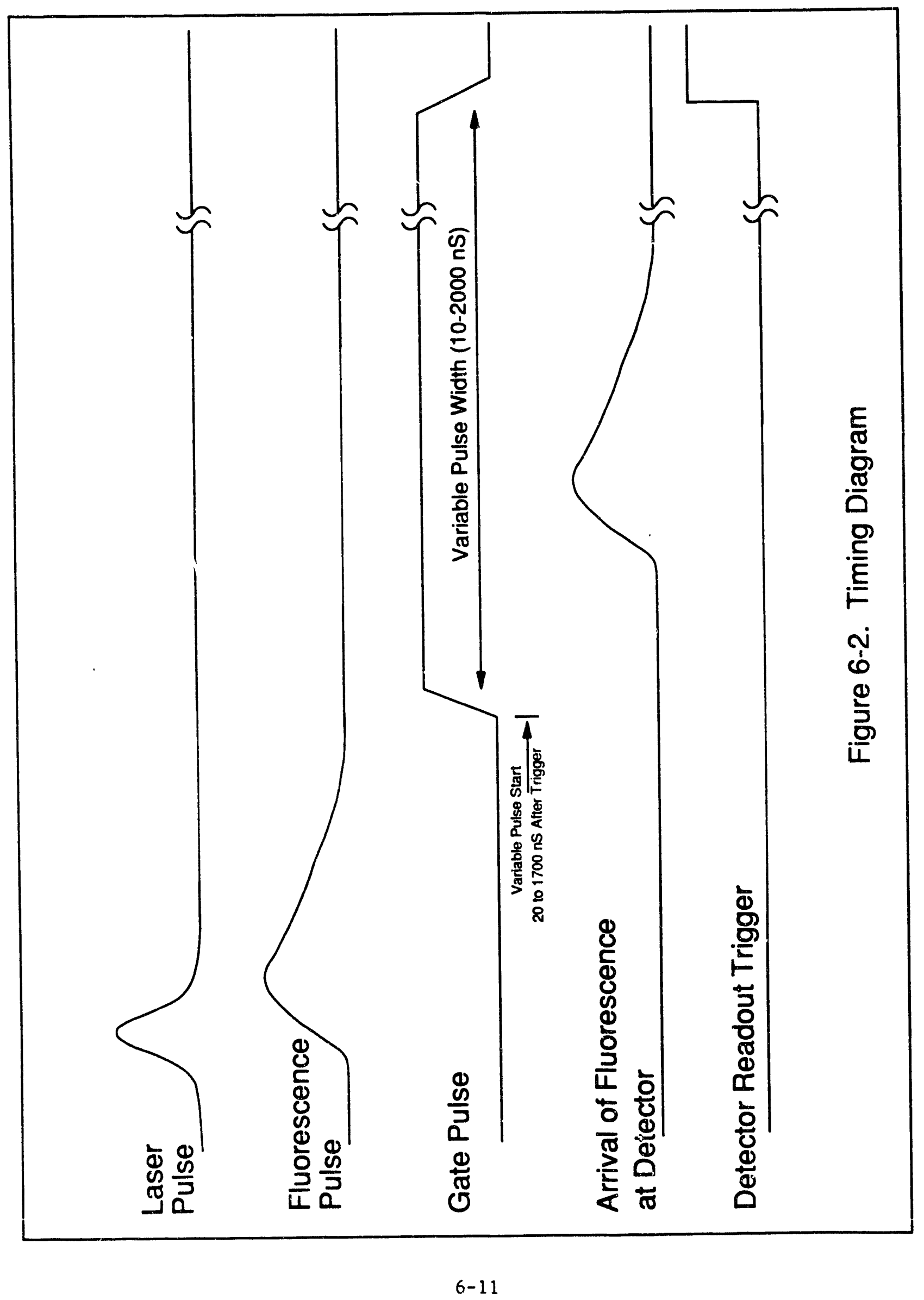




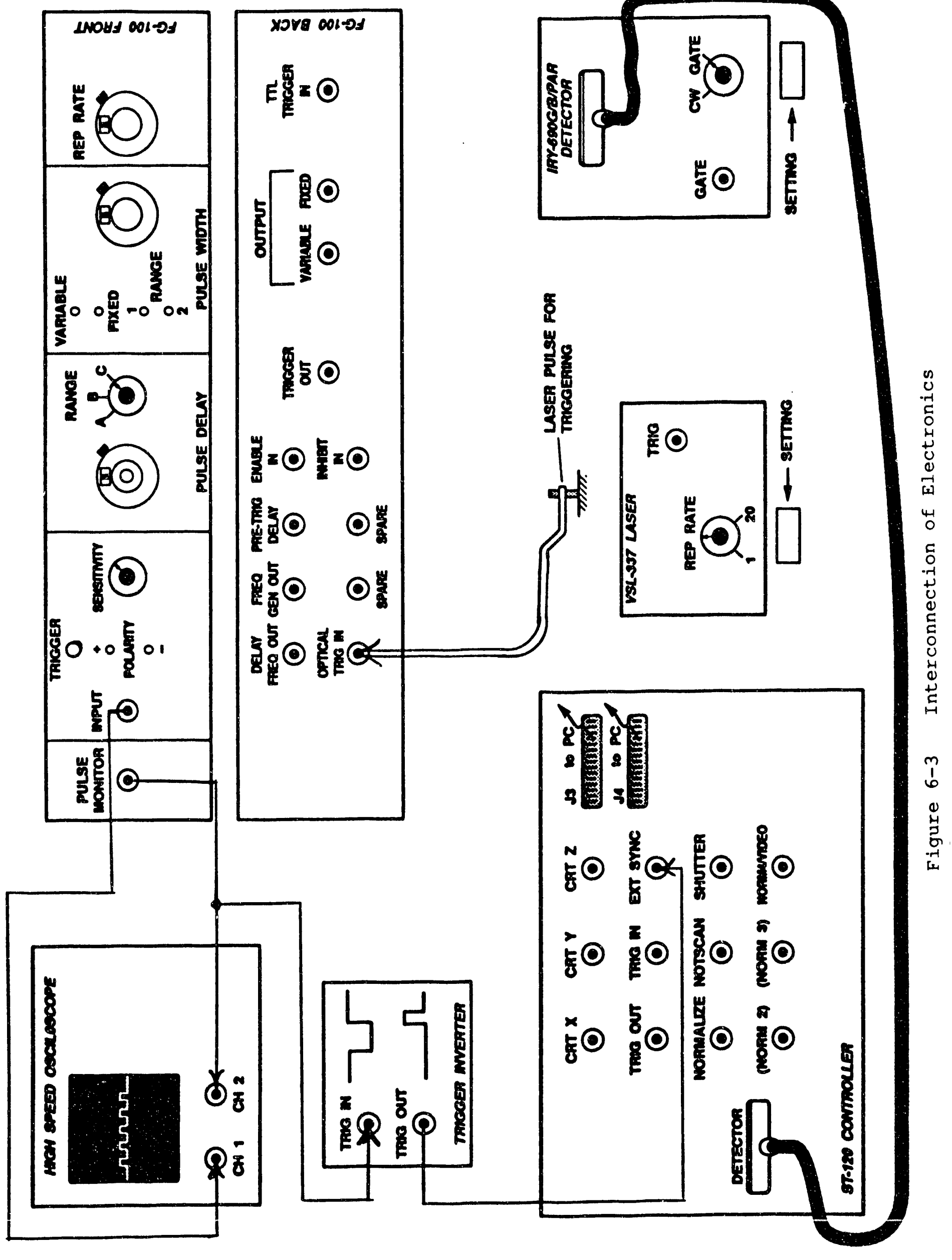




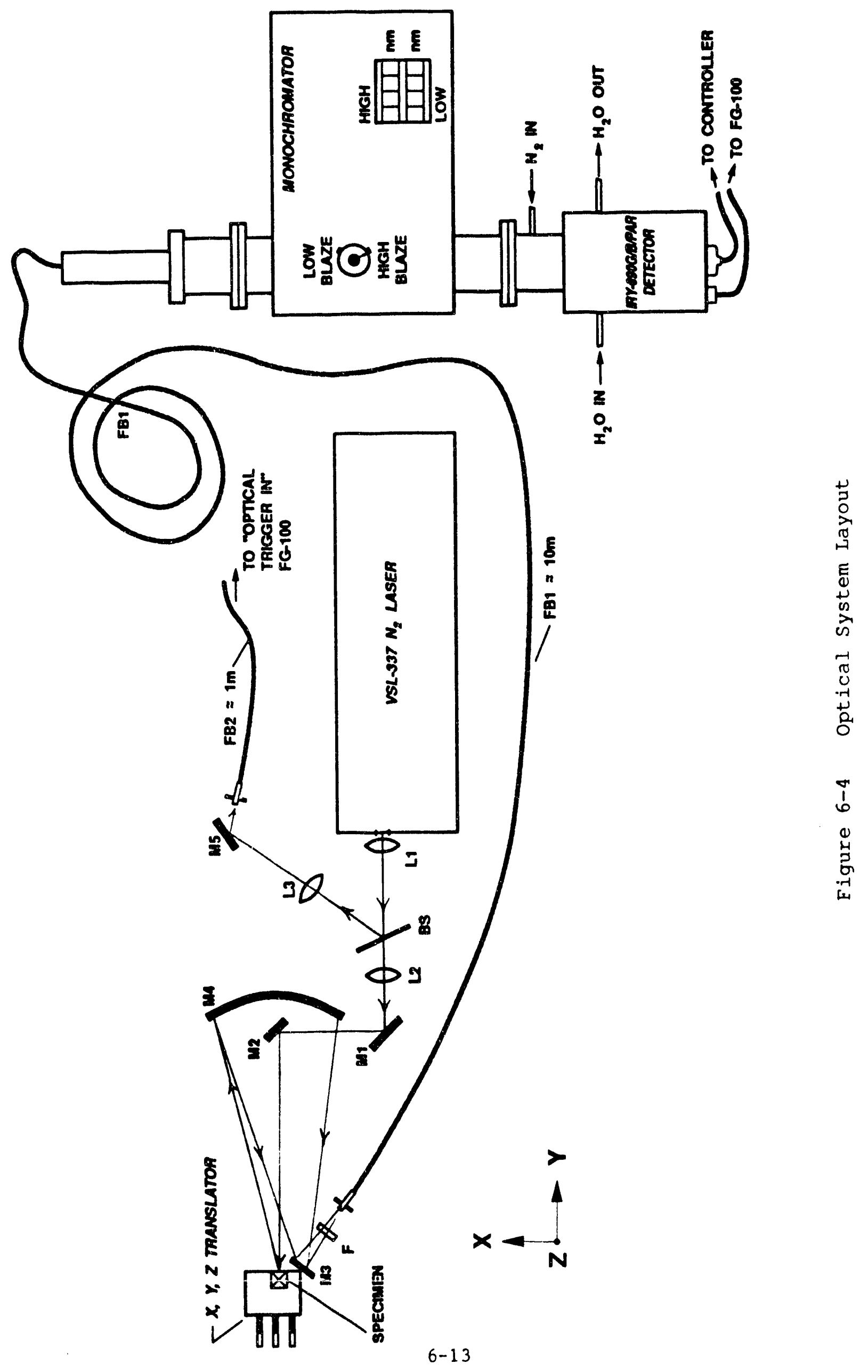




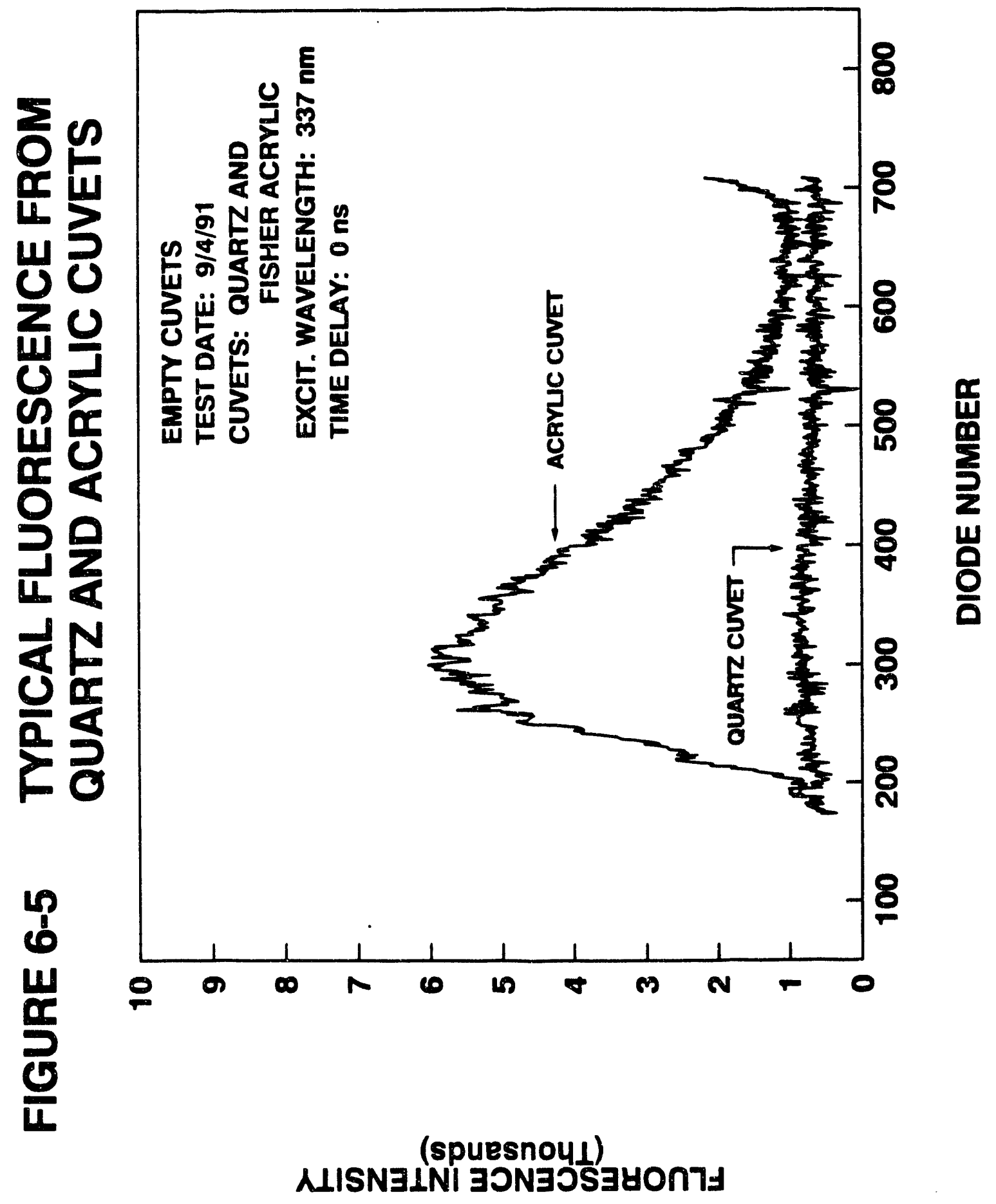




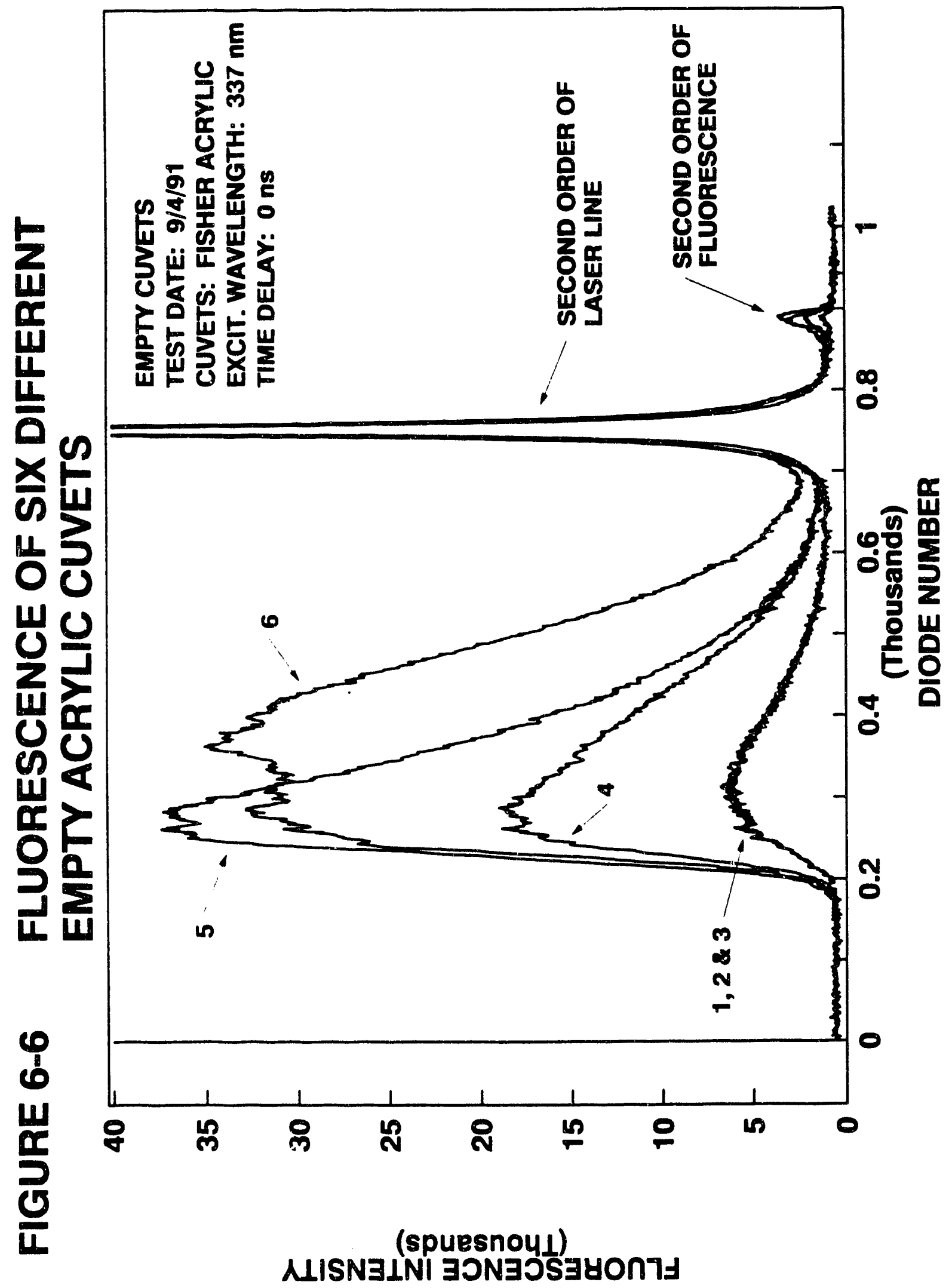




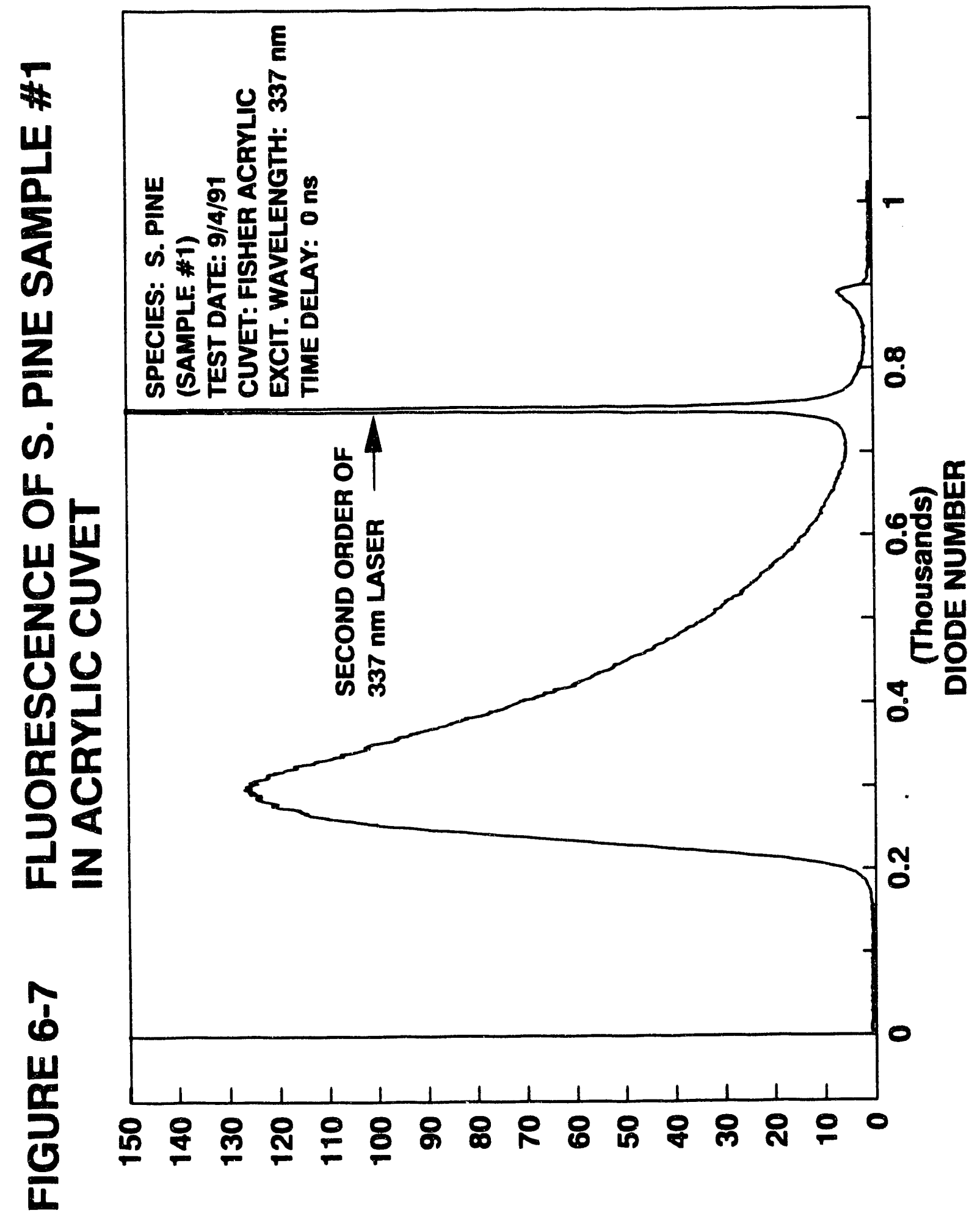

(spuesnoy1)

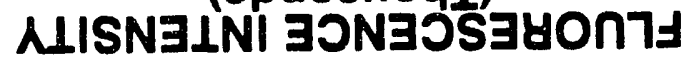




\subsection{PREPARATION AND TESTING OF PULP SAMPLES}

\subsection{PULP PROCUREMENT}

A homogeneous set of wood chips from two wood species (southern pine and northern pine) were procured and digested to varying degrees in laboratory digesters at Miami University in Oxford, Ohio. Eight cooks of each species were prepared with the objective of obtaining pulp samples with Kappa numbers ranging from 15 through 50. All cooks of each species were made with identical chemical charge but with varying time and temperature to achieve the different Kappa numbers.

After digesting, the samples were washed, screened, and refrigerated. In the case of the southern pine samples, all of the pulp was washed and screened. In the case of the northern pine samples, approximately a third of the pulp was kept in the condition as it exited the digester, a third was washed, and a third was washed and screened. Samples of the black liquor exiting the digester were also obtained and kept for future use.

The southern pine samples were digested in September 1990 while the northern pine samples were digested in June 1991.

\subsection{KAPPA NUMBER TESTING ON SAMPLES}

At the time each species was digested, Kappa number tests according to TAPPI T-236 were performed by Miami University using an automatic Kappa number analyzer. After Kappa analysis, the samples were delivered to the $B \& W$ research $l a b$ in October. 1990 and have been maintained under refrigeration since that time. The time span between the arrival of the pulp samples at $B \& W$ (October 1990) and the first meaningful fluorescence test results (January 1991) was a number of months. To assure that the pulp kappa numbers had not changed during the storage period and to confirm the original Miami test results, Fortions of the southern pine samples were sent to the Institute of Paper Science and Technology (IRST) in March 1991. The results of the IPST Kappa number testing did not compare well to the Miami test results. This left one to conclude that either the pulp Kappa number had changed, or one, or both, of the labs were in error. To eliminate 
the suspicion that the pulp had changed, portions of the southern pine samples were returned to Miami University for retesting. The second set of Miami results agreed reasonably well with the first. This led to the conclusion that the procedures used by the two labs were not compatible and that one, or both, of the lab results were in error. At the time of the writing of this report, both labs have been asked to collaborate to determine the cause of the discrepancy and are conducting further tests.

The northern pine pulp samples were tested in quadruplicate for Kappa number by Miami University at the time that the pulp was digested. No independent Kappa number tests were conducted. The results of the Kappa number testing on southern pine pulp are:

SOUTHERN PINE AVERAGE KAPPA NUMBER

\begin{tabular}{cllll} 
& \multicolumn{1}{l}{ LAB } & MIAMI & MIAMI & IPST \\
\cline { 2 - 5 } SAMPLE NUMBER & DATE & $09 / 90$ & $05 / 91$ & $04 / 91$ \\
\cline { 2 - 5 } 1 & \# OF TRIALS: & 3 & 3 & 2 \\
\hline 2 & 13.9 & 14.0 & 15.6 \\
3 & 19.6 & 18.1 & 21.2 \\
4 & 24.3 & 21.7 & 25.6 \\
5 & 28.8 & 26.9 & 31.9 \\
6 & 35.1 & 34.8 & 43.1 \\
7 & 39.6 & 37.3 & 49.5 \\
8 & 46.2 & 44.4 & 51.0 \\
& 51.6 & 46.4 & 58.5
\end{tabular}

The plot of this average data is presented in Figure 7-1 and the individual trial data is presented in Figures $7-2$ and $7-3$.

At the time of this writing, Miami University and IPST are attempting to resolve the differences in the Kappa number test results. 
The results of the Kappa number testing on northern pine pulp are:

NORTHERN PINE AVERAGE KAPPA NUMBER

\begin{tabular}{cll} 
& \multicolumn{1}{l}{ LAB } & MIAMI \\
\cline { 2 - 3 } SAMPLE & NUMBER & $06 / 91$ \\
\cline { 2 - 3 } & OF TRIAIS & 4 \\
\hline 1 & 15.1 \\
2 & 21.8 \\
3 & 24.7 \\
4 & 27.7 \\
5 & 33.8 \\
6 & 42.9 \\
7 & 47.1 \\
8 & 51.0
\end{tabular}

A plot of the data from the four individual trials, whose average is shown above, is presented in Figure 7-4.

\subsection{KLASON LIGNIN TESTS}

At the time that the southern pine pulp samples were sent to the IPST for confirmatory Kappa testing, samples were also provided for Klason lignin testing according to TAPPI $T 222$. It was thought that Klason lignin may correlate better with the fluorescence tests being conducted by $\mathrm{B} \& \mathrm{~W}$. Klason lignin is defined as the percent, by weight, of lignin in the pulp which is insoluble in an acid solution. The TAPPI procedure states that, for undigested pulps, the extractives must first be removed and the wood disintegrated mechanically prior to adding it to an acid solution. The TAPPI procedure does not require extractive removal and disintegration for pulps with Kappa numbers less than 75 since the digestion procedure generally removes almost all extractives. IPST therefore did not remove extractives or disintegrate the pulp prior to dissolving the pulp in acid.

During the Klason lignin tests, IPST noticed that the solute was tackier than normal and they had much difficulty in filtering the acid 
solution. This difficulty manifested itself in essentially unusable Klason lignin results. the TAPPI procedure gives an approximate expression for the relationship between Klason lignin and Kappa number as:

8 Klason lignin $\approx 0.15 \times$ Kappa number

The results of the IPST Klason lignin testing along with the results of the IPST Kappa number testing on the same specimens are:

SOUTHERN PINE KLASON LIGNIN, EQUIVALENT IIGNIN, AND KAPPA

\begin{tabular}{|c|c|c|c|c|}
\hline \multirow[b]{5}{*}{$\begin{array}{l}\text { SAMP IE } \\
\text { NUMBER }\end{array}$} & LAB & IPST & IPST & IPST \\
\hline & DATE & $04 / 91$ & $04 / 91$ & $04 / 91$ \\
\hline & * OF TRIALS & 1 & 1 & 2 \\
\hline & TYPE & KLASON & EQUIV.KLASON & KAPPA \\
\hline & $\begin{array}{l}\text { MEASURED OR } \\
\text { CALCULATED }\end{array}$ & MEAS. & CALC. & MEAS . \\
\hline & & $(8)$ & $0.15 \times$ Kappa & Kappa \\
\hline 1 & & 24.1 & 2.34 & 15.6 \\
\hline 2 & & 14.4 & 3.18 & 21.2 \\
\hline 3 & & 23.1 & 3.83 & 25.6 \\
\hline 4 & & 7.2 & 4.79 & 31.9 \\
\hline 5 & & 18.8 & 6.47 & 43.1 \\
\hline 6 & & 12.4 & 7.43 & 49.5 \\
\hline 7 & & 27.7 & 7.65 & 51.0 \\
\hline 8 & & 25.9 & 8.78 & 58.5 \\
\hline
\end{tabular}

A plot of this data is presented in Figure 7-5. Comparison of percent insoluble lignin (i.e., Klason lignin) to the equivalent 8 lignin from Kappa numbers reveals that the Klason lignin results are seriously in error. Upon advice from IPST that Kappa number testing is much more repeatable and accurate than Klason lignin testing, the expense of further Klason lignin testing could not be justified. 


\subsection{PULP PH TESTING}

The $\mathrm{pH}$ of lignin has been demonstrated to affect the absorbance spectra of ultraviolet light [18]. Since fluorescence is a direct result of the absorption of ultraviolet light, all pulp samples were tested in accordance with TAPPI $252 \mathrm{om}-90$, for $\mathrm{pH}$ at $25^{\circ} \mathrm{C}$ the results of that testing are:

\begin{tabular}{lcl} 
SPECIES & SAMPLE & PH \\
\hline S PINE & 1 & 9.12 \\
S PINE & 2 & 9.04 \\
S PINE & 3 & 9.05 \\
S PINE & 4 & 8.94 \\
S PINE & 5 & 8.28 \\
S PINE & 6 & 8.71 \\
S PINE & 7 & 8.91 \\
S PINE & 8 & 8.91 \\
& & \\
N PINE & 1 & 7.95 \\
N PINE & 2 & 7.72 \\
N PINE & 3 & 7.93 \\
N PINE & 4 & 8.34 \\
N PINE & 5 & 8.32 \\
N PINE & 6 & 8.16 \\
N PINE & 7 & 7.87 \\
N PINE & 8 & 7.85 \\
& &
\end{tabular}

A plot of this data is shown in Figure $7-6$.

\subsection{EXTRACTIVES IN PULP SAMPLES}

The extractives content of wood pulp can be determined according to TAPPI procedure T204 om-88. The least digested sample of each of the two pulp species, sample number 8 , was subjected to the TAPPI extractives test. The least digested of the pulps should contain the highest concentration of extractives.

$$
7-5
$$


The extractives test was conducted at the B\&W chemistry $l a b$ and the TAPPI procedure was followed, with the exception that the size of the glassware recommended was not available. This necessitated that the sample size tested be reduced from $10 \mathrm{~g}$ to $1.8 \mathrm{~g}$. the tests were conducted in duplicate and the results are:

\begin{tabular}{lccc} 
SPECIES & SAMPLE & TRIAL & \& EXTRACTIVES \\
\hline S PINE & 8 & 1 & 0.64 \\
S PINE & 8 & 2 & 0.88 \\
& & & \\
N PINE & 8 & 1 & 1.54 \\
N PINE & 8 & 2 & 0.46
\end{tabular}

\footnotetext{
After the extractives were determined, a portion of the solution into which the extractives were dissolved was placed in a quartz cell and subjected to absorbance testing over the range of wavelengths of interest $(250 \mathrm{~nm}-500 \mathrm{~nm})$. The presence of compounds in this solution which exhibited absorbance much different from that of lignin would be an indication that non-lignins were absorbing UV light and, therefore, could be the cause of the non-kappa correlating fluorescence. However, the observed absorbance spectrum was not different from that of lignin, probably due to a slight carryover of lignin.
}

These results lead one to the conclusion that, in comparison to lignin, the extractives are not strong absorbers of UV light and are therefore not likely to interfere with the lignin fluorescence. 


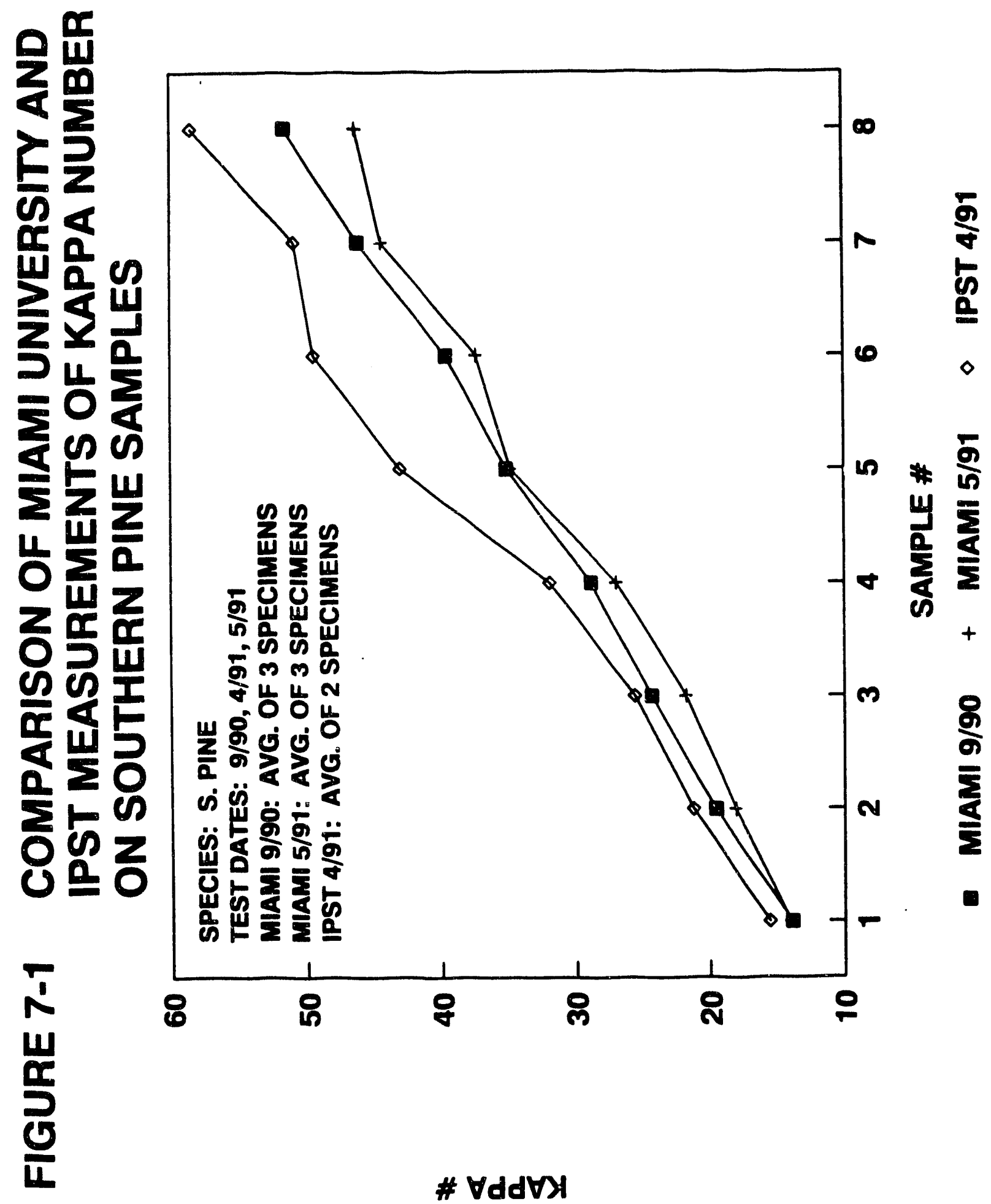




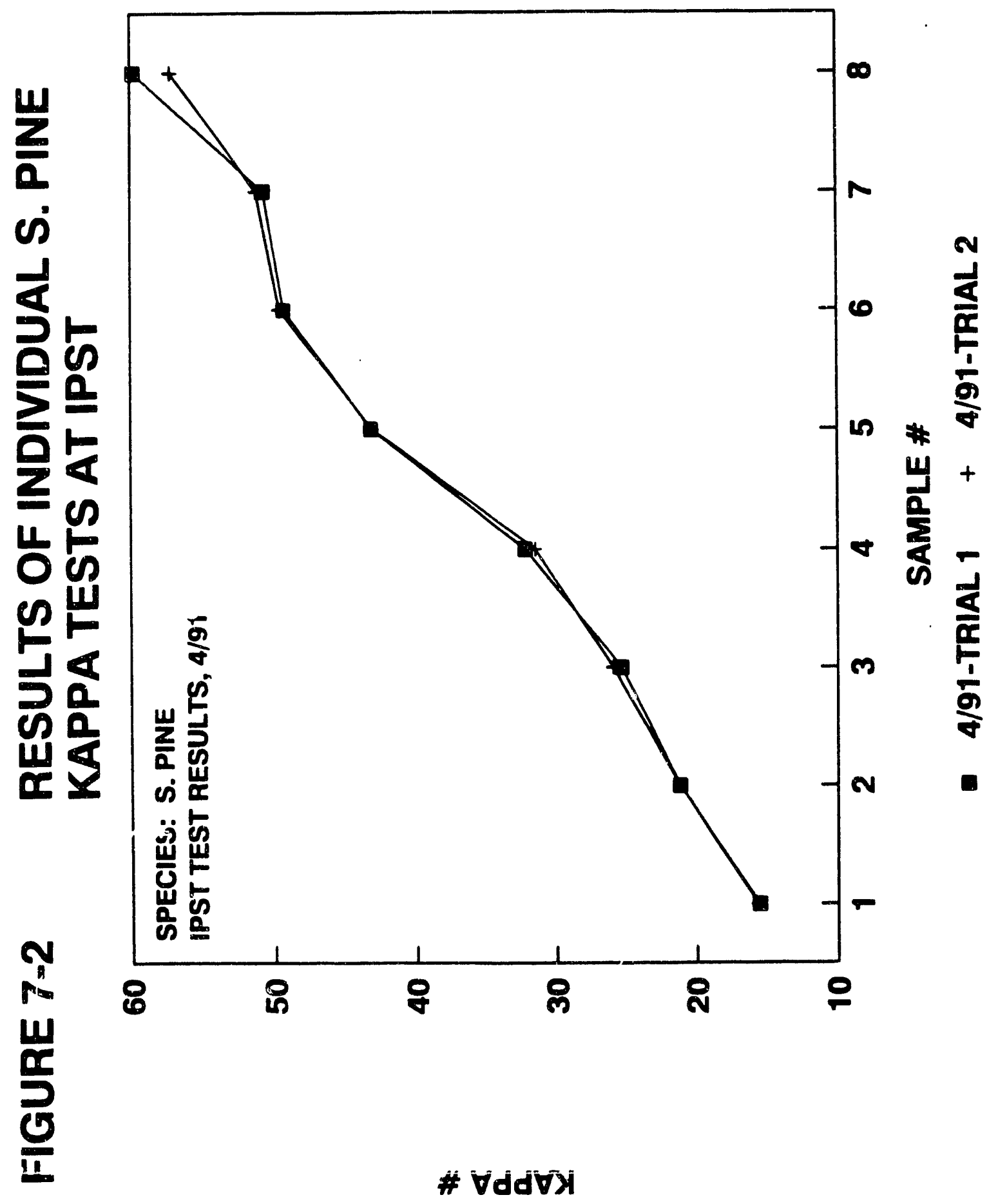


$\frac{p}{6}$

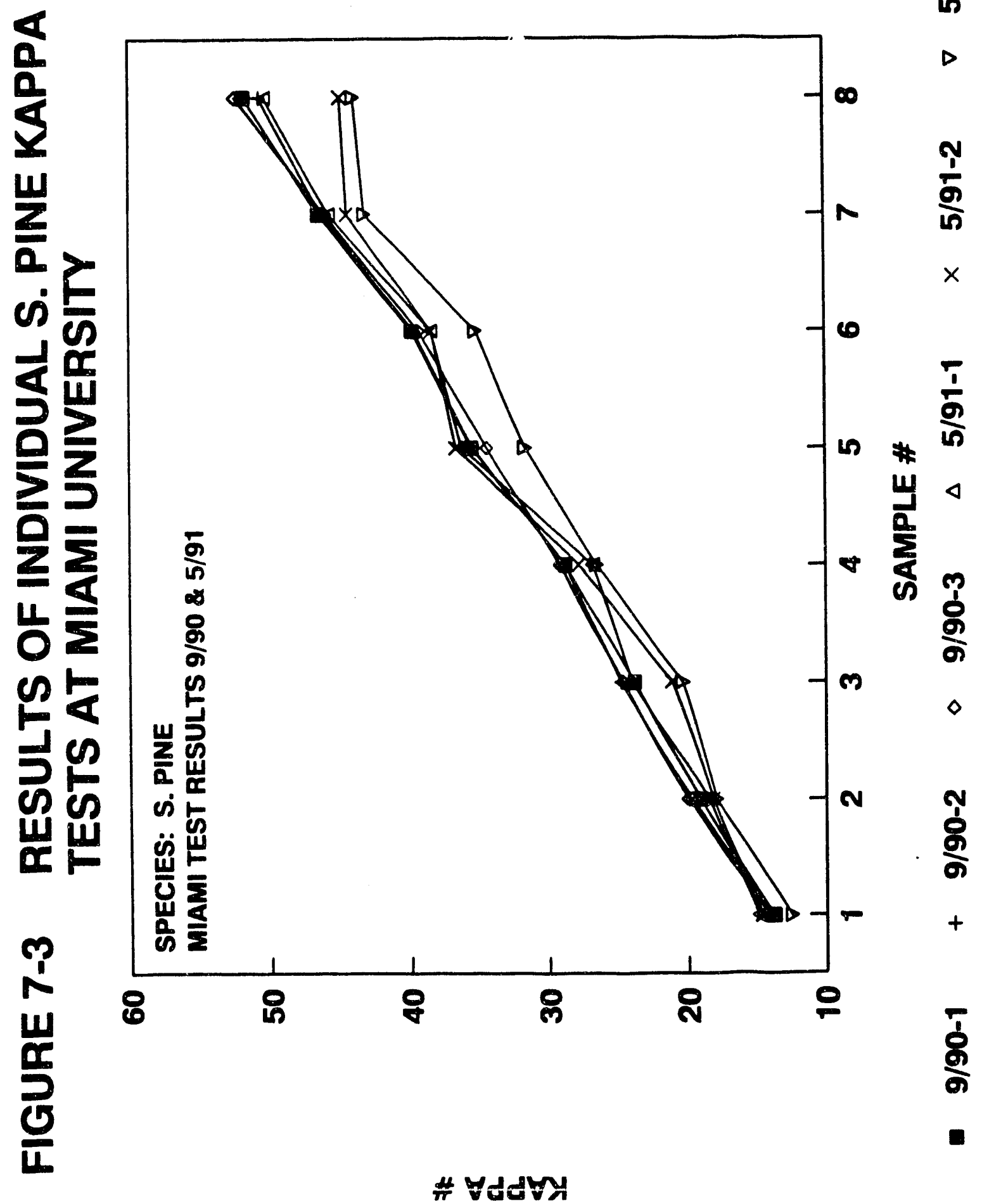




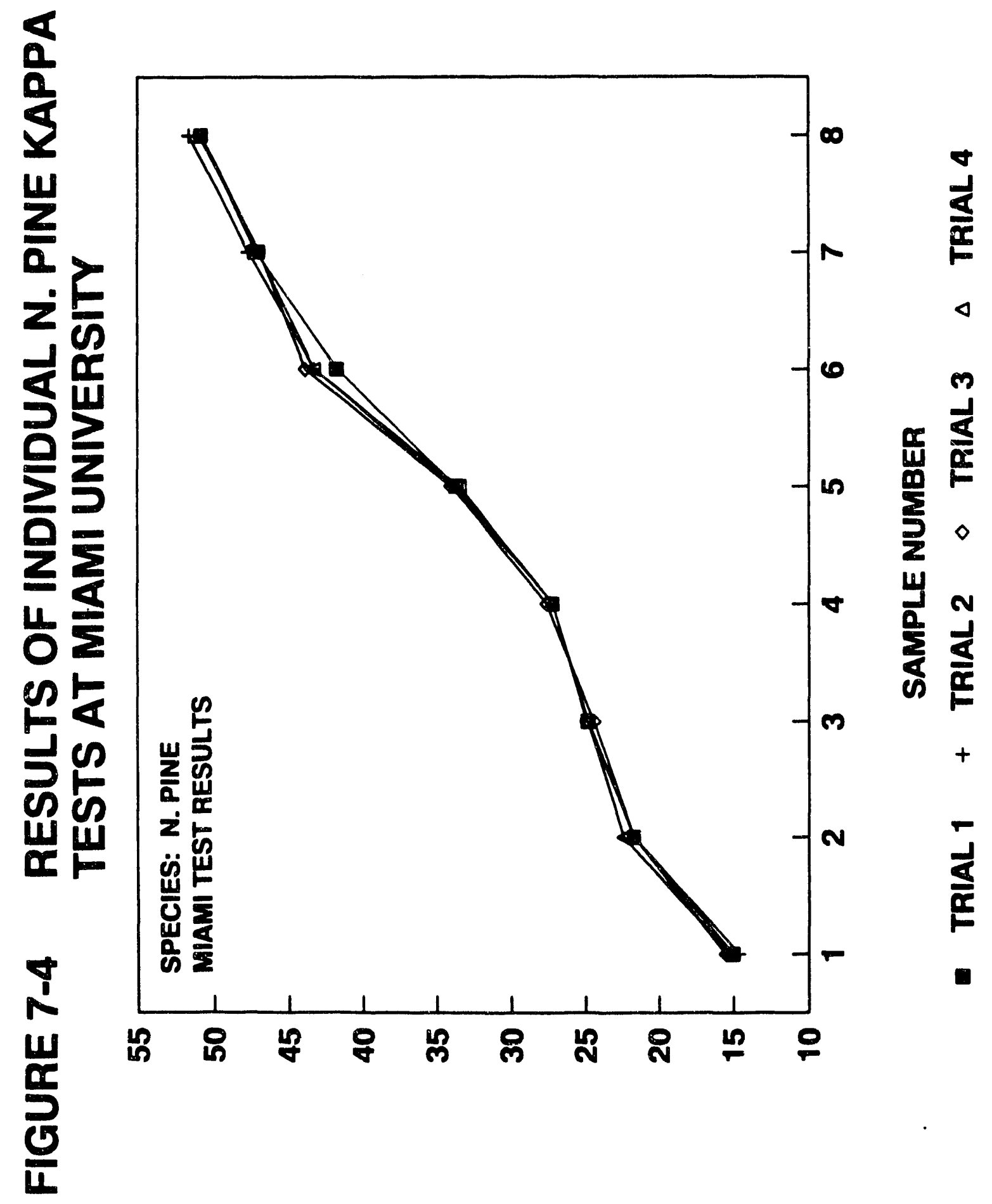

Y $\exists$ GWnN $\forall d d \forall X$ 


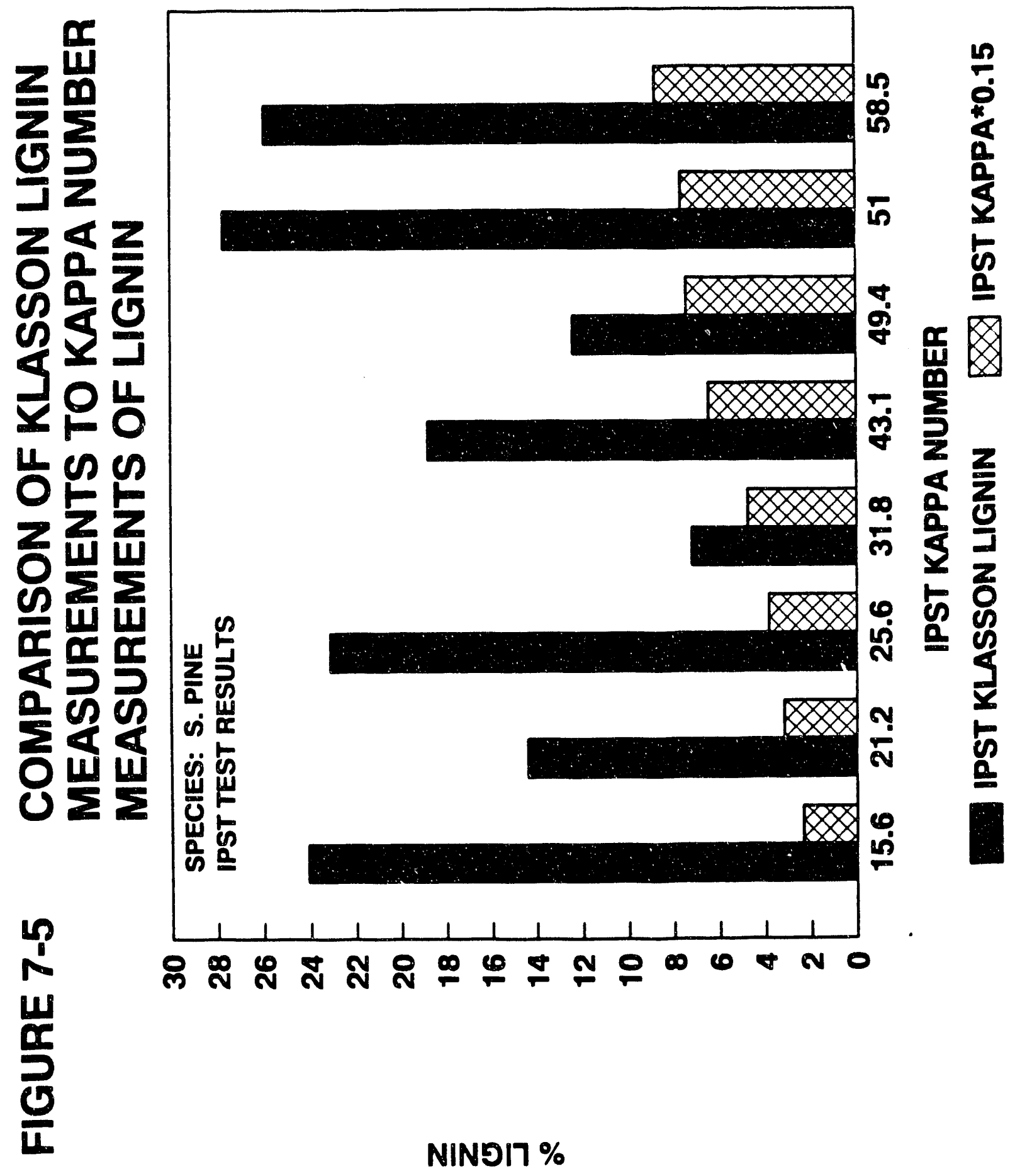




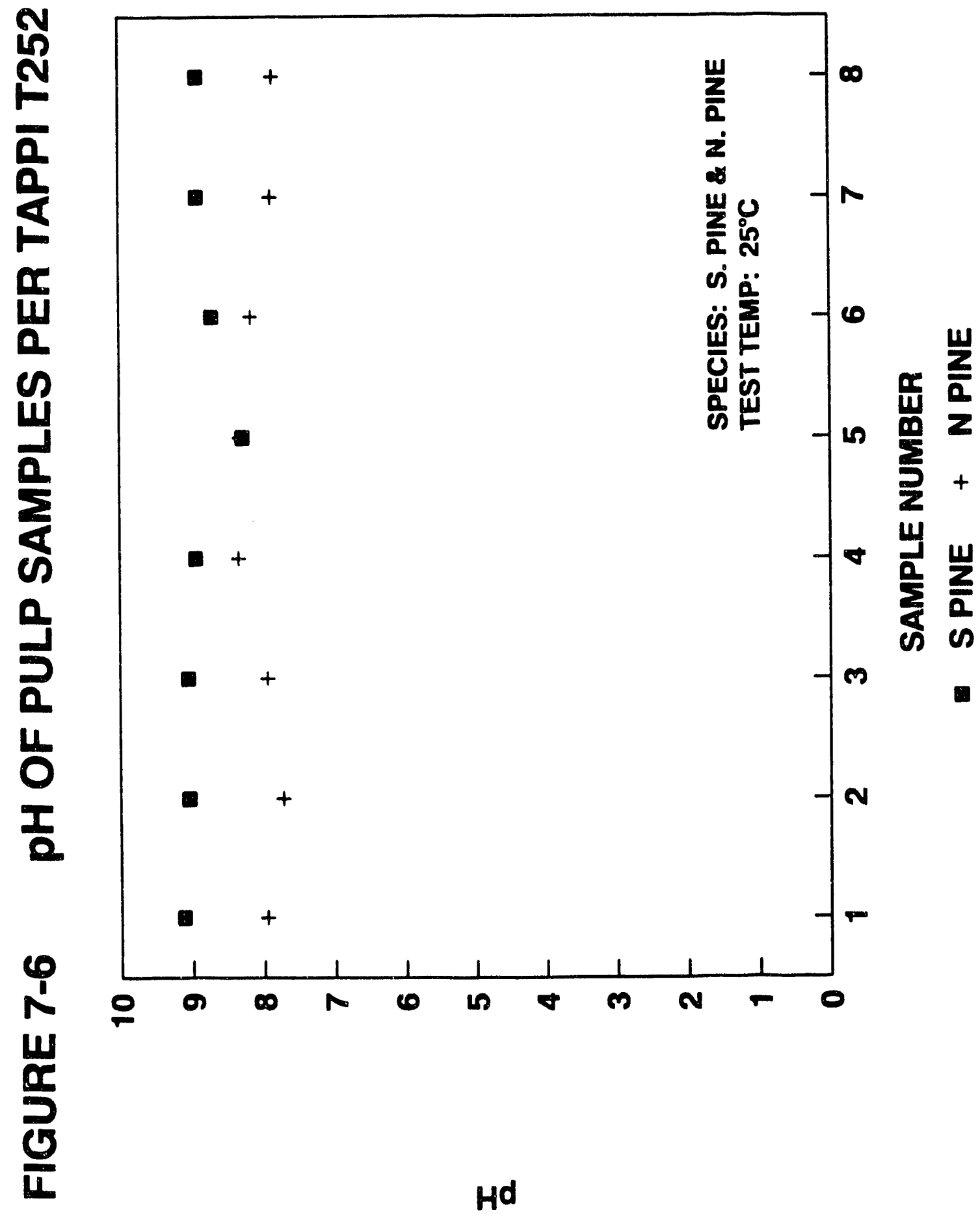




\subsection{ANALYSIS}

The detector located at the exit plane of the monochromator consists of a 1024 element silicon-photodiode array behind a gateable intensifier section. All 1024 elements of the array are read out sequentially when the controller receives a synch-pulse. Each element of the resultant 1024 element data array gives a measure of the intensity over a small wavelength range, $\Delta \lambda$. Figure $8-1$ shows typical 1024 element spectra. Because of the limited size of the intensifier section, only the central 700 elements of the 1024 array are intensified and therefore useful. The raw data stored during an experiment is of the form shown in Figure 8-1. Using a discharge lamp with a series of narrow spectral lines of known wavelength the system was calibrated so that the data could be presented as shown in Figure $8-2$, in terms of the wavelength spectrum rather than diode number. The shape of the spectra shown in Figures $8-1$ and $8-2$ are distorted by the response of the optics and the sensitivity of the detector to wavelength. The optical transmission of some major optical and electronics components is shown in Figure 8-3.

Most of the results presented in section 4.0 are given in terms of the total fluorescence intensity rather than the spectral distribution. The total fluorescence intensity, $F_{T}$, can be calculated from the raw data using the formula

$$
F_{T}=\sum_{n=1}^{1024} F_{n}
$$

A C language program with Fortran calls was written to facilitate the reduction/manipulation of the raw data. This analysis program allows the user to designate which stored files are to be analyzed and to select four ranges over which to sum the values of $F_{n}$. Once these are specified the computation is performed and the results of the analysis are stored in a LOTUS 1-2-3 compatible file. Table 8-1 shows the first few rows of an analysis file. 
Table 8-1. Format of Analysis File Output

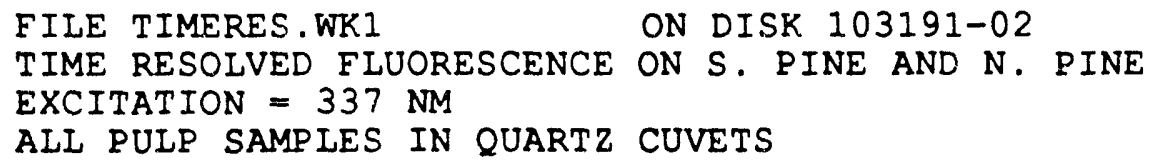

The six-character file name was encoded so that the analysis program could interpret the experimental conditions. The code is given below:

- Character 1: specifies the excitation wavelength. $A=337 \mathrm{~nm}, B=442 \mathrm{~nm}, C=488 \mathrm{~nm}$

- Character 2: is either $F$ or $B$ indicating exposure of the front or back surface of the cuvet. Since the excitation light is completely absorbed very near the surface, the front and back of the cuvets represent two independent samples which provides a convenient way to determine the sample to sample repeatability and therefore gage the representativeness of the measurement procedure.

- Character 3: is 1 or 2 for a regular spectral fluorescence test, 3 for a bleaching test, and 4 for a reflection test. In the regular fluorescence tests, the sample is raster scanned so that the 90 laser pulses constituting the total exposure are spread over an extended area with no overlap. This assures that the results are independent of bleaching effects. The 1 or 2 in the third file name digit merely indicates two different scanned areas. 
- Character 4: designates the pulp sample. A thru H correspond to southern pine samples 1 thru 8 , respectively; while I thru $P$ indicate northern pine samples 1 thru 8 .

- Characters 5\&6: indicate the gate delay time in nsec.

Note that special tests, e.g. tests on $\mathrm{pH}$ samples, use a slightly different code.

The last six columns shown in Table $8-1$ are derived from calculations made during the analysis.

The column titled Centroid of Diodes gives the results of the calculation.

$$
C \equiv \frac{\sum_{n=173}^{708} \lambda_{n} F_{n}}{\sum_{n=173}^{708} F_{n}}
$$

where $F_{n}$ is the measured response for the $n^{\text {th }}$ diode and $\lambda_{n}$ is the wavelength corresponding to the $n^{\text {th }}$ diode.

The limits of the summation (integration) can be selected in the analysis program prior to the calculation. The limits shown in Equation 8-2 were chosen to include the total range over which significant fluorescence occurs. Above and below these limits the readings are dominated by electronic noise and scattered light.

The second calculation column indicates the highest single diode reading found between the specified limits.

The third calculation column gives the results of the calculation

$$
A_{1}=\sum_{n=25}^{140} F_{n}
$$


The range (25 to 140$)$ includes only unintensified diodes and the resultant $A_{1}$ is due strictly to "dark-current" electronic noise. This information is used to correct the flucrescence data for electronic noise. In fact, the data acquisition program provides first order correction for noise by automatically subtracting a stored noise spectrum from the measured data before storing the result to the data file. The purpose of the additional correction supplied by the Equation 8-3 calculation is to correct for any slow drift of the darknoise that might occur during an extended testing period.

The average noise per diode, $d$, is calculated from the measured $A_{1}$ and used in the calculation of the last three data columns shown in Table 8-1. The formula used is

$$
A_{i}=\sum_{n=a}^{b}\left(F_{n}-d\right)
$$

where $i=2,3$, or 4 , and $a \& b$ are summation limits that are specified prior to the analysis.

In Section 4 , the results reported as total fluorescence intensity are the results of integration over the range from diode 173 to 708 which, as mentioned above, is the range over which all significant fluorescence occurs. The results of summation over this range are the same as the summation over the entire range (1 to 1024) indicated in Equation 8-1 except for the additional noise included in the Equation 8-1 calculation. 


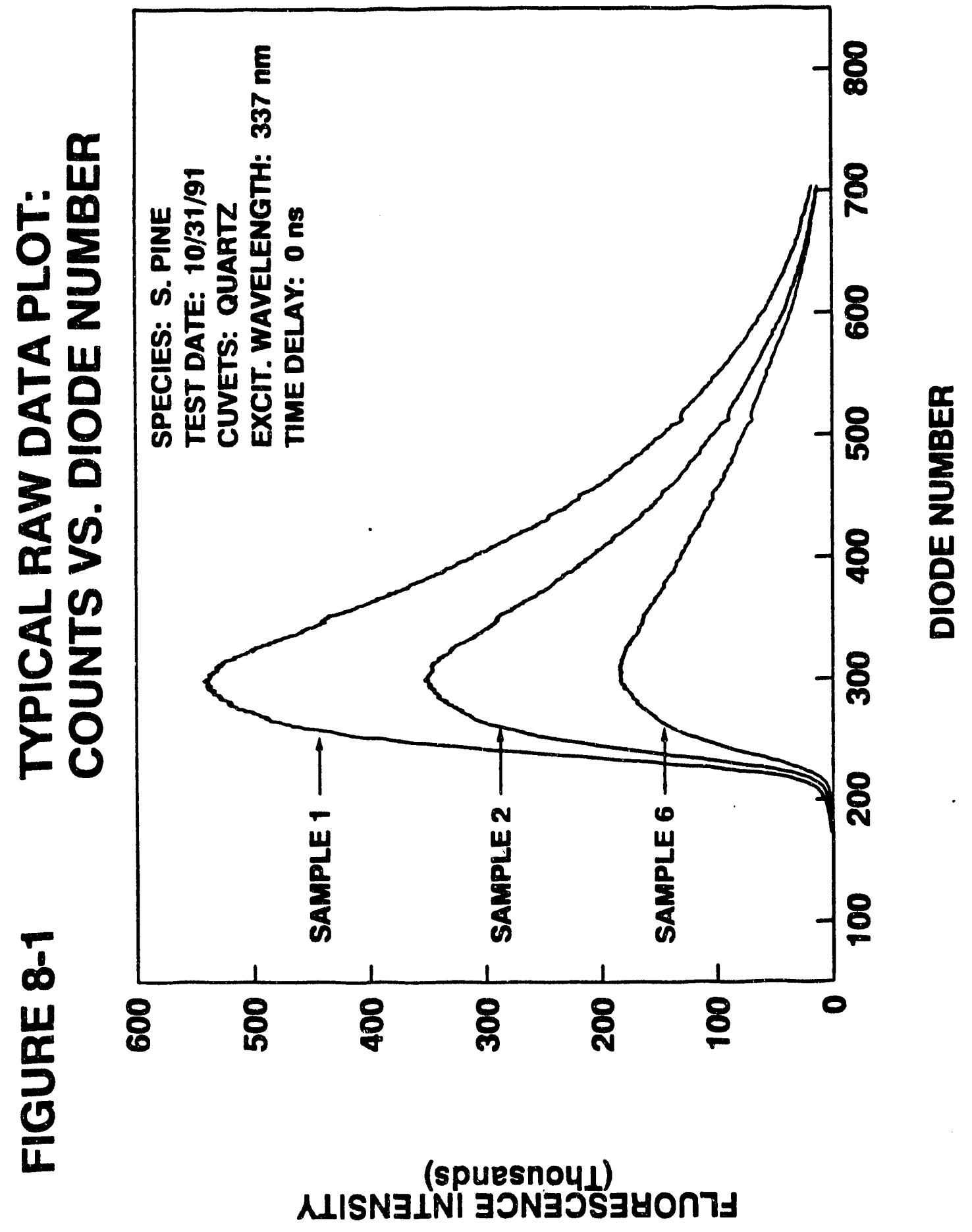

$8-5$ 


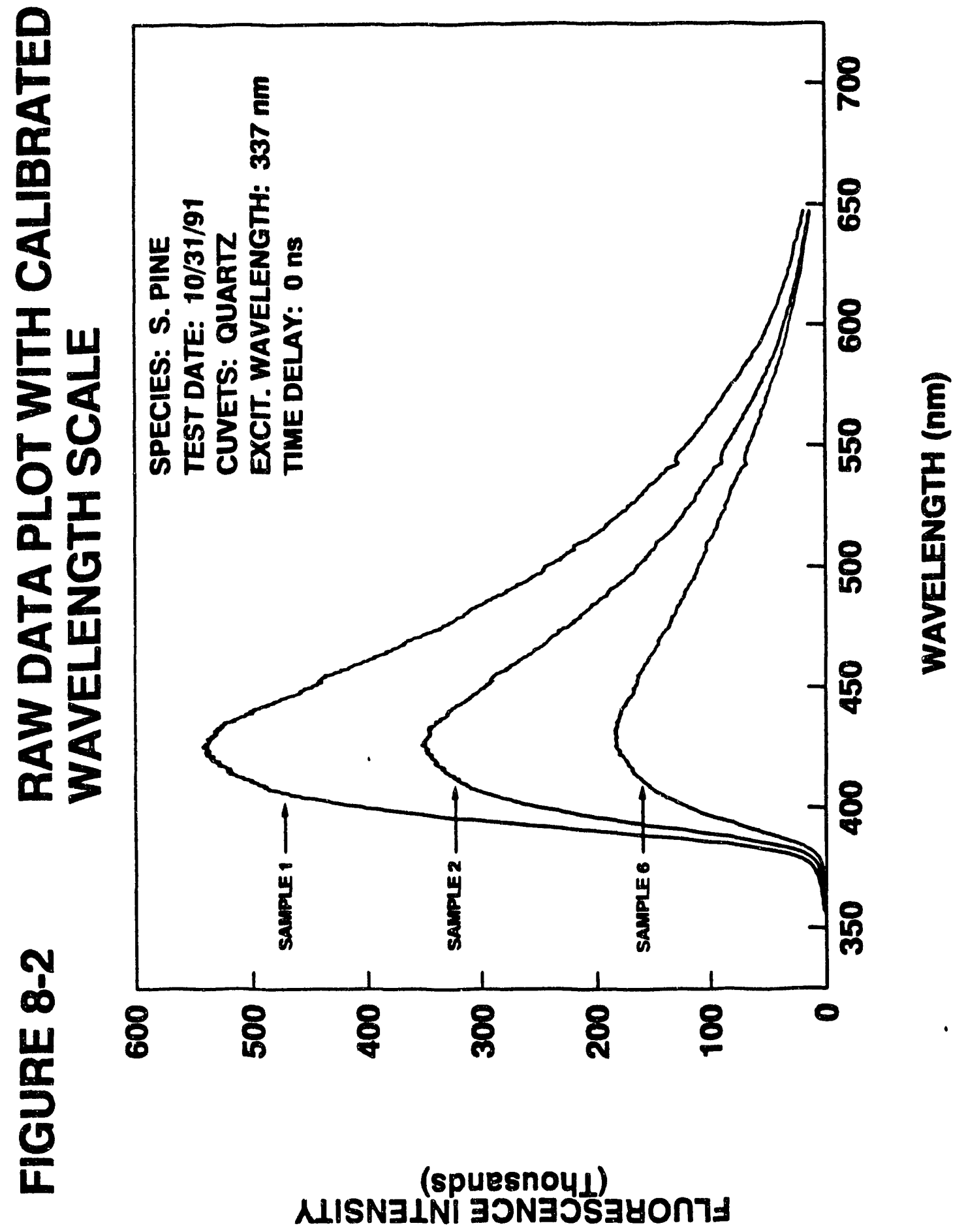




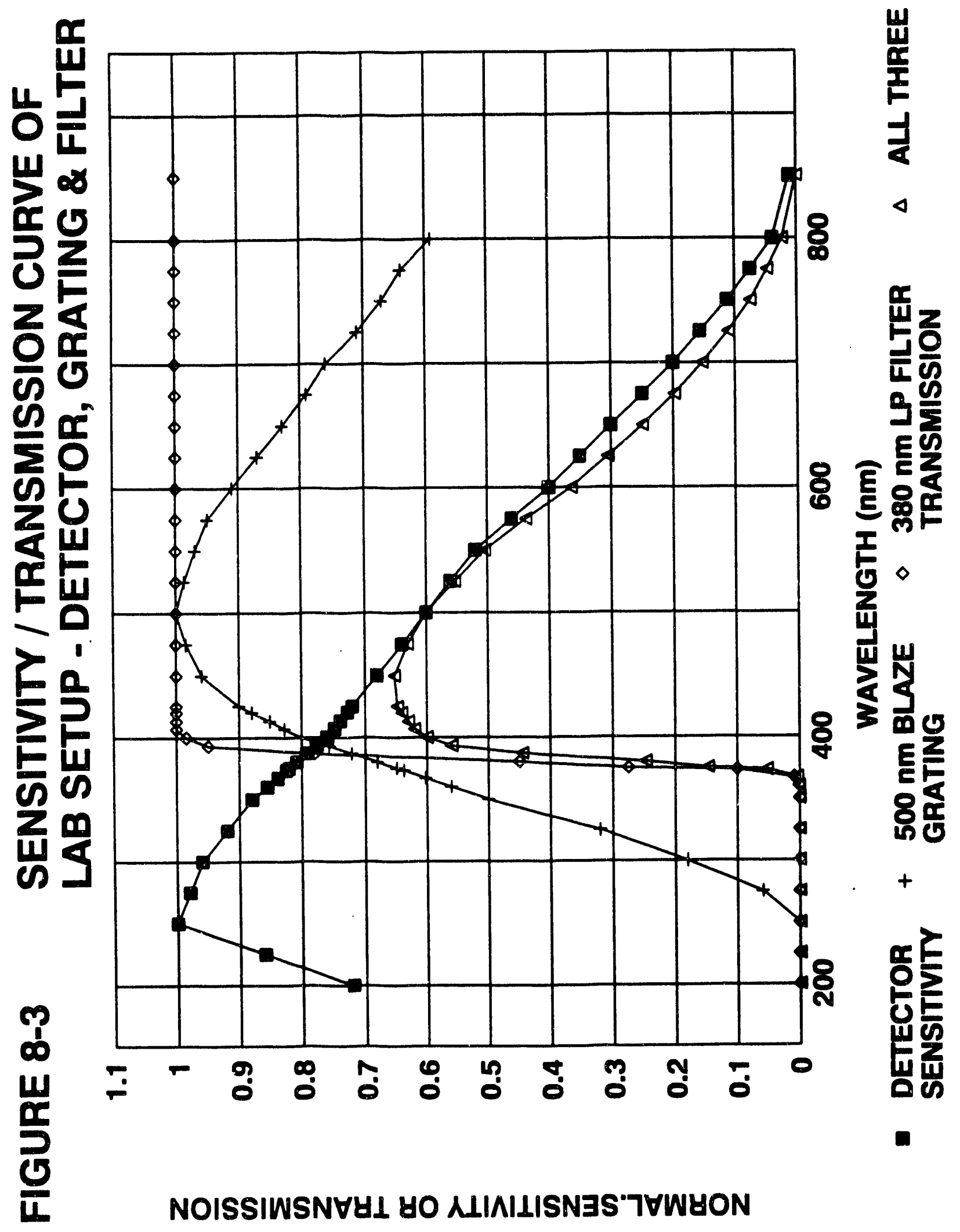




\subsection{SUPPLEMENTAL TESTING}

\subsection{EFFECT OF SPECIMEN PREPARATION ON FLUORESCENCE INTENSITY}

The wood pulp specimens were all held in standard laboratory cuvets during the fluorescence testing. In the preliminary tests, plastic (acrylic) cuvets were used but for the final tests, reported here, quartz cuvets were used to eliminate the effect of cuvet fluorescence.

The wood pulp samples were inhomogeneous and wet. A natural question arose as to the optimum way to obtain a "full" cuvet, i.e., the total mass of pulp in a "full" cuvet can vary by a factor of more than three, depending on how tigntly it is packed. To determine the importance of the packing density, the following experiment was run. Five cuvets were "filled" with very loose packing and four others with the most dense packing possible. For the dense packing, the pulp was periodically compressed and the excess liquid removed as the cuvet was being filled. After filling and allowing to equilibrate to room temperature, the fluorescence was measured with excitation on both the front and back surfaces. This resulted in 10 samples of the loosepacked and 8 samples of the dense-packed. Table 9-1 summarizes the results of this test.

Table 9-1 Results of Cuvet Packing Tests

$\begin{array}{lcc} & \begin{array}{l}\text { Average } \\ \text { Fluorescent } \\ \text { Intensity }\end{array} & \begin{array}{l}\text { Standard } \\ \text { Deviation }\end{array} \\ \text { Loose Packed Samples } & 960 & \pm 50 \\ \text { Dense Packed Samples } & 1022 & \pm 42 \\ \text { All Samples } & 989 & \pm 56\end{array}$

Although the results indicate that the packing density is relatively unimportant, there is a somewhat lower deviation among the densepacked samples. In subsequent testing, therefore, the samples were compressed into the cuvets, although perhaps not to the maximum possible density. 


\subsection{APPARATUS STABILITY}

The data presented in Section 4.0, with the exception of the phase-resolved and temperature effect results, was all taken during a series of tests on 10/31/91 thru 11/1/91. Table 9-2 shows the analysis file from those tests dealing with fluorescence excitation at $337 \mathrm{~nm}$. A similar set of files were generated for excitation at 442 $\mathrm{nm}$ and $488 \mathrm{~nm}$. In addition, there were a series of files dealing with the measurement of reflection (see section 9.6). To insure that the system sensitivity was stable throughout the series of tests, a number of "standards" were measured periodically throughout the tests. The standards were:

- an NSG Precision Cells plastic cuvet filled with distilleddeionized water. Designated as Code H.

- a Fisher Scientific plastic cuvet filled with distilleddeionized water. Designated as Code F.

- the face of the aluminum mounting block used to hold the cuvet on the translation table. Designated as Code $A$.

The results of the measurements on the Standards are shown in Figures $9-1 A$ and $9-1 B$. It $c a n$ be seen that the readings ali are repeatable within $\pm 5 \%$ with the exception of the third and fourth readings on the Code $F$ (Fisher acrylic) standard. The reason for these high readings is unexplained but appears to be some artifact rather than a real response change, since the code $A$ (aluminum) and Code $H$ (NSG plastic) readings do not show the change. The sequence of readings was:

$\begin{array}{llll}\text { High } & F(3) & \text { e } & 49 \text { minutes elapsed } \\ \text { Normal } & H(3) & \text { e } & 50 \text { minutes elapsed } \\ \text { Normal } & A(2) & \text { e } & 54 \text { minutes elapsed } \\ \text { High } & F(4) & \text { e } 121 \text { minutes elapsed } \\ \text { Normal } & H(4) & \text { e } 122 \text { minutes elapsed }\end{array}$

The fact that the $H$ and $A$ readings taken between the two high $F$ readings were normal, strongly suggests that the change was related just to the Code $F$ standard rather than the system. 
In May 1991, a series of tests were conducted on eight southern pine samples in acrylic cuvets at various time delays ranging from -6 $\mathrm{ns}$ to $12 \mathrm{~ns}$ (note $-6 \mathrm{~ns}$ is essentially the same as $0 \mathrm{~ns}$ ). The time delay of -6 ns was executed twice and the 0 ns was executed once. These tests were executed over a period of seven hours, thus providing an opportunity to observe the repeatability of the laboratory setup on pulp fluorescence over three trials. Each trial was executed on the front face of the cuvets as well as the back face of the cuvets, which constitutes two separate specimens for each sample. All tests were conducted at an excitation wavelength of $337 \mathrm{~nm}$.

The sequence of the tests is presented in Table 9-3 and the results are plotted in Figures 9-1C, 9-1D, and 9-1E. Figure 9-1C contains the results of all six trials (three on the front face and three on the back face).

Figure 9-1D contains the results of the three front face trials only. The maximum difference between any two trials is $10.8 \%$ ( $\pm 5.2 \%$ ) and occurs for sample number 2 (KAPPA $=21$ ). For all other samples the error is less than $\pm 3 \%$.

Figure 9-1E contains the results of the three back face trials only. The maximum difference between any two trials is $7.38( \pm 3.65 \%)$ and occurs for sample number 7 (KAPPA $=51$ ). For all other samples the error is less than $\pm 3 \%$.

\subsection{BLEACHING}

When the laser is allowed to continually irradiate the same spot on the pulp sample, the fluorescence intensity decreases and the spectral distribution drifts toward the red due to photochemical bleaching. Figure 9-2 shows the results of an experiment where a fixed spot on the pulp sample received $10^{4}$ laser pulses. The spectra in Figure 9-2 were taken at intervals of 1000 pulses. The total fluorescence intensity drops by $27 \%$ from the first spectrum to the second which, if the drop were linear with exposure, would indicate a bleaching effect of $.027 \% /$ pulse. The effect is in fact not linear with exposure. The percentage of decrease in fluorescent intensity is less for each successive curve. The effect during the first few 
pulses is, therefore, more than .0278 which is the average over the first 1000 pulses. The rate of change of the bleaching effect with total exposure seen in the Figure 9-2 data suggests that the initial bleaching rate may be as high as $0.18 /$ pulse.

\subsection{TEMPERATURE EFFECT TESTS}

The effect of pulp temperature on fluorescence intensity was determined using the standard set-up and procedure, i.e., exposing the sample to multiple pulses while scanning the sample so that each subsequent pulse hits a new area. During the temperature tests, however, the same specimen was scanned 27 different times. If the scan were over exactly the same area each time, this could introduce a bleaching errox on the order of a few percent. Because the laser pulsing was not synchronized with the specimen scanning motors the bleaching effect is estimated at about $1 \%$.

For the temperature tests, a thermocouple was inserted into a pulp filled quartz cuvet approximately $1 \mathrm{~mm}$ from the irradiated surface. The cuvet was held on the translation stage against an aluminum block that is approximately a $4 \mathrm{~cm}$ cube. This cube was heated by a hot air gun until the thermocouple read $172^{\circ} \mathrm{F}$. A series of baffles protected the specimen from direct exposure to the heating air to avoid drying. After heating, the aix gun was turned off and the system allowed to equilibrate for five minutes. Then a series of data scans were run as the temperature slowly dropped. The large thermal mass of the aluminum block moderated the rate of decrease in temperature to a few degrees over the period of a data scan.

An earlier attempt to measure the effect at temperatures below room zemperature involved putting the specimen in a freezer prior to a series of scans. These tests indicated a general trend consistent with the high temperature results, but were somewhat noisy and unreliable due to condensation on the cuvet face.

\subsection{PH TESTS}

According to Reference 18, the UV absorption spestrum of lignin can be described by a model of 13 overlapping gaussian absorption

$$
9-4
$$


bands, whose relative intensities are dependent on $\mathrm{pH}$. To explore how this $\mathrm{pH}$ dependent absorption effects the fluorescent properties, a series of tests were made with $\mathrm{pH}$ buffered pulp samples.

Samples were prepared for this test by soaking washed and screened pulp samples for 24 hours at room temperature in the following solutions; distilled-deionized water, Fisher pH 7 buffer solution, and Fisher $\mathrm{pH} 10$ buffer solution. After the 24 hour soak, the pulp was loaded into Fisher acrylic cuvets using the standard technique of compressing the pulp and removing the excess solution. Standard fluorescence measurements were then made on the resultant 48 spocimens ( 2 wood species $\times 8$ Kappa numbers $\times 3 \mathrm{pH}$ ). The results of litmus paper testing of the buffered specimens are presented in Table 9-4.

Figures $9-3$ and $9-4$ show the fluorescence intensity as a function of Kappa number for the northern and southern pine samples, respectively. In both species the overall fluorescence intensity increases with increasing $\mathrm{pH}$. Figures $9-5$ and $9-6$ show the effect of $\mathrm{pH}$ on the wavelength centroid. The centroid tends to shift toward longer wavelengths with increasing $\mathrm{pH}$ in both wood species, although the effect is smaller for the southern than the northern pine.

The 48 acrylic cuvets (2 species $x 8$ samples $x 3 \mathrm{pH}^{\prime} \mathrm{s}$ ) used in the tests were all taken from the same carton. As discussed in Section 6.9, some significant differences in cuvet fluorescence were discovered after the $\mathrm{pH}$ tests were completed. Therefore, only the trends shown in Figure 9-3 through 9-6 can be relied upon (i.e., shift toward higher intensity and longer wavelength with increasing $\mathrm{pH}$ ).

\subsection{REFLECTION TESTS}

In the phase-resolved ciata taken at Duke University, reflected light from several non-lasing plasma lines from the He-Cd laser were superimposed on the fluorescence spectrum. A plot of the intensity of the strongest of these reflected lines vs Kappa number is shown in Figure 9-7 for $40 \mathrm{MHz}$ modulation and in Figure 9-8 for $60 \mathrm{MHz}$ modulation. There seems to be a good correlation between the Ieflection at $10 \mathrm{MHz}$ and Kappa number; whereas the reflection at 60

$$
9-5
$$


$\mathrm{MHz}$ is erratic. This is in contrast to the fluorescence results shown in Figures $4-5$ and 4-6, where the $60 \mathrm{MHz}$ results correlate better with lignin concentration than the $40 \mathrm{MHz}$ results.

To explore the reflection properties further, two He-Ne lasers were added to the $B \& W$ apparatus shown in Figure 6-4. One of these emitted at $633 \mathrm{~nm}$ while the other's output was at $543 \mathrm{~nm}$. Both beams were brought to focus at the same point on the cuvet samples as the fluorescence excitation laser. The size of the focused spots was comparable to the size of the excitation laser spot. A series of files were recorded with the samples being scanned over the same area as for the fluorescence tests. The resultant files consisted of two peaks corresponding to the reflected light at the two laser wavelengths.

The results of these tests are presented in Figures 9-9 through 9-12. The repeatability from front to back surface is not good. This is most likely due to the fact that reflection depends strongly on the morphology of the surface. Although the scanned area is large enough to give representative sampling of the fluorescence, the variability of reflection with position is too large to provide adequate averaging with the scanned area used. The results at both wavelengths show the same variability, which is consistent with the interpretation that the results are dominated by local variability that is not averaged out.

If there is a correlation between the reflection and Kappa number similar to that seen in the phase-resolved data, it is masked by the non-repeatability of the reflection data.

\subsection{DERIVATIVE SPECTROSCOPY}

A technique, commonly employed in UV spectroscopy to separate the absorption effects due to species with overlapping spectral lines, is to take the first and sometimes higher order derivatives of the measured spectrum.

Figure 9-13 shows the fluorescence spectra and the first three derivatives for southern pine samples \#1 through \#6. Although the derivatives do show that there are repeatable features in the

$$
9-6
$$


structure, none of the features appear to offer a way to separate the closely spaced samples 4,5 and 6 . 
TABLE 9-2 ANALYSIS FILE FROM 10/31/91 TEST OF $337 \mathrm{~nm}$ EXCITATION

FILE TIMERES. WK1 ON DISK 103191-02

TIME RESOLVED FLUORESCENCE ON S. PINE AND N. PINE ALL PULP SAMPLSE IN QUARTZ CUVETS

FILE

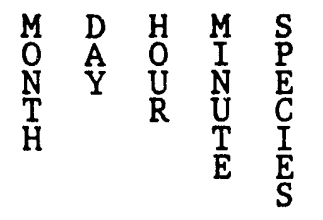
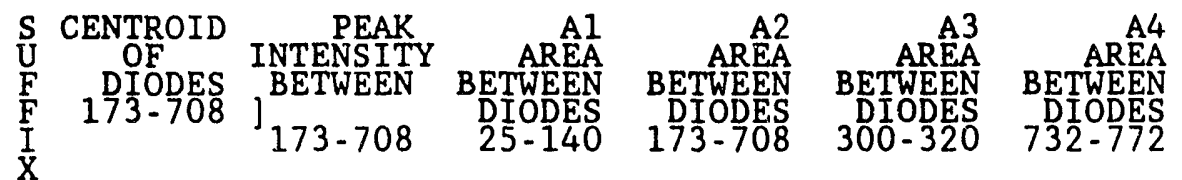

$\begin{array}{lllllllll}A F 1 A 00 & 10 & 31 & 14 & 38 & \text { SP } & F & 1 & 00 \\ A F 1 B 00 & 10 & 31 & 14 & 40 & \text { SP } & \text { F } & 2 & 00\end{array}$

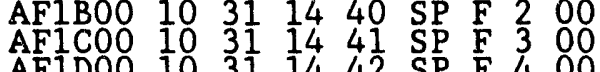

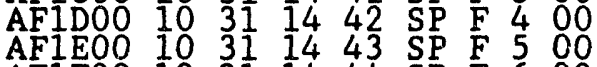

AFIFOO 10 31 14444 SP $F \quad 6 \quad 00$

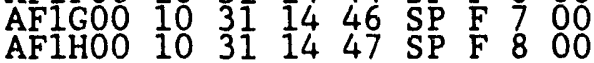

$\begin{array}{lllllllll}\mathrm{AB} 1 \mathrm{AOO} 0 & 10 & 31 & 14 & 59 & \mathrm{SP} & \mathrm{B} & 1 & 00 \\ \mathrm{AB} 1 \mathrm{~B} 00 & 10 & 31 & 15 & 0 & \mathrm{SP} & \mathrm{B} & 2 & 00\end{array}$

$\begin{array}{lllllllll}A B 1 C O 0 & 10 & 31 & 15 & 1 & \text { SP } & B & 3 & 00 \\ A B 1 D O 0 & 10 & 31 & 15 & 3 & \text { SP } & \text { B } & 4 & 00\end{array}$

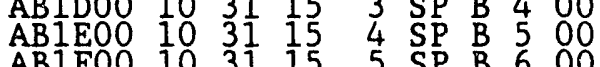

$A B 1 F 00103115 \quad 5$ SP B 600

$\begin{array}{lllllllll}A B 1 G 00 & 10 & 31 & 15 & 6 & \text { SP } & B & 7 & 00 \\ A B 1 H & 10 & 31 & 15 & 7 & \text { SP } & \text { B } & 8 & 00\end{array}$

$370 \cdot 6$
$373: 7$
$379: 6$
$386: 5$
$390: 3$
393.2
3995
398.4

398.4

$370 \cdot 1$

379.9

390.4

393.1

398.5

AF1A06 $10 \quad 31 \quad 15 \quad 55$ SP F 106

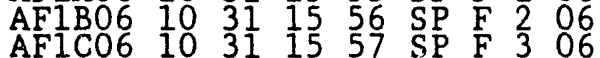
AFID06 1031 15 58 SP F 406

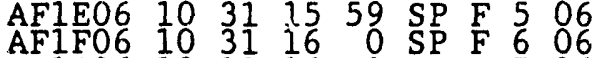
AFIG06 $103116 \quad 1$ SP F 706 AFIHO6 1031 16 25 SP $F$

AB1A06 $10 \quad 31 \quad 15 \quad 27$ SP $B \quad 1 \quad 06$

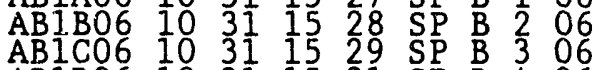

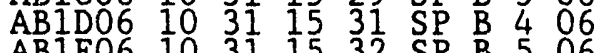
$A B 1 E 06 \quad 10311532$ SP B 506

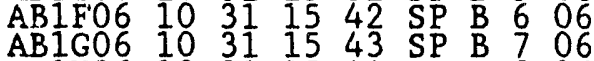

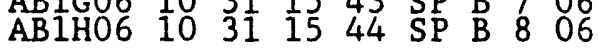

AF1A12A10 $3116 \quad 4 . \quad S P F$

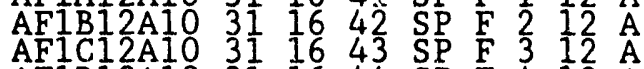
AFIDI2A10 311644 SP F 4 12 A

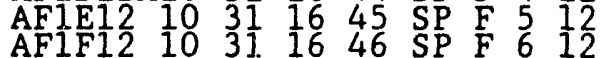
AFIGI2 1031 16 47 SP F 7 12

AF1H12 10 31 $16 \quad 48$ S. F $\quad$ F 812

$\begin{array}{lllll}\mathrm{AB} 1 \mathrm{~A} 12 & 10 & 31 & 17 \\ \mathrm{AB} 1 \mathrm{~B} 12 & 10 & 31 & 17\end{array}$ $A B 1 C 12$ 10 3117 $A B 1 D 122103117$ $A B 1 F 12$ 10 3117

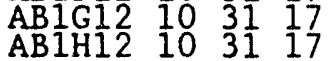

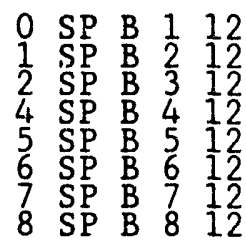

$369: 5$
$371: 8$
$375: 1$
$380: 1$
$382: 3$
382.5
382

385.1

369

372.2

380.5

$38 \frac{1}{3} .7$

384.5

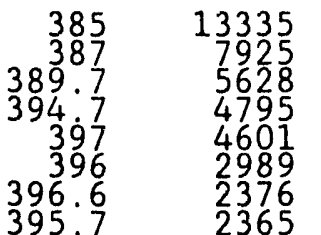

395.7

$\begin{array}{rr}384.7 & 13157 \\ 386.5 & 7586 \\ 389.1 & 5000 \\ 396.4 & 4833 \\ 398.8 & 4390 \\ 394.9 & 2835 \\ 397.6 & 2542 \\ 390.7 & 2728\end{array}$

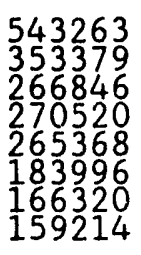

533598
343415
251312

260656

174027

168405
156223

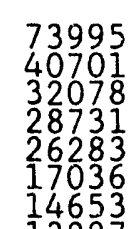

13227

72368

29992

27455

14896

10644

13335
7925
5628

4795

2376

2365 $\begin{array}{rr}20922 & 1 \\ 11505 & 728+08 \\ 77406 & 57503628 \\ 8279 & 61844368 \\ 8636 & 61628545 \\ 4628 & 44105776 \\ 3108 & 40152830 \\ 3243 & 39861918\end{array}$

20431
$100797171 \mathrm{~F}+08$

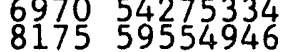

814160793396

349241593733

371340774474
314538946924

11090198

7215069

5504359

5602096

5483022

3828327

3316134

10832518

7056447

5182744

5400090

3608935

3478950

3239757

$\begin{array}{ll}-2638 & 15275814 \\ -3733 & 8524582 \\ -4841 & 6868947 \\ -4707 & 6426870 \\ -5332 & 5957408 \\ -5220 & 3904177 \\ -6200 & 3348782 \\ -5871 & 3077718\end{array}$

1511750

828089

587212

540359

305064

272319

$\begin{array}{lll}-2776 & 14952999 & 1483405\end{array}$

$-43259218638$

$-5240$

$-7596$

-5450
-3855
-5476

$-54763250253$

$-77753009316$

-6799
-6841

$-7939$

$-7672$

$-7546$

.7718

-6573
-6459

-6579
-7617
-6299

$-6299$

.7034

-6471
-6329
6132194

6225143

3355327

3009316
1800104
1262870

1150976

103519

575042

892962

617224

560543

305766

214978

274748

161990

94051

90089

46028

44661

271671

2937534

1713778
1170263

1175430

1102035

665780

594205
660604
10189

95183

88112

47138
395460

287984

273201

372380

285569

282375

387290

263528

319380

371093

27015

276183

34624

18903

15976

15364
9816

8401
7690

33184

22160

15129

8797

6218
8438

6184
1827
1058
1147
1292
-440
1176
-699

4752

2484

922

905
-719

-668
-839 
TABLE 9-2 ANALYSIS FILE FROM 10/31/91 TEST OF $337 \mathrm{~nm}$ EXCITATION (CONT)

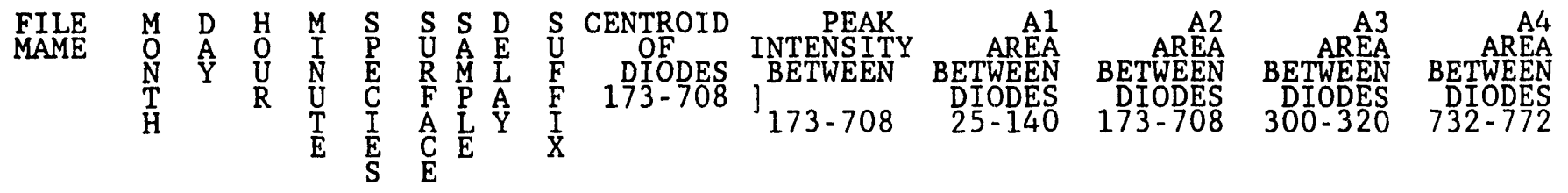

AFIIO0 $10 \quad 31 \quad 14 \quad 48$ NP F 100 AFIJO0 $10 \quad 311449$ NP F 200 AFIKO0 10031 14 51 NP F 3300 AFILOO 10031 14 52 NP F 4 O 00 AFINOO $10311454 \mathrm{NP} F \quad 600$

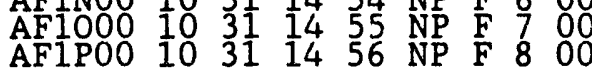

AB1I00 $10 \begin{array}{llllllll}10 & 31 & 15 & 8 & \mathrm{NP} & \mathrm{B} & 1 & 00\end{array}$

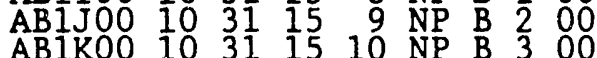
ABILOO 10 31 15 11 NP B 400 $A B I M O O 10311512$ NP B 500

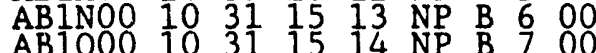
$A B 1 P 00 \begin{array}{lllllllllll}10 & 31 & 15 & 15 & N P & B & 8 & 00\end{array}$

AF1I06 $10 \quad 31 \quad 16 \quad 4$ NP F 1106

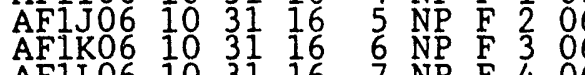
AF1L06 $103116 \quad 7 \quad \mathrm{NP} F$

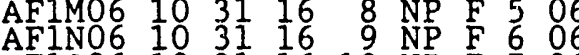

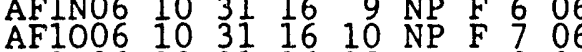
AFIP06A10 31 16 18 NP F 806 A

$A B 1 I 06 \quad 10 \quad 31 \quad 15 \quad 46 \quad N P \quad B \quad 106$

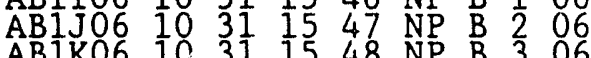
AB1L06 $10 \quad 31 \quad 15 \quad 49$ NP $B \quad 406$

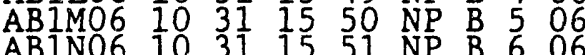
$A B 1006 \quad 10 \quad 31 \quad 15 \quad 52$ NP $B 706$ $\begin{array}{llllllll}A B 1 P 06 & 10 & 31 & 15 & 53 & \text { NP } & \text { B } 8 & 06\end{array}$

$\begin{array}{lllllllll}\text { AFII12 } & 10 & 31 & 16 & 49 & \mathrm{NP} & \mathrm{F} & 1 & 12 \\ \text { AFIJI2 } & 10 & 31 & 16 & 50 & \mathrm{NP} & \mathrm{F} & 2 & 12\end{array}$ AFIK12 $1031016 \quad 51$ NP F 312

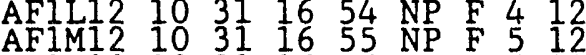
AF1N 12 10 311655 NP F 612

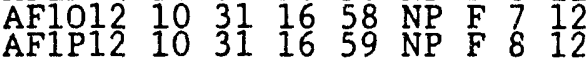

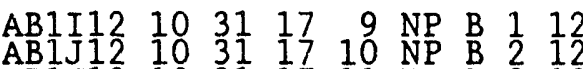

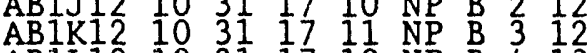

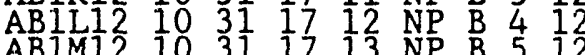
$A B 1 N 12 \quad 10 \quad 31 \quad 17 \quad 14 \quad N P$ B 6

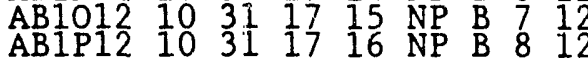

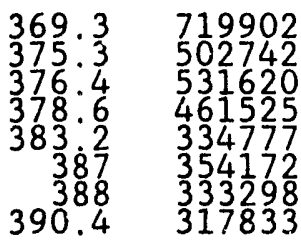

$369.1 \quad 684227$

$374: \frac{1}{3} \quad 460429$

$379.7 \quad 396973$

$383.8 \quad 297812$

$387 \cdot \frac{1}{6} \quad 301577$

390.9281860

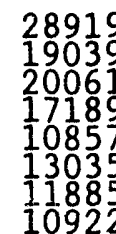

$1.4 E+08$
$1 \cdot 1 \mathrm{E}+08$
$1 \cdot 1 \mathrm{E}+08$
97622810
73590103
80020035
75869801
73775737

14763113
10310074
10917733
9538776
6886078
7317619
689415
6602568

471372

464229

435967

371253

437370
427914

438481

$26871 \quad 1.4 \mathrm{E}+08 \quad 14004796$

$1688495474782 \quad 9445445$

1793599425455

1387685089721

957265892885

1001768332949

920165957638

8151079

6147013

6243072

6196664

5865696

440709

361008

421896

0208

342114

378980

396336

$\begin{array}{rrrrrr}370 & 91070 & -1509 & 18801778 & 1866854 & 41008 \\ 373.9 & 55983 & -3311 & 11880742 & 1135571 & 27346 \\ 375 & 58452 & -3397 & 12637662 & 1201914 & 30314 \\ 376.3 & 47715 & -4440 & 10366632 & 982171 & 25325 \\ 378.4 & 33415 & -5183 & 7403269 & 685717 & 17888 \\ 38007 & 33695 & -4668 & 7559277 & 690424 & 21099 \\ 381.6 & 30063 & -5562 & 6779634 & 616058 & 18730 \\ 382.8 & 26510 & -5473 & 6079329 & 548488 & 16664 \\ 369.4 & 94922 & -1723 & 19502135 & 1942889 & 41762 \\ 373.1 & 61020 & -3126 & 13003840 & 1246264 & 29422 \\ 375.1 & 57915 & -3275 & 12491152 & 1189284 & 30511 \\ 376.7 & 45118 & -4222 & 9864945 & 930028 & 24296 \\ 378.8 & 32736 & -4407 & 7284902 & 675574 & 17204 \\ 381.6 & 30365 & -4932 & 6849725 & 622226 & 17754 \\ 381.7 & 29420 & -4262 & 6643471 & 603658 & 16494 \\ 383.4 & 27458 & -4401 & 6240522 & 561880 & 17277\end{array}$

$\begin{array}{rr}384.7 & 16471 \\ 390.1 & 9253 \\ 391.1 & 10101 \\ 393.1 & 7805 \\ 394.8 & 5439 \\ 398.6 & 5107 \\ 397.8 & 4916 \\ 399.1 & 4484\end{array}$

$-6032 \quad 365873$

$-6362$

2209836

$-6854$

186294

6634

$-6807$

-6627
-7018

131466

1291107

1198309

$-6038$

384.

391.

17015

10012

394.6

397.7

$398 \cdot 3$
400.1

7641

$-6148$

3768469

$-6744$

229461

2352064

$-6402$

184046

$-6710$

1243682

-6234
-6390

11213271 $\begin{array}{rr}335023 & 7255 \\ 190155 & 4336 \\ 199980 & 4570 \\ 156274 & 3390 \\ 108784 & 1512 \\ 103250 & 2291 \\ 97334 & 1479 \\ 88211 & 1518\end{array}$

$347070 \quad 7438$

$202373 \quad 4913$

$154482 \quad 3258$

$99054 \quad 1371$

$\begin{array}{ll}97038 & 1792 \\ 86143 & 1306\end{array}$ 
TABLE 9-3 SEQUENCE OF TESTING ON 5/29/9

TRIAL SAMPLE CUVET ....TIME...

FACE (HR) (MIN)

$\begin{array}{lllll}1 & 2 & \text { F } & 9 & 25 \\ 1 & 5 & \text { F } & 9 & 29 \\ 1 & 1 & \text { F } & 9 & 33 \\ 1 & 8 & \text { F } & 9 & 35 \\ 1 & 4 & \text { F } & 9 & 37 \\ 1 & 3 & \text { F } & 9 & 39 \\ 1 & 7 & \text { F } & 9 & 40 \\ 1 & 6 & \text { F } & 9 & 42 \\ 3 & 2 & \text { B } & 9 & 44 \\ 3 & 5 & \text { B } & 9 & 47 \\ 3 & 1 & \text { B } & 9 & 48 \\ 3 & 8 & \text { B } & 9 & 49 \\ 3 & 4 & \text { B } & 9 & 51 \\ 3 & 3 & \text { B } & 9 & 52 \\ 3 & 7 & \text { B } & 9 & 54 \\ 3 & 6 & \text { B } & 9 & 55 \\ 2 & & & & \\ 2 & 2 & \text { F } & 14 & 19 \\ 2 & 5 & \text { F } & 14 & 21 \\ 2 & 1 & \text { F } & 14 & 23 \\ 2 & 8 & \text { F } & 14 & 24 \\ 2 & 4 & \text { F } & 14 & 25 \\ 2 & 3 & \text { F } & 14 & 27 \\ 2 & 7 & \text { F } & 14 & 28 \\ 2 & 6 & \text { F } & 14 & 29 \\ & & & & \end{array}$


TABLE 9-3 SEQUENCE OF TESTING ON $5 / 29 / 9$ (CONT)

TRIAL SAMPLE CUVET ....TIME...

$$
\text { FACE (HR) (MIN) }
$$

$\begin{array}{rrrrr}1 & 2 & \text { B } & 14 & 31 \\ 1 & 5 & \text { B } & 14 & 33 \\ 1 & 1 & \text { B } & 14 & 35 \\ 1 & 8 & \text { B } & 14 & 36 \\ 1 & 4 & \text { B } & 14 & 37 \\ 1 & 3 & \text { B } & 14 & 38 \\ 1 & 7 & \text { B } & 14 & 40 \\ 1 & 6 & \text { B } & 14 & 41 \\ 3 & 2 & \text { F } & 15 & 59 \\ 3 & 5 & \text { F } & 16 & 2 \\ 3 & 1 & \text { F } & 16 & 4 \\ 3 & 8 & \text { F } & 16 & 5 \\ 3 & 4 & \text { F } & 16 & 6 \\ 3 & 3 & \text { F } & 16 & 7 \\ 3 & 7 & \text { F } & 16 & 9 \\ 3 & 6 & \text { F } & 16 & 10 \\ & & & & \\ 2 & 2 & \text { B } & 16 & 12 \\ 2 & 5 & \text { B } & 16 & 15 \\ 2 & 1 & \text { B } & 16 & 16 \\ 2 & 8 & \text { B } & 16 & 17 \\ 2 & 4 & \text { B } & 16 & 18 \\ 2 & 3 & \text { B } & 16 & 20 \\ 2 & 7 & \text { B } & 16 & 21 \\ 2 & 6 & \text { B } & 16 & 22\end{array}$


FIGURE $9-4$ RESULTS OF LITMUS PAPER TESTS OF BUFFERED PULP SAMPLES

FILE"LITMUS.WK1" PROJ 4040 (LIGNIN IN PULP)

DATE OF TESTING: $8 / 21 / 91(14: 15-15: 15)$

BY M MALITO \& $K$ NEVITT

PAPER USED FOR TESTS WAS FROM "MICRO ESSENTIAL LAB, INC"

$\mathrm{H} 2 \mathrm{O}$ : pHydron 5.6-6.8

$\mathrm{pH} 7$ : pHydron $6.8-8.4$

pH 10: pHydron $9.2-10.6$

PRIOR TO TESTING, A BROAD RANGE PH PAPER WAS USED TO VERIFY

THAT THE ABOVE NOTED PAPER RANGES WERE APPROPRIATE.

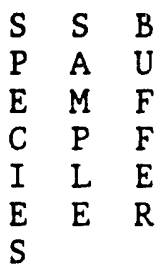

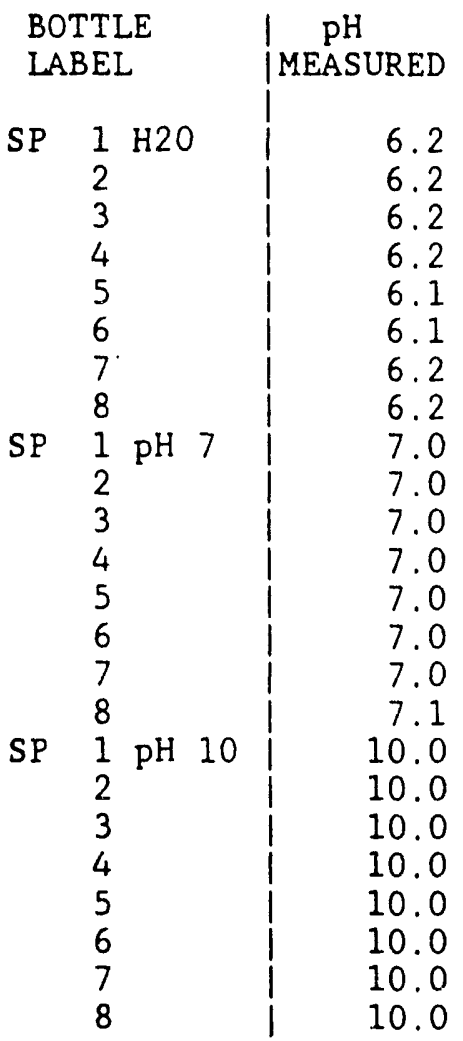

$\begin{array}{lll}\text { S } & \text { S } & \text { B } \\ \text { P } & A & \text { U } \\ \text { E } & M & F \\ C & P & F \\ \text { I } & \text { L } & \text { E } \\ \text { E } & \text { E } & \text { R } \\ \text { S } & & \end{array}$

\begin{tabular}{|c|c|c|}
\hline \multicolumn{2}{|c|}{$\begin{array}{l}\text { BOTTLE } \\
\text { LABEL }\end{array}$} & $\begin{array}{c}\mathrm{pH} \\
\text { MEASURED }\end{array}$ \\
\hline NP & $1 \mathrm{H} 2 \mathrm{O}$ & 6.2 \\
\hline & $\begin{array}{l}2 \\
3\end{array}$ & $\begin{array}{l}6.1 \\
6.2\end{array}$ \\
\hline & 4 & 6.3 \\
\hline & 5 & 6.2 \\
\hline & 6 & 6.2 \\
\hline & 7 & 6.2 \\
\hline & 8 & 6.2 \\
\hline NP & $1 \mathrm{pH} 7$ & 7.0 \\
\hline & & 7.0 \\
\hline & 3 & 7.1 \\
\hline & 4 & 7.1 \\
\hline & 5 & 7.0 \\
\hline & 6 & 7.1 \\
\hline & 7 & 7.1 \\
\hline & 8 & 7.1 \\
\hline NP & $1 \mathrm{pH} 10$ & 10.1 \\
\hline & 2 & 10.1 \\
\hline & 3 & 10.0 \\
\hline & 4 & 10.0 \\
\hline & 5 & 10.1 \\
\hline & 6 & 10.1 \\
\hline & 7 & 10.1 \\
\hline & 8 & 10.1 \\
\hline
\end{tabular}




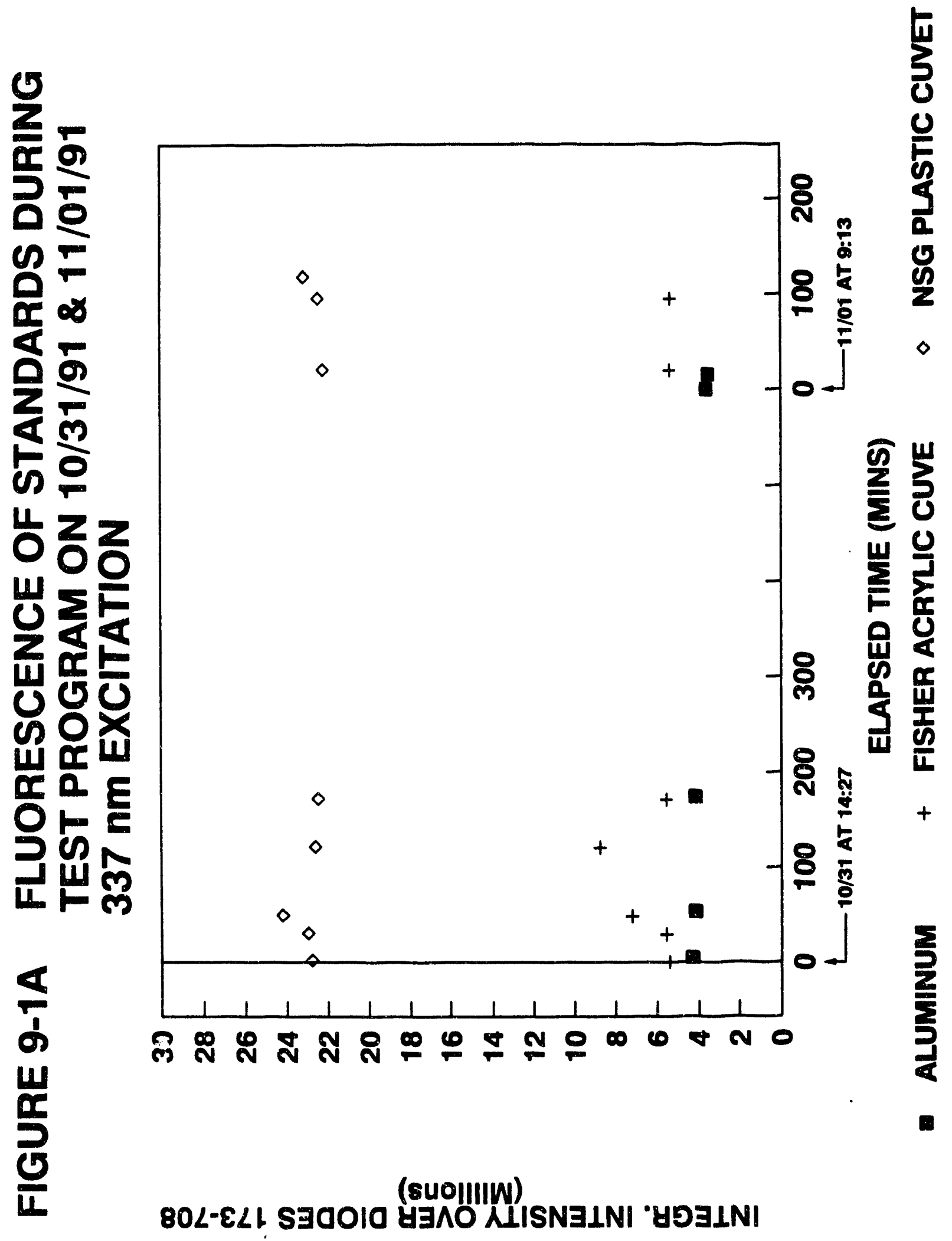




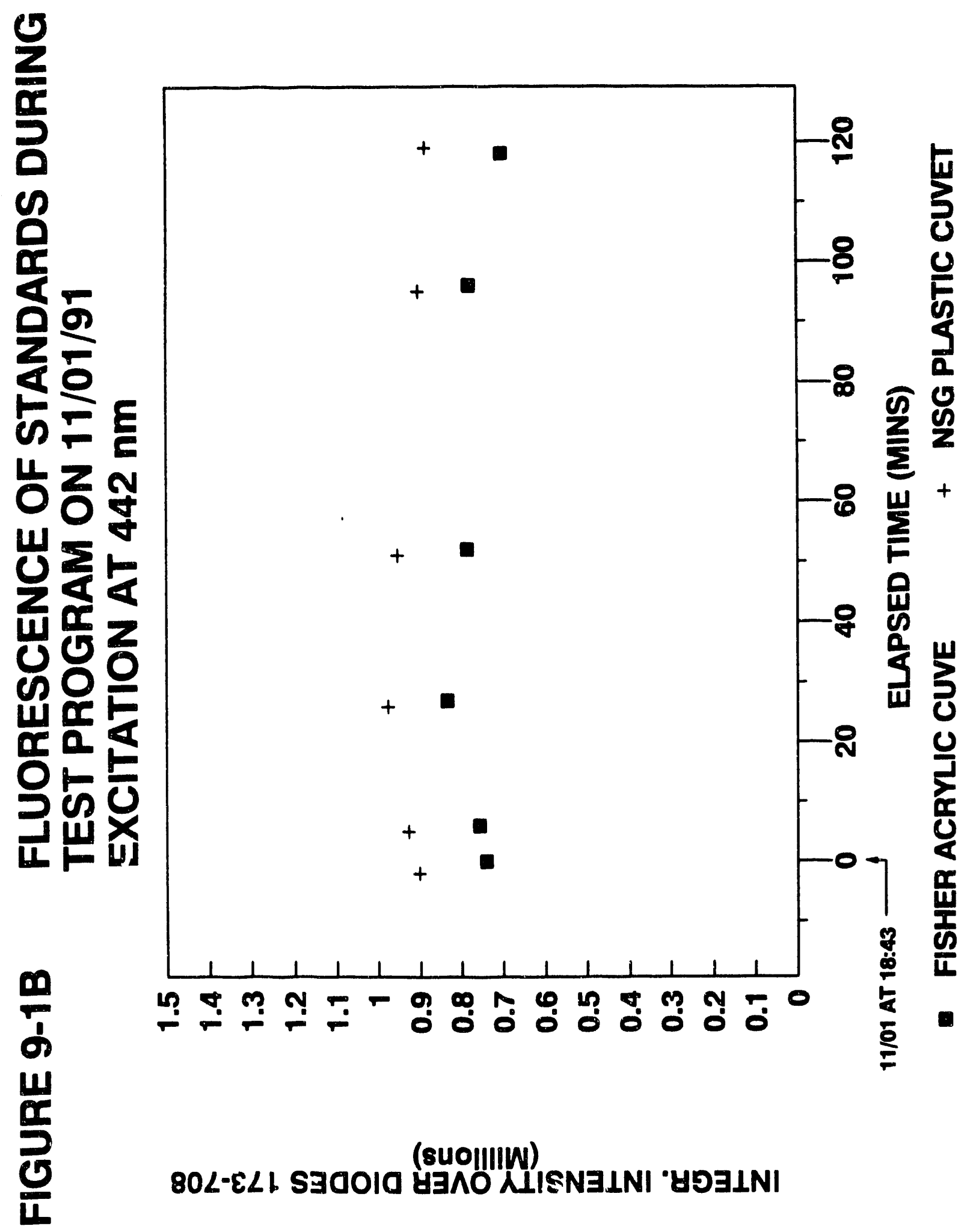




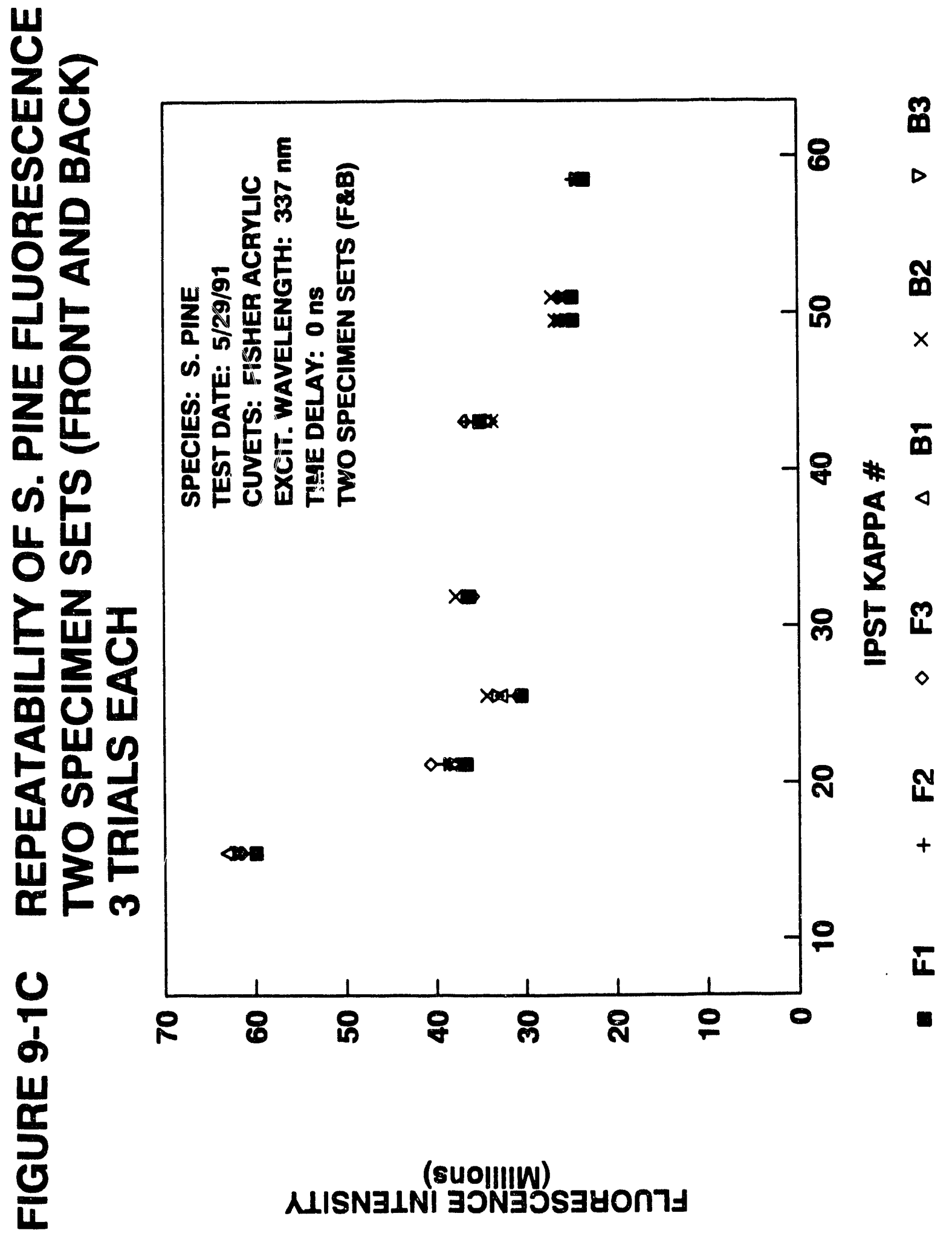




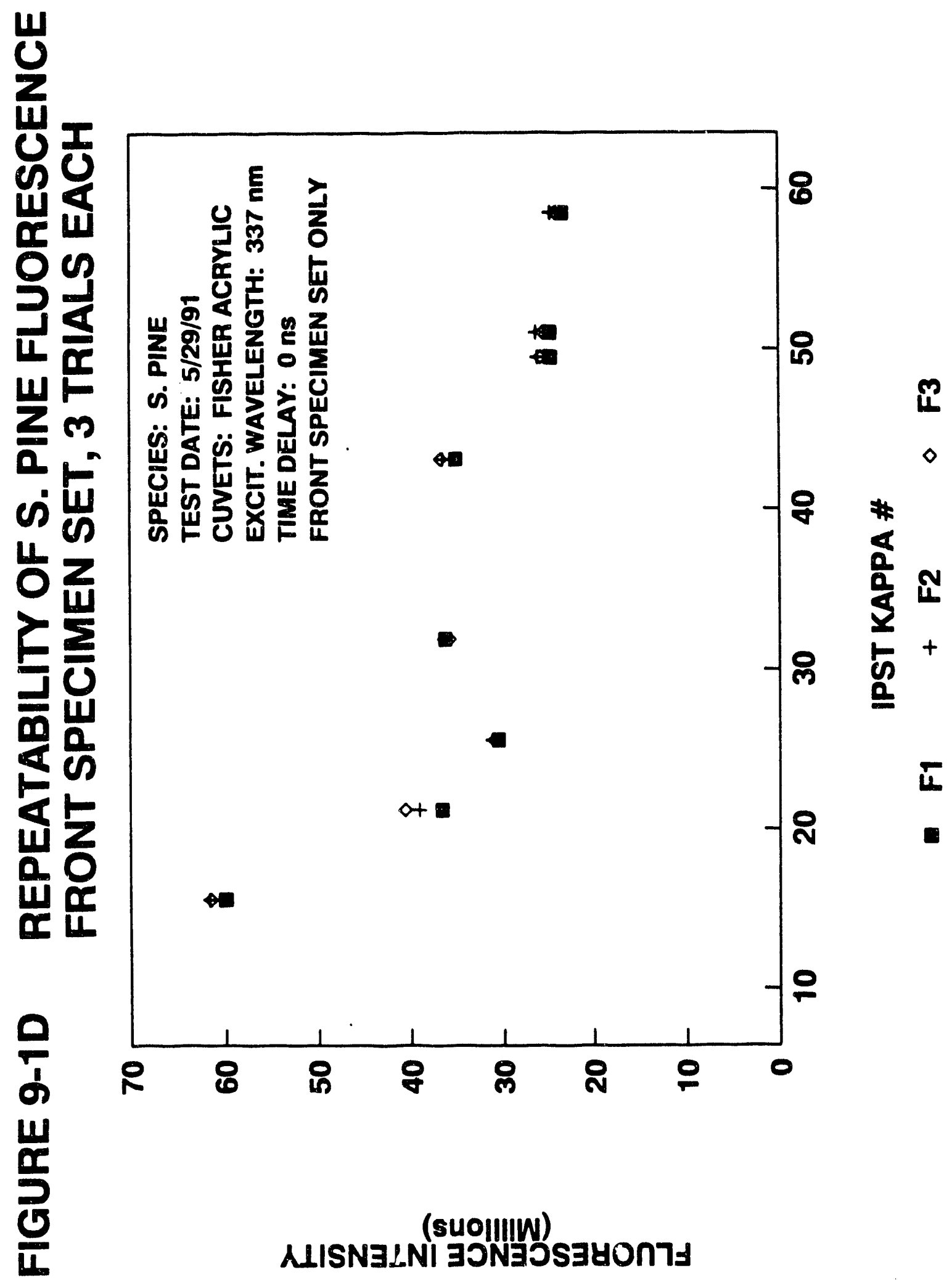




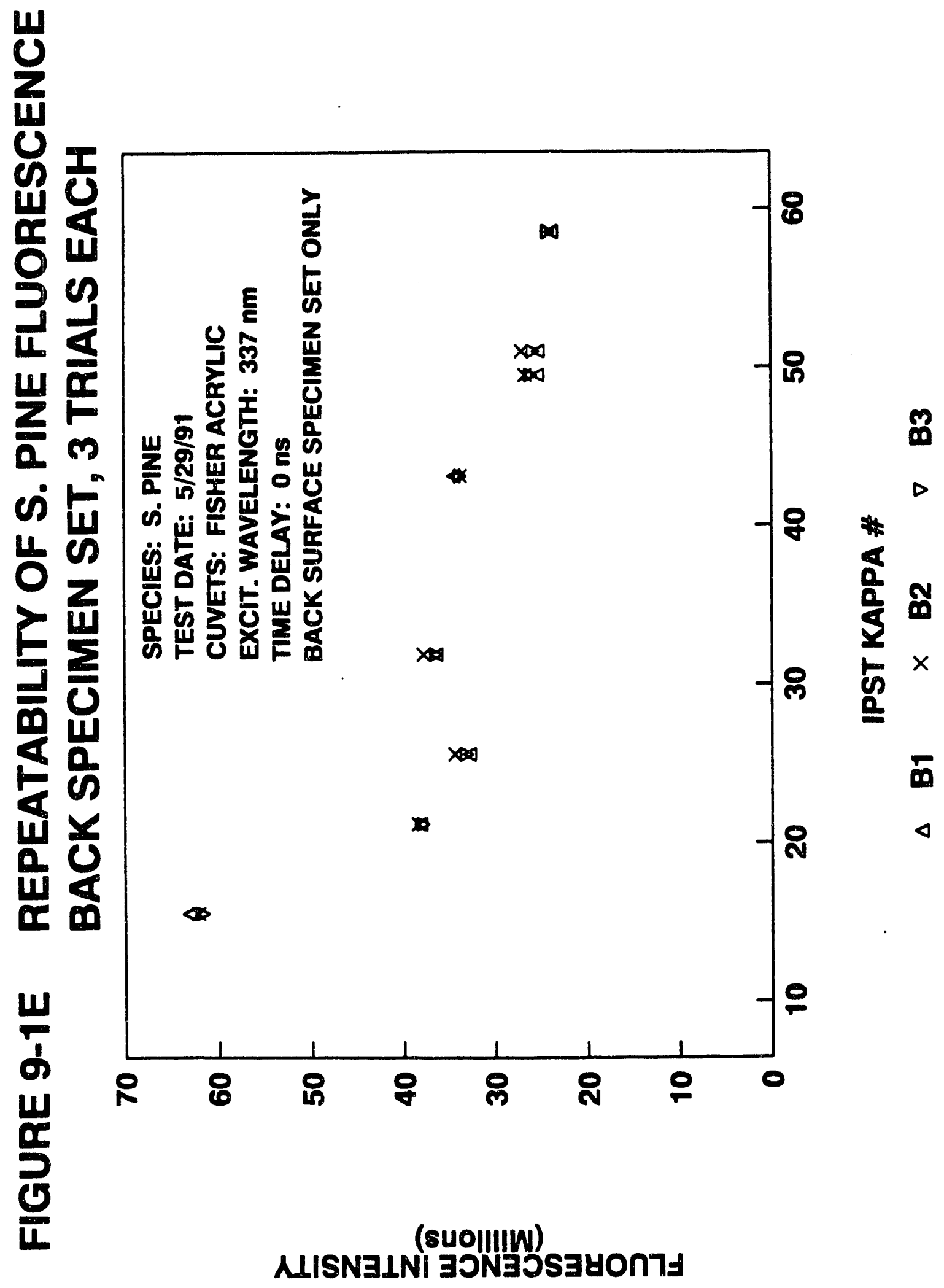




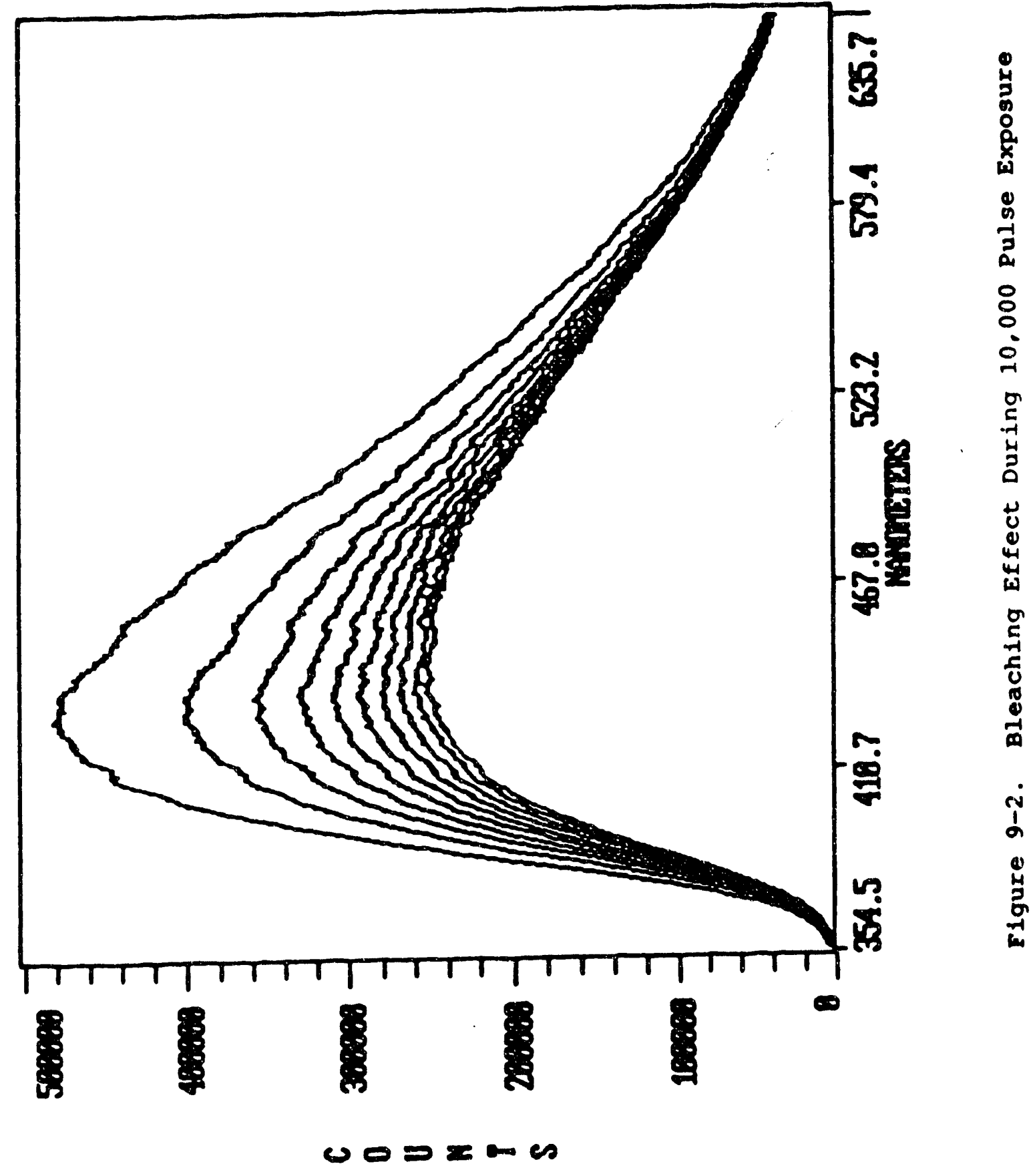




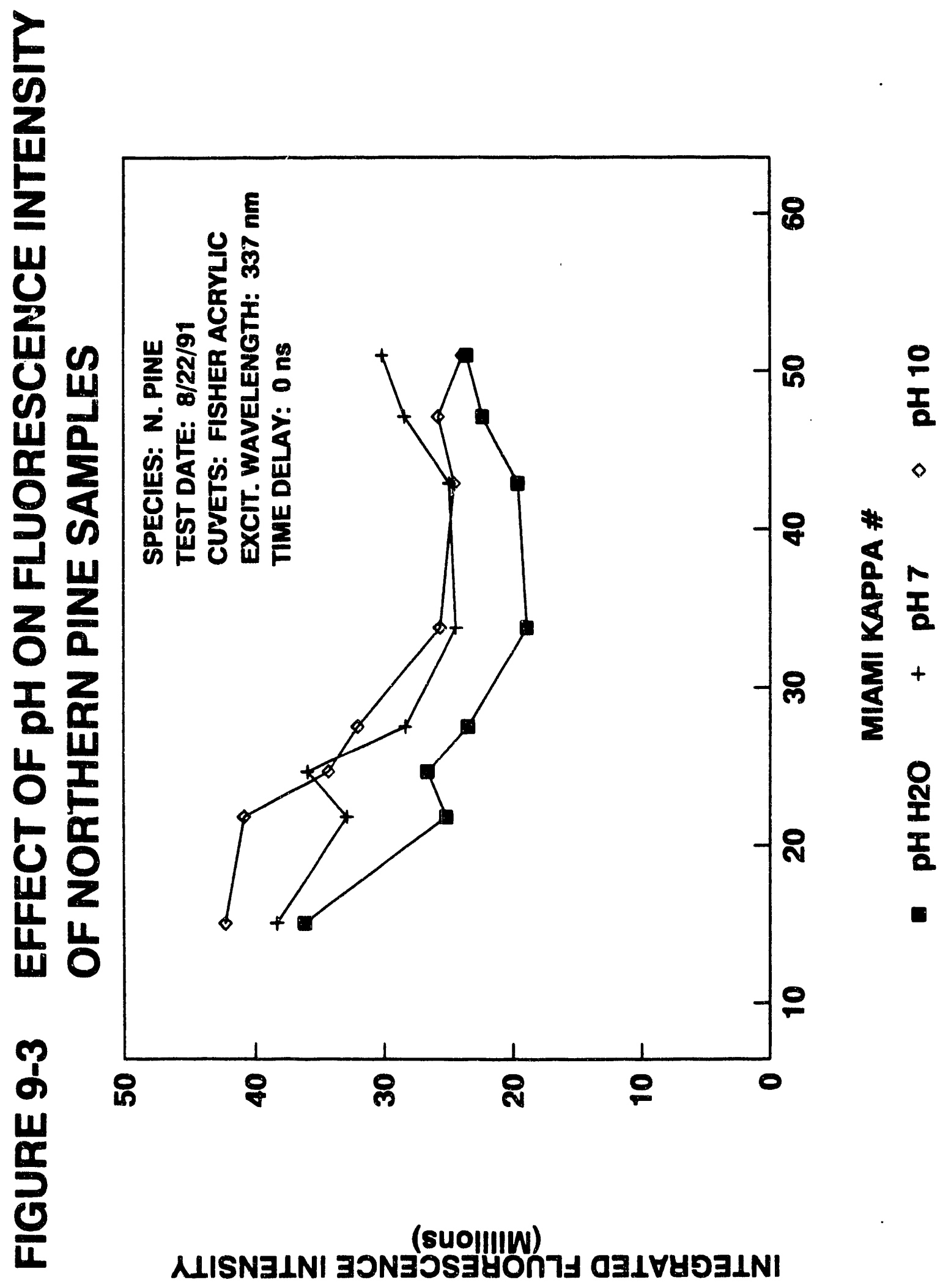




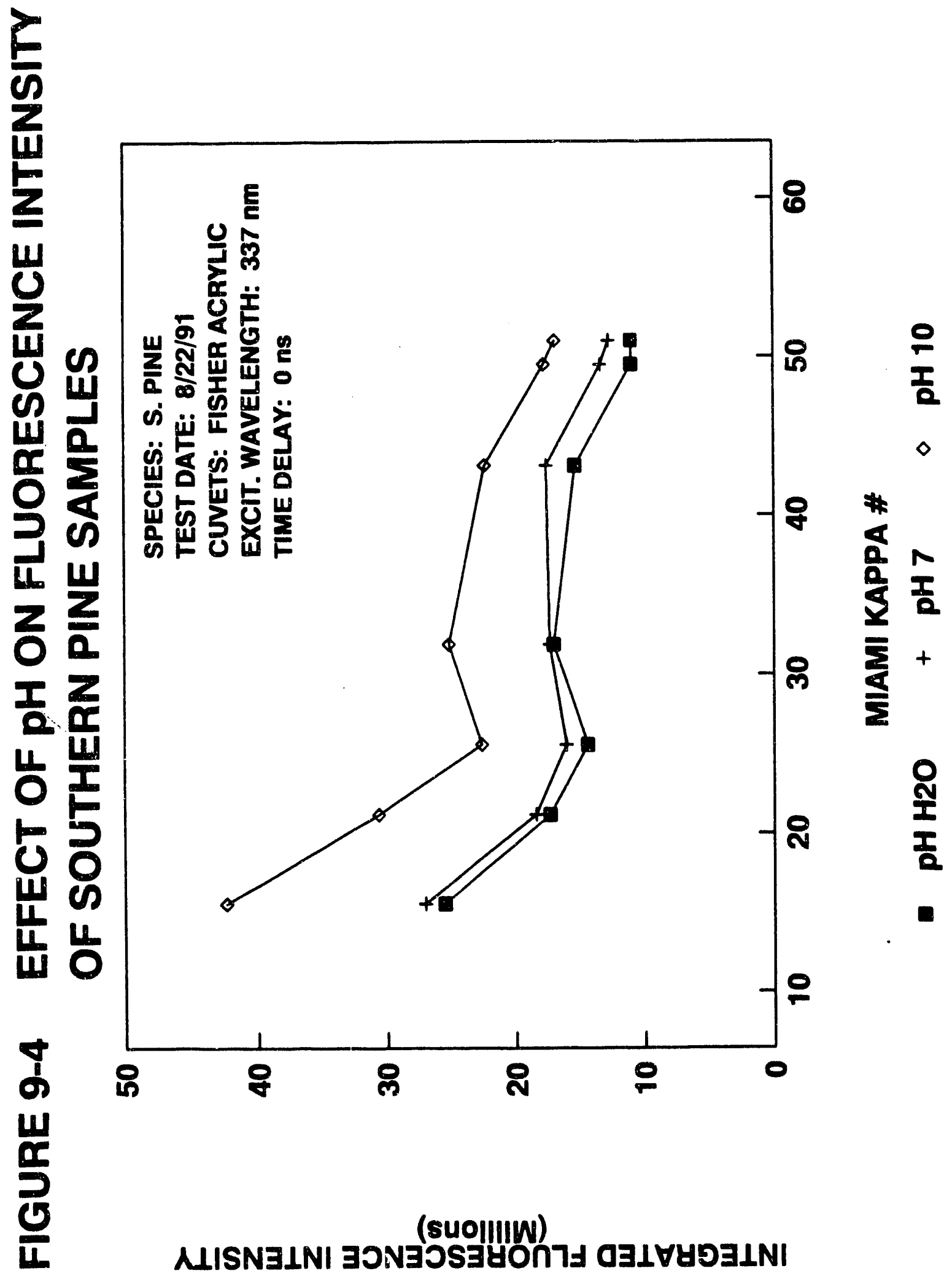




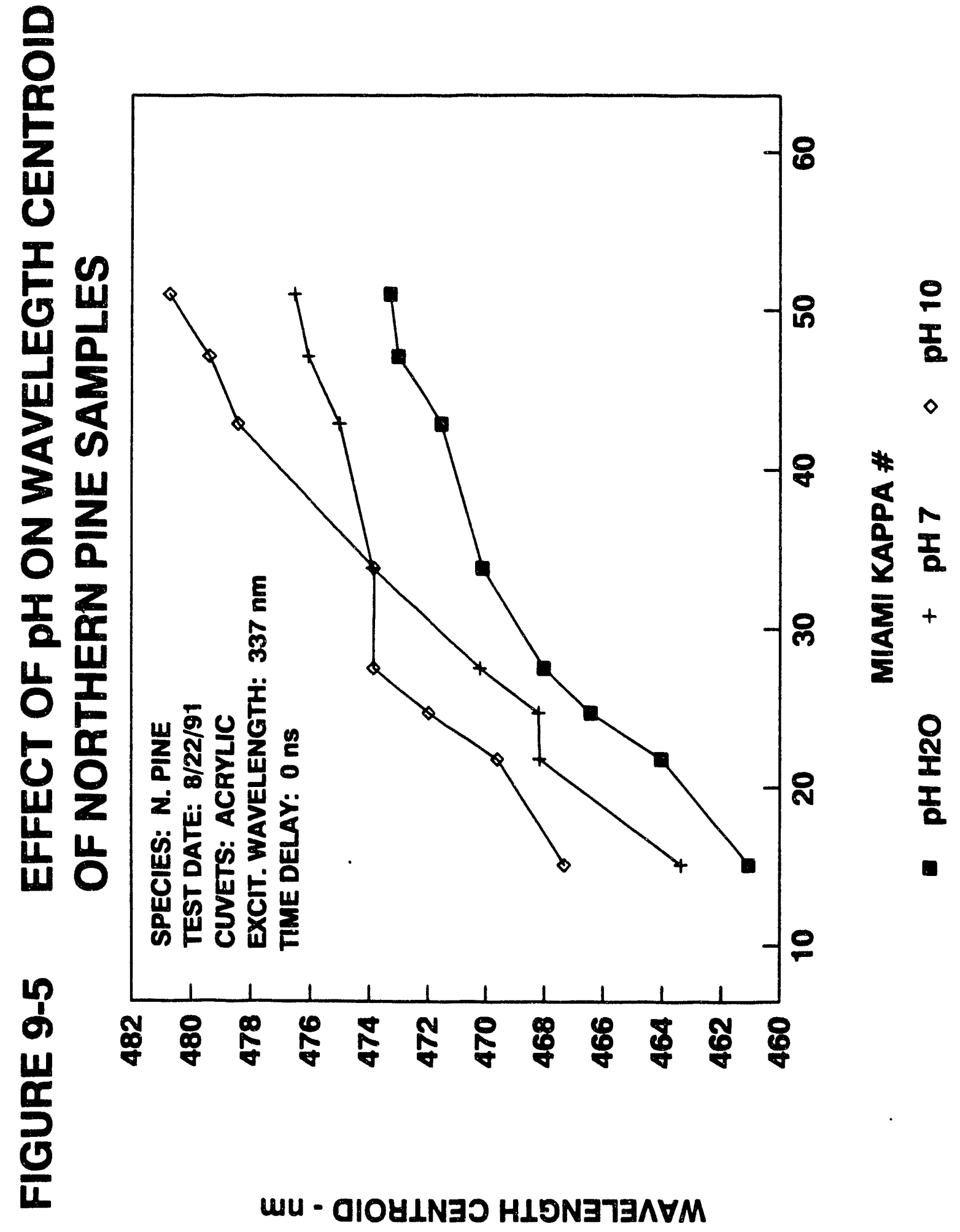




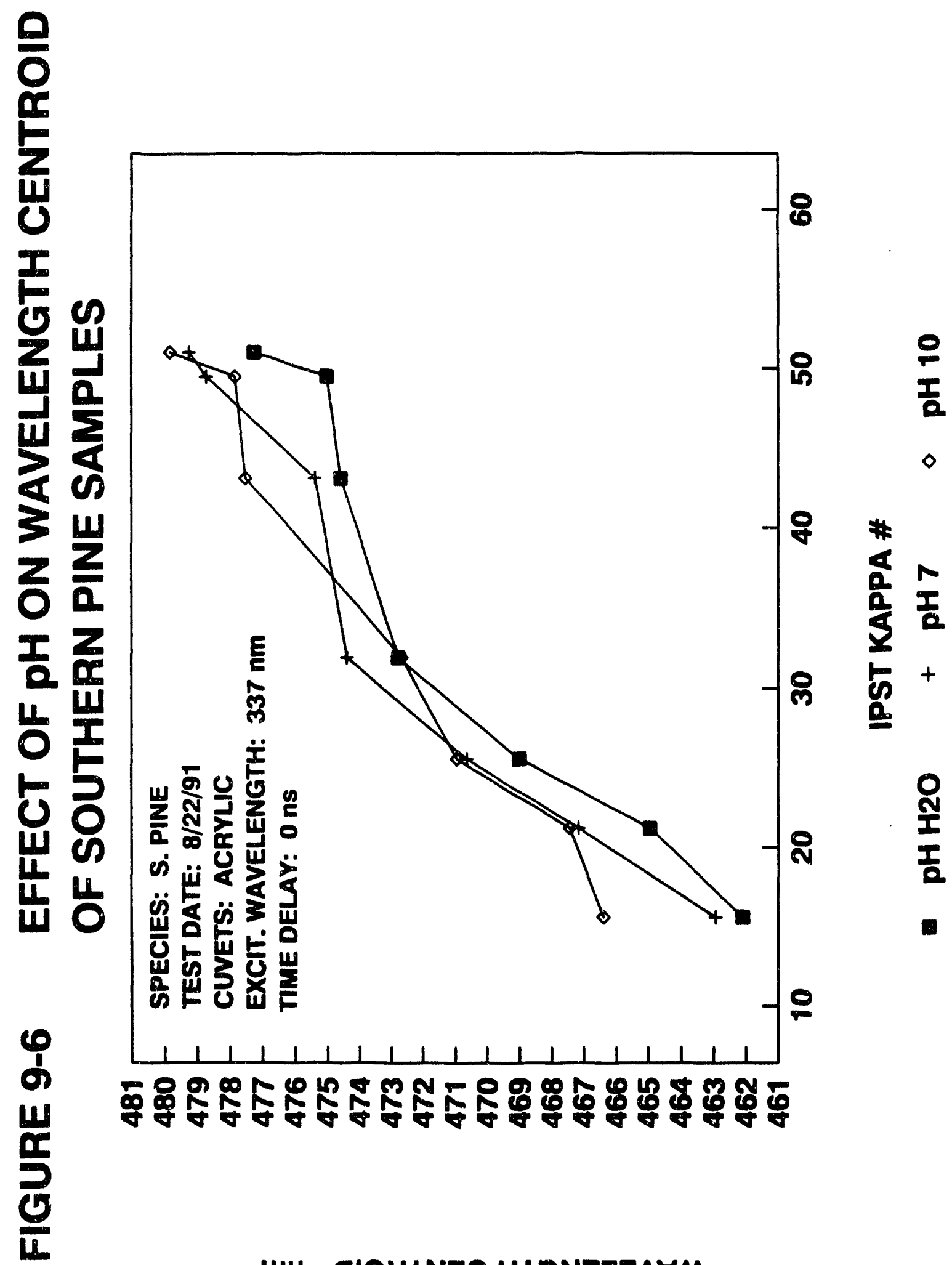

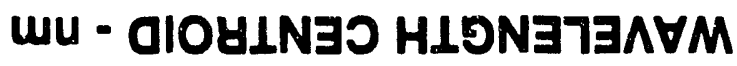


S. PINE, PHASE RESOLV. AT $40 \mathrm{MHz}$ REFL. INTENS. AT $442 \mathrm{~nm}$ "PH40442"

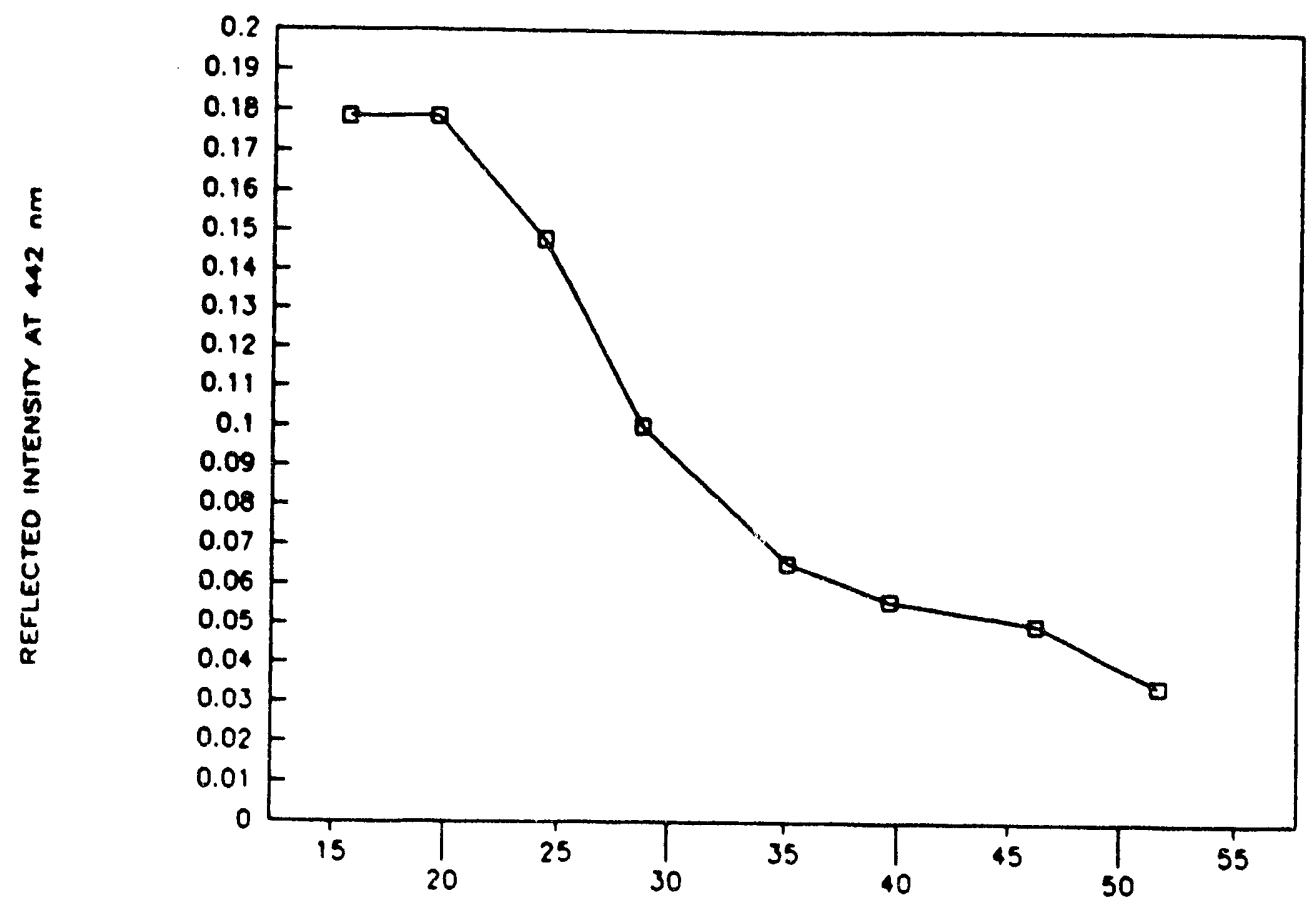

MIAMI KAPPA NUMBER Figure 9-7 Intensity of $442 \mathrm{~nm}$ Reflected Light as a Function of Kappa
Number for $40 \mathrm{MHz}$ Modulation

S. PINE, PHASE RESOLV. AT $60 \mathrm{MHZ}$ REFL. INTENS. AT $442 \mathrm{~nm}$ "PH60442"

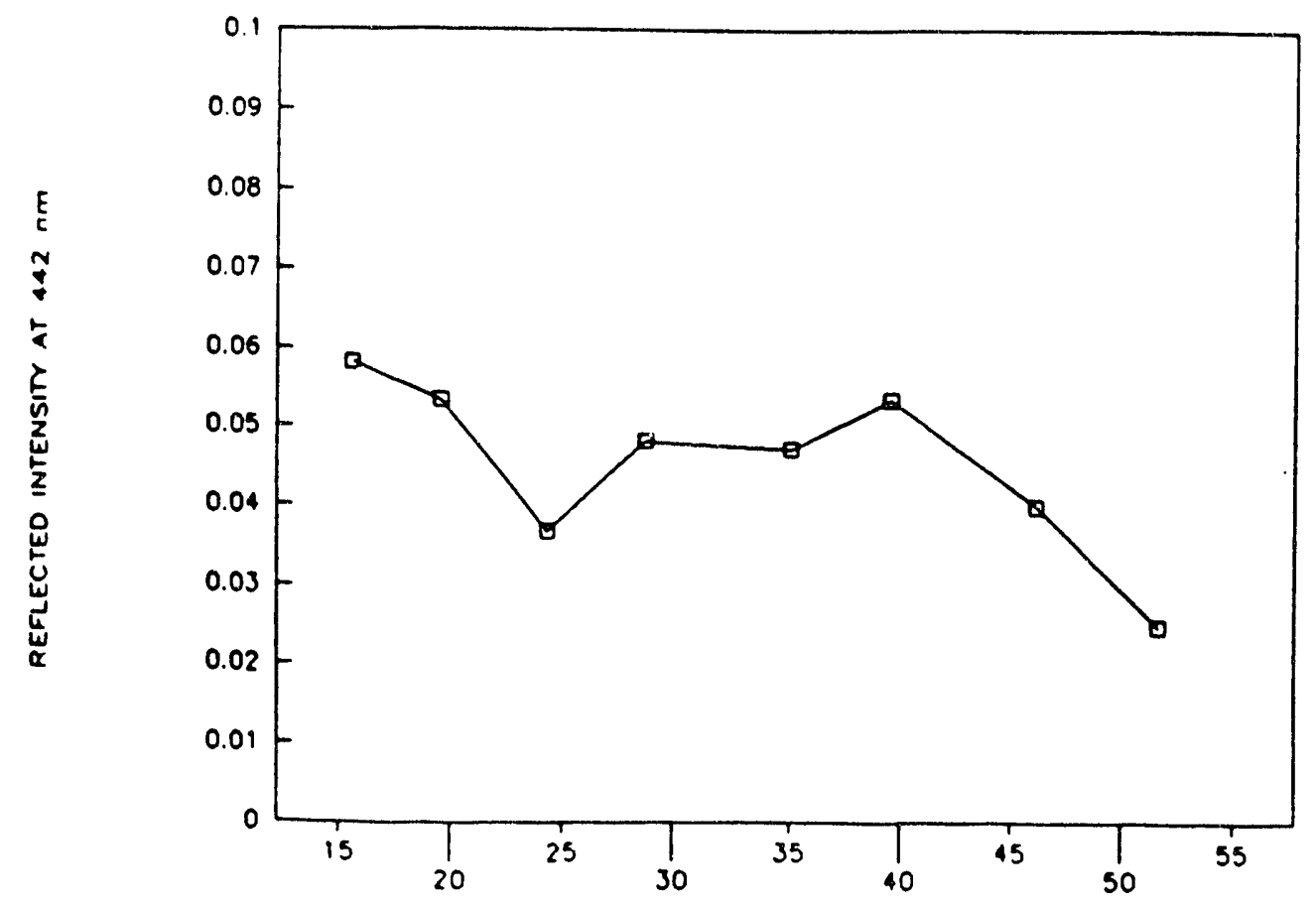

MLAMI KAPPA NUMBER Figure 9-8 Intensity of $442 \mathrm{~nm}$ Reflected Light as a Function of Kappa
Number for $60 \mathrm{MHz}$ Modulation 
S PINE TESTS $11 / 1 / 91$

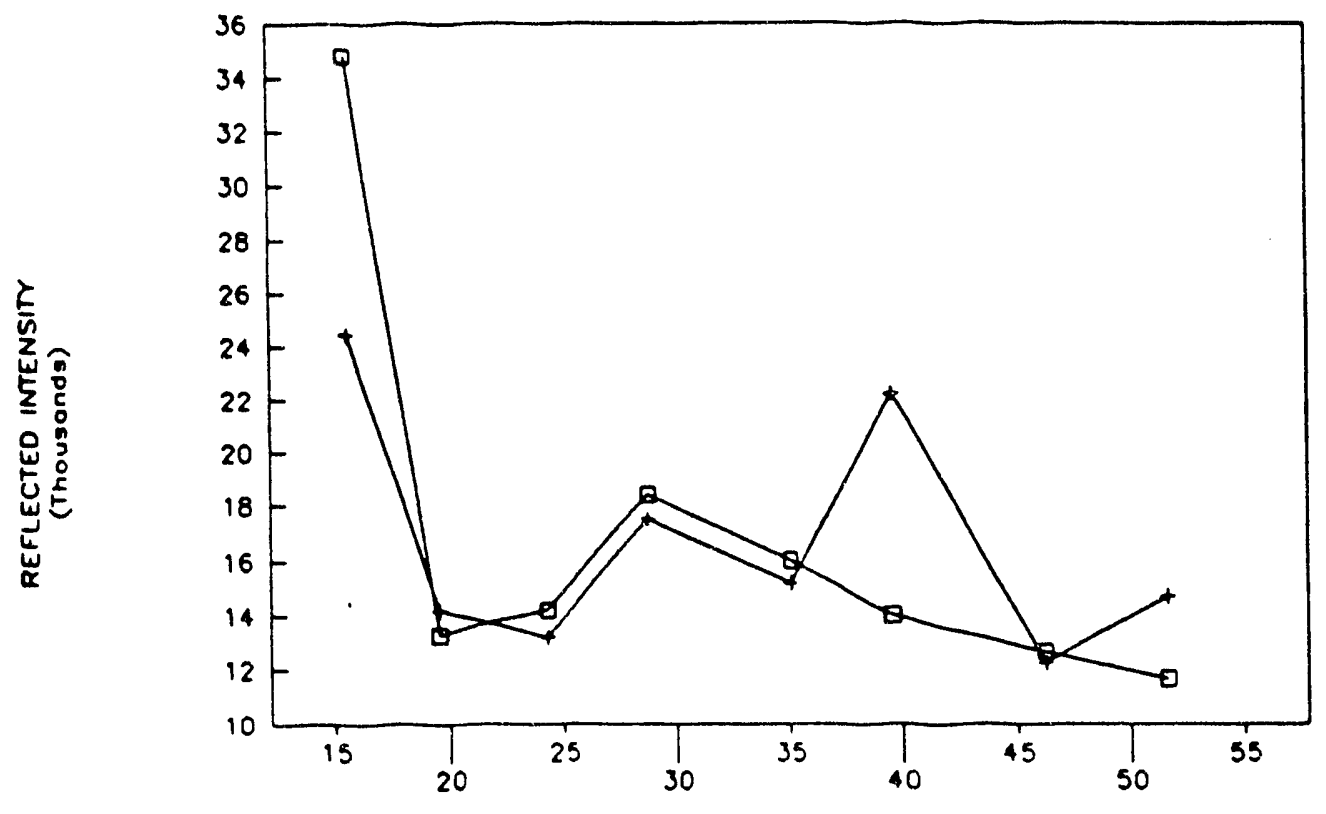

MIAMI KAPPA NUMBER

- FRONT SURF

+ BACK SURF

Figure 9-9 Intensity of $633 \mathrm{~nm}$ Reflection vs Kappa Number for Southern Pine Samples

S PINE TESTS $11 / 1 / 91$

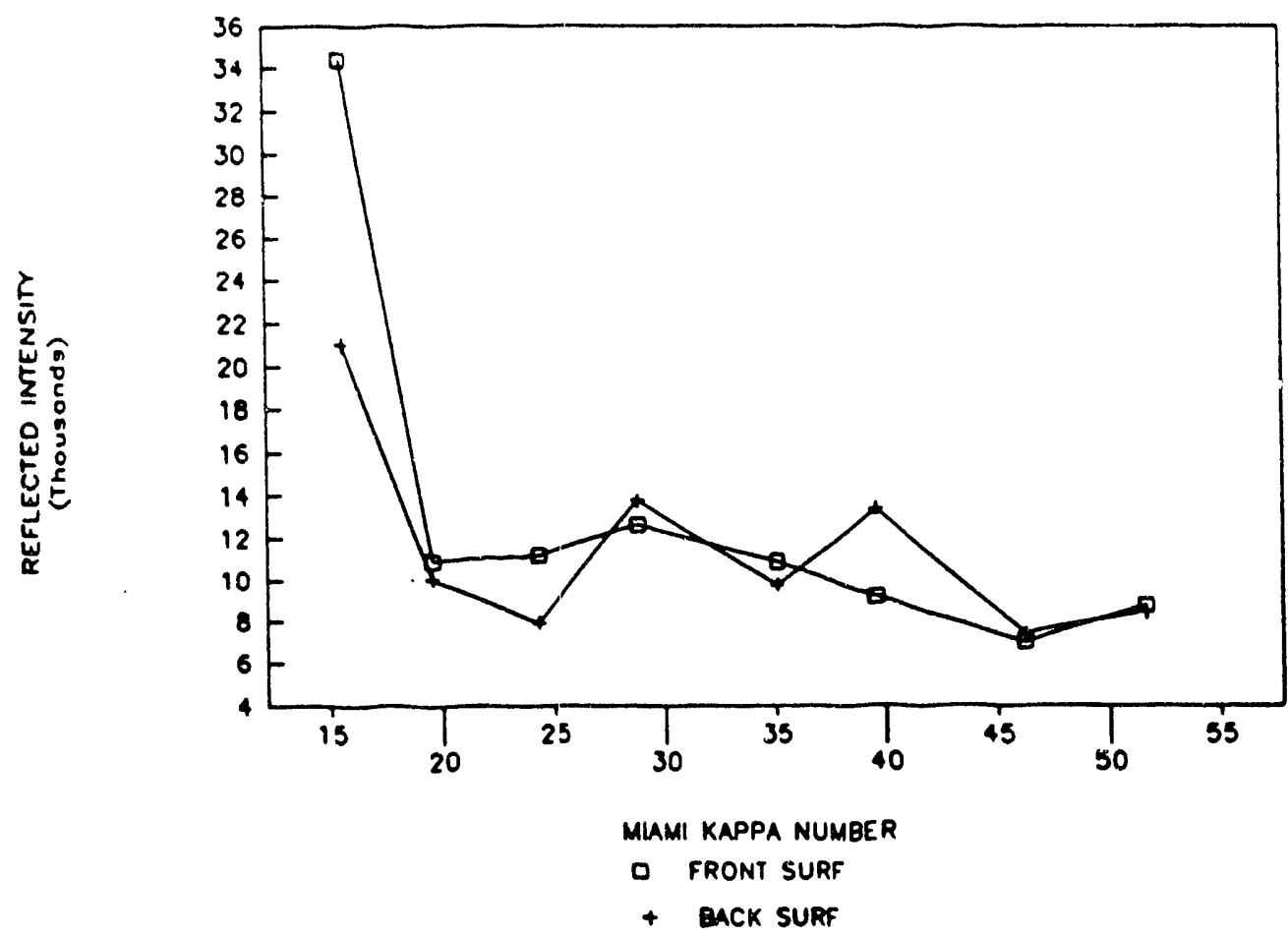

Figure 9-10 Intensity of $543 \mathrm{~nm}$ Reflection vs Kappa Number for Southern Pine Samples 
N PINE TESTS $11 / 1 / 91$

$633 \mathrm{~nm}$

"NPF8633"

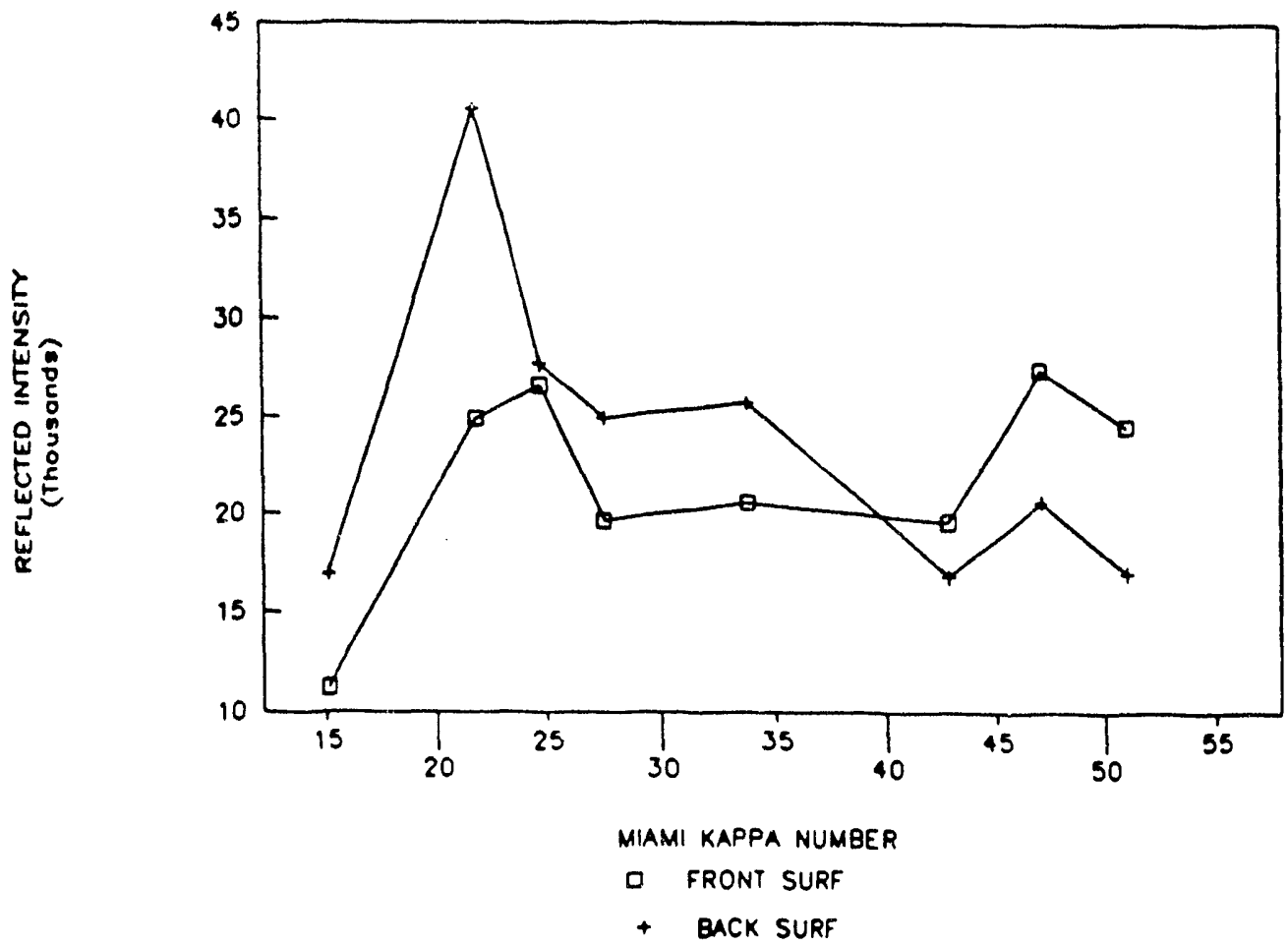

Figure 9-11 Intensity of $633 \mathrm{~nm}$ Reflection vs Kappa Number for Northern Pine Samples
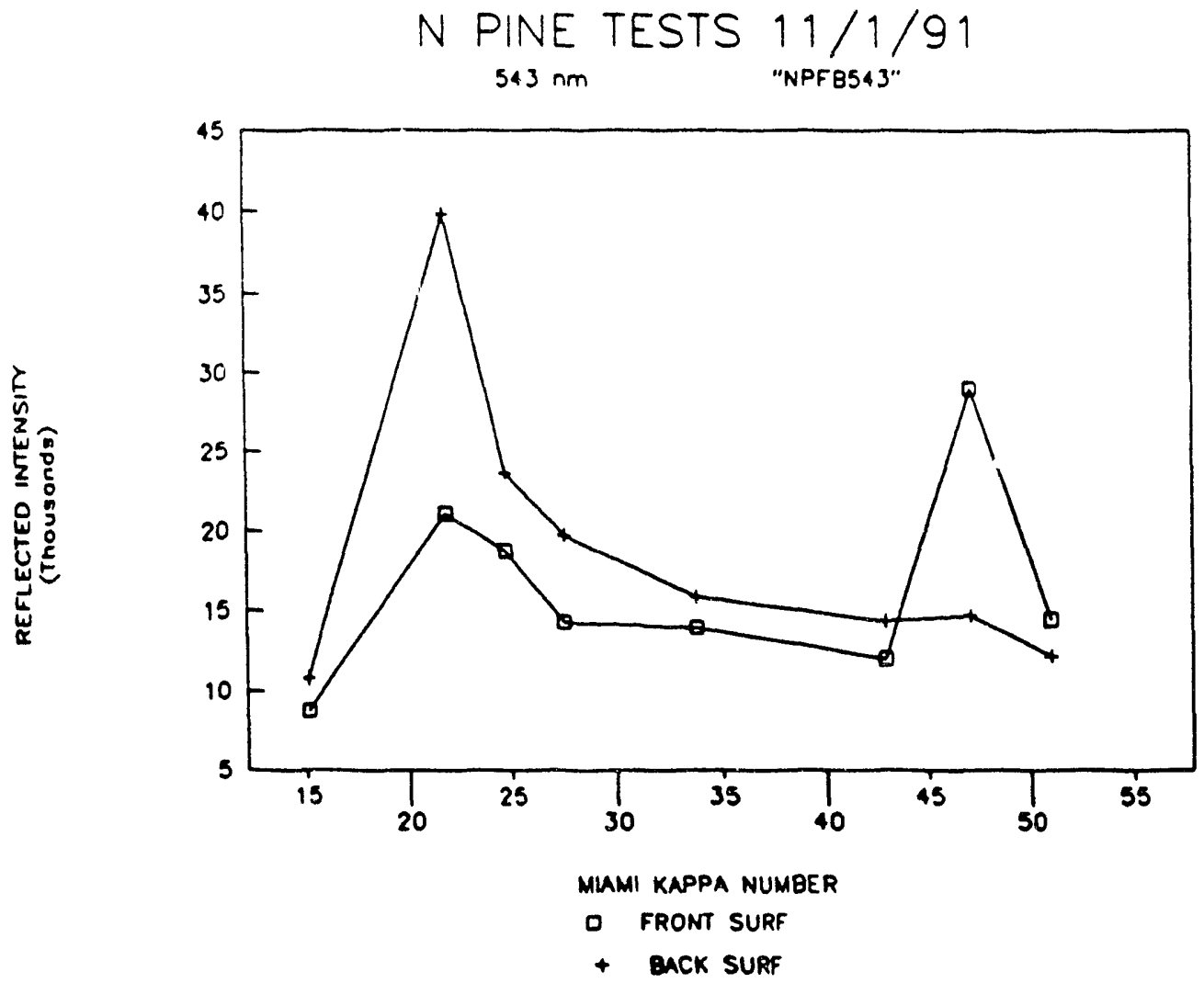

Figure 9-12 Intensity of $543 \mathrm{~nm}$ Reflection vs Kappa Number for Northern Pine Samples 

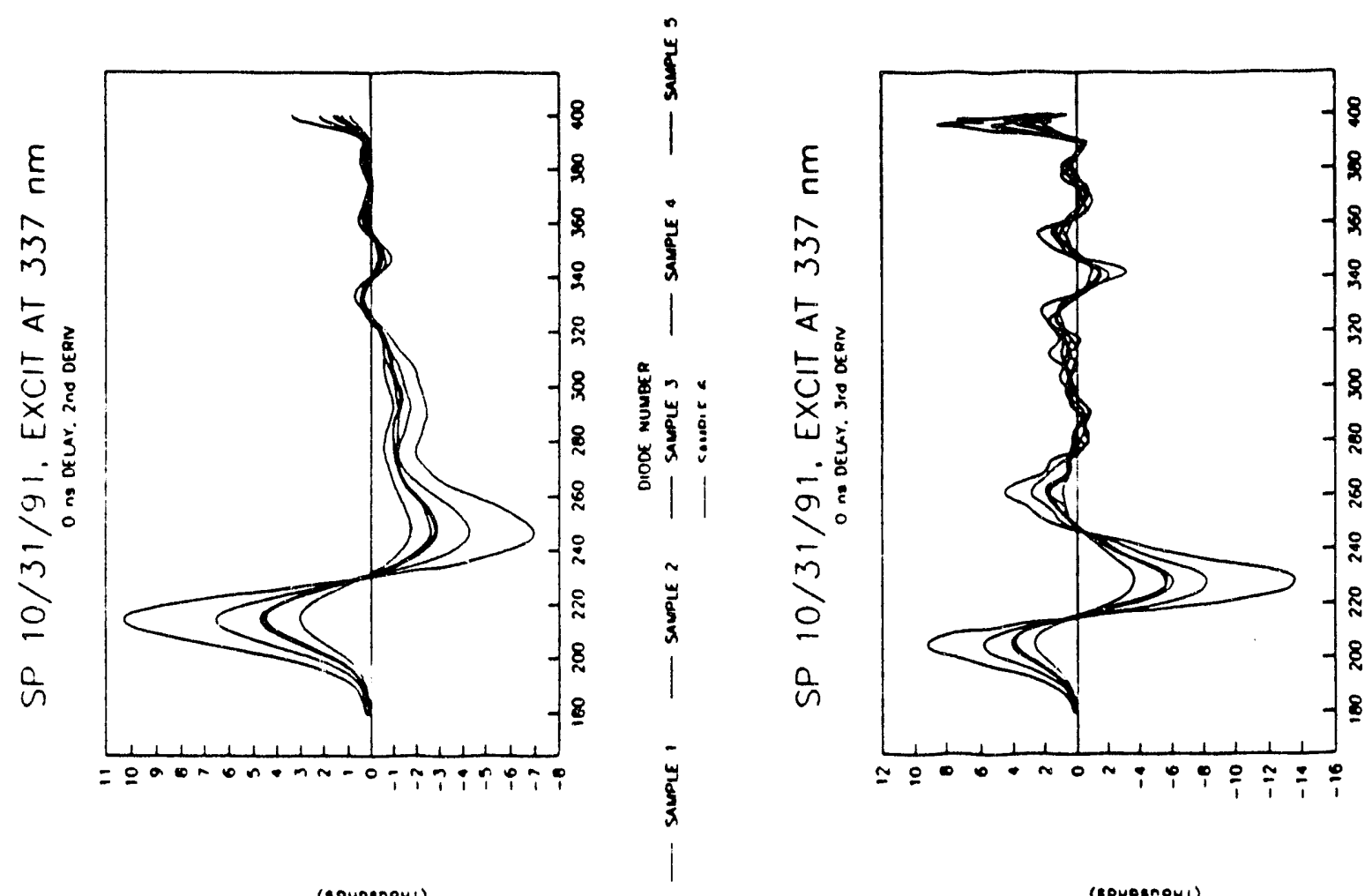

|

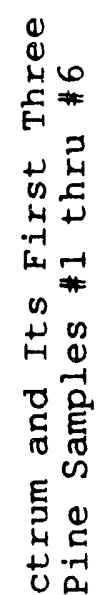

NISNIINI CORZ 90 AIY3O DU 2

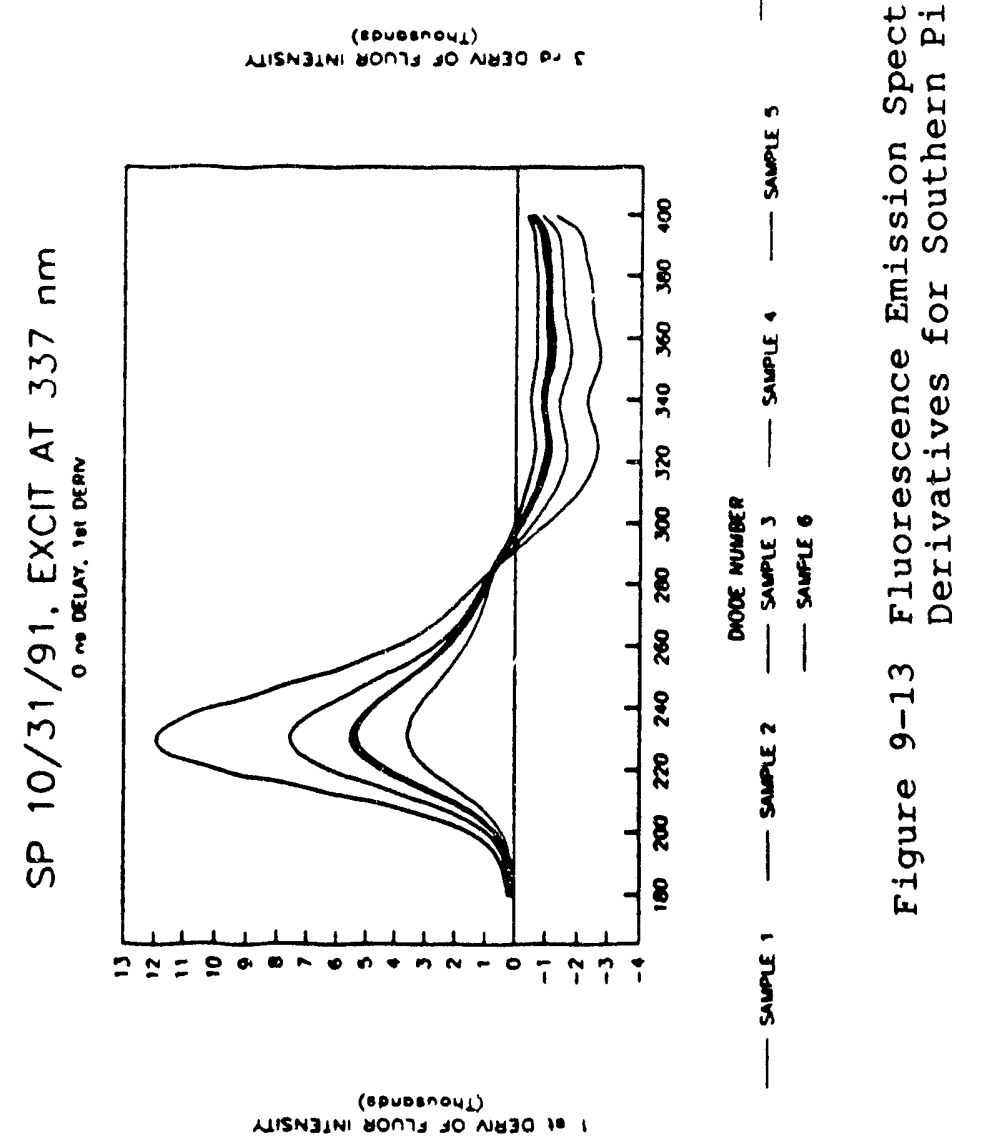

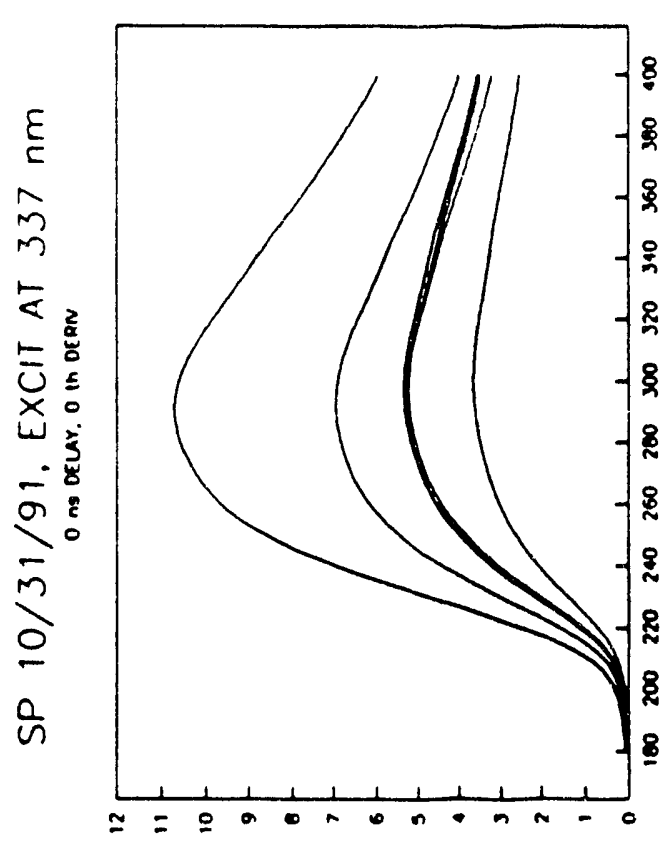

(eovornonj)

LISN3LNI GONIS 90 NE3O WIO

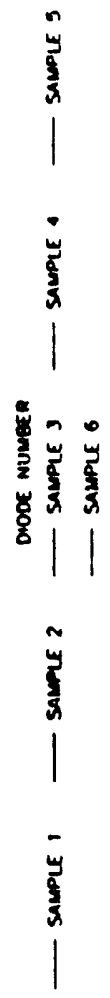

|

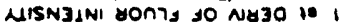




\subsection{REFERENCES}

1. Smook, G. A., Handbook for Pulp \& Paper Technologists, Joint Textbook Committee of the Paper Industry of the United States and Canada, 1982.

2. TAPPI Procedure T236 hm-85, "Kappa Number of Pulp".

3. "Advanced Sensor Development Program for the Pulp and Paper Industry," Annual Report No. 1, DOE/RR/06010-T13 (DE83017094), U.S. Department of Energy, Dec. 13, 1982.

4. "Advanced Sensor Development Program for the Pulp and Paper Industry," Annual Report No. 2, DOE/PR/06010-T33 (DE84008548), U.S. Department of Energy.

5. Horvath, J. J., Semerjian, H. G., "Laser Excited Fluorescence Studies of Black Liquor", Proceedings of the SPIE, Vol. 665, June 1986, pp. 258-264.

6. "Research and Development in Sensor Technology," DOE/NBM-7012450 (DE87012450), U.S. Department of Energy, April 1987.

7. "Report of the Critical Review Panel on the Advanced Sensor Program for the Paper Industry," prepared for the U.S. Department of Energy, July 1988.

Q. Tikka, P.O., and Virkola, N. E., "A New Kraft Pulping Analyzer for Monitoring Organic and Inorganic Substances," TAPPI Journal, June 1966, pp. 66-71.

9. Williams, D.J., "The Application of Ultra-Violate Absorption Characteristic of Lignin to the Control of Pulp Uniformity," Appita, Vol. 22, 0.2, September 1968, pp. 45-52.

10. Carpart, R., Obese-Jecty K., LeCardinal, G., and Gelus, M., "Contribution to the On-Line Kraft Pulping Control," PRP 4 Proceedings, Ghent, 1980.

11. "Kubulnieks, E., Lundqvist, S., and Pettersson, T., "The STFI OPTI-Kappa Analyzer, Applications and Accuracy", TAPPI Journal, November 1987, pp. 38-42.

12. "Kappa Number Analyzer," Preliminary Data Sheet D218.66e-a, The Bonnier Technology Group, Decatur, Ga., 1988.

13. Kleinert, T.N., and Joyce, C.S., "Short Wavelength Ultraviolet Absorption of Various Lignins and Related Substances," Part I, Pulp and Paper Magazine, Can. 58, No. 5, April 1957, pp. 154-158.

14. Joyce, C.S. and Kleinert, T.N., Ibid., Part II, Pulp and Paper Magazine, Can. 58, No. 6, May 1957, pp. 131-148.

15. Kleinert, T.N. and Joyce, C.S. Ibid., Part III, Pulp and Paper Magazine, Can. 58, No. 7, June 1957, pp. 215-219. 
16. Kleinert, T.N. and Joyce, C.S., Ibid., Part IV, Pulp and Paper Magazine, Can. 58, Oct. 1957, pp. 147-152.

17. Hartler, N. and Norrstrom, H., Light Absorbing Properties of Pulp and Pulp Components", TAPPI, Vol. 52, No. 9, September, 1969.

18. Norrstrom, H., and Teder, A., "Absorption Bands in Electronic Spectra of Lignins, Part 2 Band Intensities for Alkali Lignins from Spruce," Svensk Paperstidning, 15 June 1971.

19. Sjostrom, E., and Haglund, P., "Spectrophotometric Determination of the Dissolution of ignin During Sulfite Cooking, "TAPPI, Vol. 47 , No. 5, May 1964 .

20. Berben, S.A., Rademacher, J.P., Sell, L.O., and Easty, D.B., "Estimation of Iignin in Wood Pulp by Diffuse Reflectance Fourier-Transform Infrared Spectrometry," TAPPI Journal, November 1987, pp. 129-133.

21. Bublitz, W.J., "Fluorescence of Pulping Liquors: A Tool for Digester Control"?

22. Baumgartner, D.J., Feldman, M.H., and Gibbons, C.I., "A Procedure for Trancing Kraft Mill Effluent from an Ocean by Constituent Fluorescence," Water Research, Pergamom Press, Vol. 5, 1971, pp. 533-544.

23. Bublitz, W.J. and Wade, D.C., "Applying Waste Liquor Fluorescence to Control Pulp Quality," Svensk Papperstidning, No. 18, 1979.

24. Wilander, A., Kvarnas, H. and Iindell, T., "A Modified Fluorometric Method for Measurement of Lignin Sulfonates and Its In-Situ Application in Natural Waters," Water Research, Vol. 8, 1974, pp. 1037-1045.

25. Demas, J.N., "Excited State Lifetime Measurements," Academic Press, New York, 1983. 

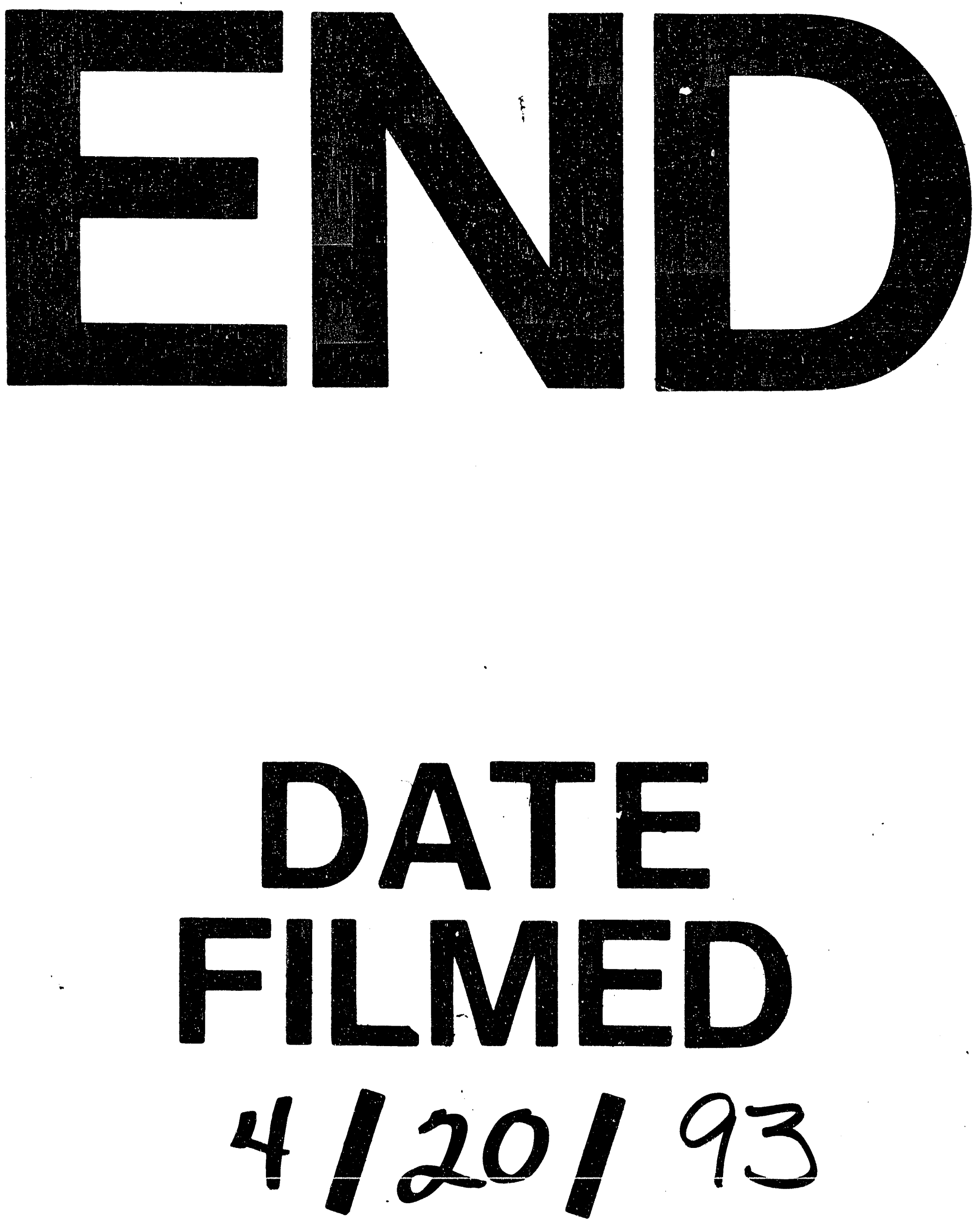
